Cite this: Chem. Soc. Rev., 2012, 41, 6519-6554

\title{
Ice nucleation by particles immersed in supercooled cloud droplets $\dagger$
}

\author{
B. J. Murray, ${ }^{* a}$ D. O'Sullivan, ${ }^{a}$ J. D. Atkinson ${ }^{a}$ and M. E. Webb ${ }^{b}$ \\ Received 1st June 2012 \\ DOI: $10.1039 / \mathrm{c} 2 \mathrm{cs} 35200 \mathrm{a}$
}

The formation of ice particles in the Earth's atmosphere strongly affects the properties of clouds and their impact on climate. Despite the importance of ice formation in determining the properties of clouds, the Intergovernmental Panel on Climate Change (IPCC, 2007) was unable to assess the impact of atmospheric ice formation in their most recent report because our basic knowledge is insufficient. Part of the problem is the paucity of quantitative information on the ability of various atmospheric aerosol species to initiate ice formation. Here we review and assess the existing quantitative knowledge of ice nucleation by particles immersed within supercooled water droplets. We introduce aerosol species which have been identified in the past as potentially important ice nuclei and address their ice-nucleating ability when immersed in a supercooled droplet. We focus on mineral dusts, biological species (pollen, bacteria, fungal spores and plankton), carbonaceous combustion products and volcanic ash. In order to make a quantitative comparison we first introduce several ways of describing ice nucleation and then summarise the existing information according to the time-independent (singular) approximation. Using this approximation in combination with typical atmospheric loadings, we estimate the importance of ice nucleation by different aerosol types. According to these estimates we find that ice nucleation below about $-15{ }^{\circ} \mathrm{C}$ is dominated by soot and mineral dusts. Above this temperature the only materials known to nucleate ice are biological, with quantitative data for other materials absent from the literature. We conclude with a summary of the challenges our community faces.

${ }^{a}$ School of Earth and Environment, University of Leeds, Leeds, LS2 9JT, UK.E-mail: b.j.murray@leeds.ac.uk

${ }^{b}$ School of Chemistry, University of Leeds, Leeds, LS2 9JT, UK

$\dagger$ Part of the atmospheric chemistry themed issue.

\section{Introduction}

Clouds in the Earth's atmosphere substantially modify climate. ${ }^{1-3}$ They interact with both incoming shortwave and outgoing longwave radiation and can strongly influence local and

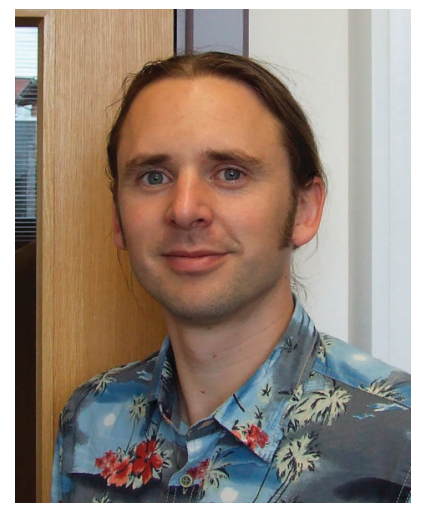

B. J. Murray
Dr Ben Murray is a Reader in Aerosol Science at the University of Leeds, where he has held an academic post since 2006. He received his PhD from the University of East Anglia (UEA) where he studied the heterogeneous chemistry of mesospheric ice clouds with Professor John Plane. After a short postdoctoral position at UEA he embarked on a post-doctoral fellowship with Professor Allan Bertram at the University of British Columbia. His research focuses on heterogeneous ice nucleation, aerosol properties and the phases of ice in the atmosphere.

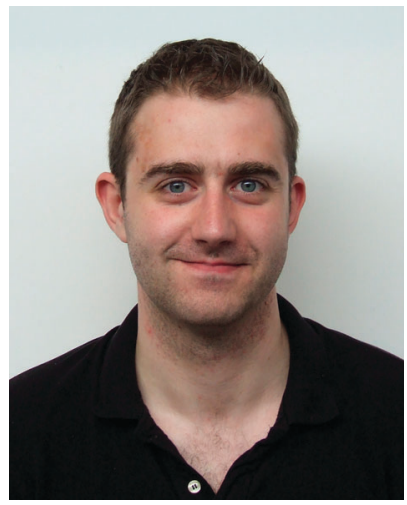

D. O’Sullivan
Dr Daniel O'Sullivan is a postdoctoral researcher at the University of Leeds, and has worked in Dr Ben Murray's group since 2011. He graduated from University College Cork, Ireland, in 2007 with a BSc (Hons) in Chemistry. He then went on to complete a PhD under the supervision of Prof. John R. Sodeau at University College Cork in 2011. His postgraduate research focused on examining the ice-mediated reactivities of tropospheric gases such as interhalogens, organo-nitrates and sulphur dioxide. Daniel's current research interests are centred on examining the importance of primary biological aerosol particles as ice nuclei in mixed-phase clouds. 
regional wind patterns. Additionally, clouds are an integral part of the hydrological cycle and are responsible for water transport and precipitation, which controls water availability and drives numerous environmental processes. Ice formation in clouds strongly impacts their properties and plays a major role in precipitation formation. However, ice nucleation on solid aerosol particles remains poorly understood and quantified. In this review we assess our current state of knowledge of heterogeneous ice nucleation under conditions relevant for mixed phase (water and ice) clouds between $0{ }^{\circ} \mathrm{C}$ and about $-37{ }^{\circ} \mathrm{C}$.

There are several reviews of ice nucleation in the atmosphere which incorporate findings from field measurements, laboratory studies and modelling work, ${ }^{4-8}$ as well as a recent article on ice throughout nature. ${ }^{9}$ These reviews cover multiple modes of ice nucleation for many cloud types including tropospheric mixed phase and ice clouds as well as clouds in the polar stratosphere and mesosphere. In contrast, this review is a detailed assessment of laboratory studies of ice nucleation by particles immersed in supercooled water and how this fundamental information can inform our quantitative understanding of mixed phase clouds.

We start with a general discussion of the importance of ice nucleation in mixed phase clouds and the cloud types in which ice nucleation is important. Our theoretical understanding and methods of describing ice nucleation are then presented. We then go on to examine laboratory studies of mineral dusts, carbonaceous combustion aerosol, biological species and volcanic ash in some detail. The ice nucleation efficiency of these materials is quantified using a time-independent temperature-dependent parameter, which allows comparison between different experimental methods and aerosol species. Using estimated concentrations of these aerosol species in the atmosphere we evaluate the potential concentration of ice particles (or the potential ice nuclei concentration) which they could produce. This highlights which aerosol species are most important for ice nucleation in mixed phase clouds and also where experimental data is lacking.

\subsection{Aerosol-cloud interactions and ice formation}

The radiative properties and lifetime of clouds are particularly sensitive to aerosol concentration, composition and size. ${ }^{1}$ This sensitivity arises because the nucleation of droplets and ice crystals directly from the vapour phase is never favourable in the troposphere. Instead, aerosol particles are required to serve as cloud condensation nuclei $(\mathrm{CCN})$ to form liquid cloud droplets or as ice nuclei (IN) to form ice particles. The number of droplets which form in a cloud tends to increase with increasing aerosol number, resulting in clouds containing a greater number of smaller droplets which more effectively scatter light, thus increasing albedo, and also increase cloud lifetime. ${ }^{2}$ Anthropogenic emissions have increased aerosol concentration in the atmosphere and this is thought to have increased the amount of solar radiation being reflected back to space through increased albedo. ${ }^{1}$ Ice nucleation causes further changes to clouds which at present are difficult to quantify. While the uncertainties associated with the indirect effects of aerosol (i.e. changes in radiative properties of clouds due to anthropogenic aerosols) on liquid clouds are large, the effect of ice nucleation is even less well understood. In their latest report, the Intergovernmental Panel on Climate Change (IPCC), were unable to estimate the radiative forcing of aerosol on clouds through ice nucleation. ${ }^{1}$

There are two broad categories of tropospheric clouds in which ice is present: cirrus and mixed phase types. Cirrus clouds form in the upper troposphere and typically form from liquid solution droplets which may freeze homogeneously or via heterogeneous mechanisms involving ice nuclei. ${ }^{10-12}$ While these clouds are important in terms of climate, ${ }^{13}$ transport of water vapour, ${ }^{14,15}$ and chemistry, ${ }^{16}$ for this review we focus on mixed phase clouds.

Mixed phase clouds exist at temperatures between $0{ }^{\circ} \mathrm{C}$ and about $-37{ }^{\circ} \mathrm{C}$ and tend to occur in the low and middle troposphere where clouds have an important impact on climate, ${ }^{3}$ and are integral to the hydrological cycle. ${ }^{7}$ This can include clouds which form in very different dynamical conditions and are discussed in more detail in Section 1.3. The upper

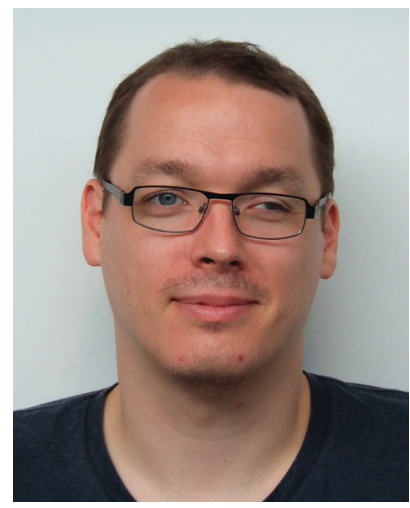

J. D. Atkinson
Mr James Atkinson is in his third year of study for a PhD at the University of Leeds under the supervision of Dr Ben Murray and Dr Steven Dobbie. He received his $B S c$ in Meteorology from the University of Leeds in 2009. His research interests focus on cloud microphysical processes which he addresses through laboratory experiments with particular emphasis on ice nucleation by mineral dusts.

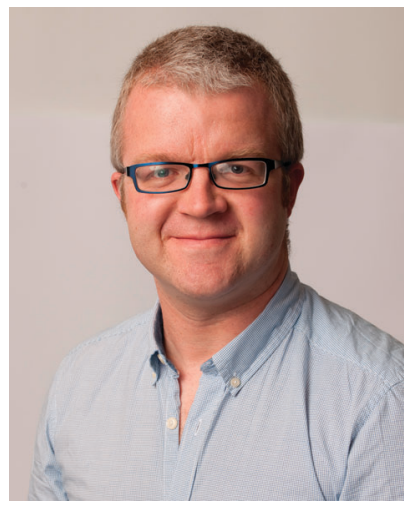

M. E. Webb
Dr Michael Webb is a Lecturer in Chemical Biology in the School of Chemistry at the University of Leeds. Following a PhD in Biological Chemistry with Professor Chris Abell at the University of Cambridge he undertook postdoctoral work with Professor Stephen Benkovic at the Pennsylvania State University and with Professor Alison Smith in the Department of Plant Sciences at Cambridge before moving to Leeds in 2007. His major research interests are in enzyme mechanism, the regulation of biosynthetic pathways and chemical probes of protein post-translational modification. He has been collaborating with Dr Ben Murray on the role of biological materials in atmospheric ice nucleation since 2010. 
temperature limit of mixed phase clouds is defined by the melting of ice at $0{ }^{\circ} \mathrm{C}$, but cloud-sized water droplets can persist in a supercooled state to below $-37^{\circ} \mathrm{C}$ in the absence of particles which can catalyse ice formation. ${ }^{7,17}$ These clouds can glaciate at any temperature below $0{ }^{\circ} \mathrm{C}$ in the presence of the right type of ice nucleating particle, but these particles tend to be rare in comparison with $\mathrm{CCN}$. This has profound implications for cloud properties and precipitation.

\subsection{Aerosol and ice nucleating particle concentrations}

Aerosol concentrations vary substantially depending on location and season. ${ }^{18-20}$ In general the aerosol concentration is lower in remote marine locations than continental regions, ranging from $<10^{2} \mathrm{~cm}^{-3}$ in clean remote locations to $>10^{4} \mathrm{~cm}^{-3}$ in urban locations and $10^{2}-10^{3} \mathrm{~cm}^{-3}$ in the free troposphere. ${ }^{18,19}$ Only a subset of these aerosol particles can serve as IN with typical IN concentrations ranging from $10^{-4}$ to $10^{-1} \mathrm{~cm}^{-3}, 7,21-24$ with extreme values in excess of $1 \mathrm{~cm}^{-3}$ within desert dust plumes. ${ }^{25}$ These measurements indicate that IN are rare in comparison to particles capable of serving as CCN. In an aircraft campaign Rogers et al. ${ }^{23}$ reported that a fraction of $10^{-3}$ to $10^{-5}$ of the background aerosol served as IN; they also observed no correlation between IN and CCN concentrations. The fraction of aerosol serving as IN in marine air has been reported to be many orders of magnitude lower. ${ }^{26}$ More recently it has been shown that in regions not influenced by sea salt aerosol, IN concentrations are correlated to the number of aerosol particles larger than $0.5 \mu \mathrm{m} .{ }^{21}$ In addition, observations show the number of particles capable of serving as IN increases dramatically with decreasing temperature. ${ }^{7,22,27}$ In summary, only a small proportion of aerosol particles can serve as IN at all temperatures and considerable seasonal and spatial variability exists.

\subsection{Clouds containing supercooled water droplets}

Clouds in the Earth's atmosphere have been classified by the meteorological community into types based largely upon visual characteristics and altitude. ${ }^{28}$ These visual characteristics are determined by a combination of dynamical and microphysical behaviour.

Mid-level clouds, forming at altitudes of $\sim 2-6 \mathrm{~km}$ (at midlatitudes), include altostratus and altocumulus, are usually composed of ice crystals and supercooled water droplets. ${ }^{28}$ Altostratus are uniform layer clouds which are thin enough to allow the sun to be visible and can extend over thousands of square miles. Altocumulus are patches of cloud in the shape of rounded lumps or flattened globules which are often arranged into groups, lines or waves. ${ }^{28}$ They form in regions of wide scale ascent with velocities of $5-10 \mathrm{~cm} \mathrm{~s}^{-1}\left(0.015-0.03{ }^{\circ} \mathrm{C} \mathrm{min}^{-1}\right.$; assuming a wet lapse rate of $\left.5{ }^{\circ} \mathrm{C} \mathrm{km}^{-1}\right),{ }^{28}$ although localised updrafts can be substantially faster. ${ }^{29}$

Low-level clouds, typically below $2 \mathrm{~km}$, include stratocumulus and stratus clouds. Stratus are uniform featureless clouds and form fog when they reach the ground. Arctic stratus mixed phase clouds have received significant attention in recent years due to their large spatial extent and substantial impact on the Arctic climate. ${ }^{30}$ Stratocumulus are low level clumps or globules of cloud with well-defined bases as low as a few hundred meters and tops at $\sim 2 \mathrm{~km}$. Vertical velocities in these clouds are typically less than $10 \mathrm{~cm} \mathrm{~s}^{-1}\left(0.03{ }^{\circ} \mathrm{C} \mathrm{min}^{-1}\right){ }^{28}$

Other mixed phase cloud types have a much greater vertical extent. Nimbostratus can extend from close to the ground into the mid-troposphere and are associated with rain or snow. These clouds are often caused by regions of large scale slow ascent such as warm fronts. Cumulus clouds are detached dense clouds with heaped tops and flat bottoms and can extend from as low as $\sim 0.5 \mathrm{~km}$ up to $\sim 6 \mathrm{~km}$. These clouds are associated with areas of fast ascent, with updraft velocities in the range of $1-5 \mathrm{~m} \mathrm{~s}^{-1}\left(0.3-1.5{ }^{\circ} \mathrm{C} \mathrm{min}{ }^{-1}\right)$, caused by convection or cold fronts. If the ascent is strong enough (sometimes referred to as deep convection), they can grow into cumulonimbus clouds and begin to produce precipitation. Such clouds can extend to altitudes of $12 \mathrm{~km}$ in the midlatitudes or even higher in the tropics. ${ }^{28}$ Cumulonimbus have the greatest updraft speeds of all clouds, with velocities in the $10 \mathrm{~s}$ of meters per second $\left(10 \mathrm{~m} \mathrm{~s}^{-1}\right.$, or $36 \mathrm{~km} \mathrm{~h}^{-1}$, is equivalent to $3{ }^{\circ} \mathrm{C} \mathrm{min}^{-1}$ ) which are driven in part by the release of latent heat from droplet and ice formation.

In addition, clouds can form as air is forced to ascend over a hill or mountain. These orographic clouds include lenticular clouds which are striking lens shaped clouds with sharp edges. Downwind the air may be set into an oscillation with clouds, known as wave clouds, forming in the uplift phase. These clouds have received attention by the cloud community because they provide a well-defined system and have been used as a 'natural laboratory' in aircraft field experiments. ${ }^{31-33}$

Given that IN are rare in the Earth's atmosphere it is perhaps not a surprise that many clouds can persist in a supercooled liquid state. In deep convective clouds liquid water has been observed down to $-37.5^{\circ} \mathrm{C},{ }^{34}$ which is close to the limit defined by laboratory experiments for homogeneous freezing. If we consider a cloud of supercooled droplets $10 \mu \mathrm{m}$ in diameter, $99 \%$ of them will freeze within 1 minute at $-37.5{ }^{\circ} \mathrm{C}$ according to measured nucleation rate co-efficients. ${ }^{17}$ Significant amounts of supercooled water (not including haze solution particles) are unlikely to persist at lower temperatures and this probably defines the lower limit to supercooled water in the troposphere. In other clouds with weaker updrafts this temperature limit is several degrees warmer due to an increase in time scales.

In many clouds glaciation occurs at much higher temperatures. In general the fraction of clouds which contain supercooled water decreases with decreasing temperature, ${ }^{35-39}$ this reflects the measurements discussed in Section 1.2 showing that the number of aerosol particles capable of serving as IN increases with decreasing temperature. The fraction of midlevel stratus clouds containing ice in four locations around the globe is shown in Fig. 1; there are some striking differences. For example, the fraction of clouds containing ice is $\sim 70 \%$ at $-19{ }^{\circ} \mathrm{C}$ above Leipzig ( $51^{\circ} \mathrm{N}$, northern Germany); whereas at a similar latitude in the southern hemisphere (Punta Arenas, $\left.53^{\circ} \mathrm{S}\right)$ the same fraction frozen is only achieved below $-34{ }^{\circ} \mathrm{C} .{ }^{38-41}$ Kanitz et al. ${ }^{41}$ suggest that this difference is due to the presence of more extensive sources of IN in continental Europe compared to Punta Arenas which receives air from the Pacific Ocean. At Cape Verde off the west coast of Africa, cloud glaciation only occurs with a frequency of about $5 \%$ at $-20{ }^{\circ} \mathrm{C}$. 


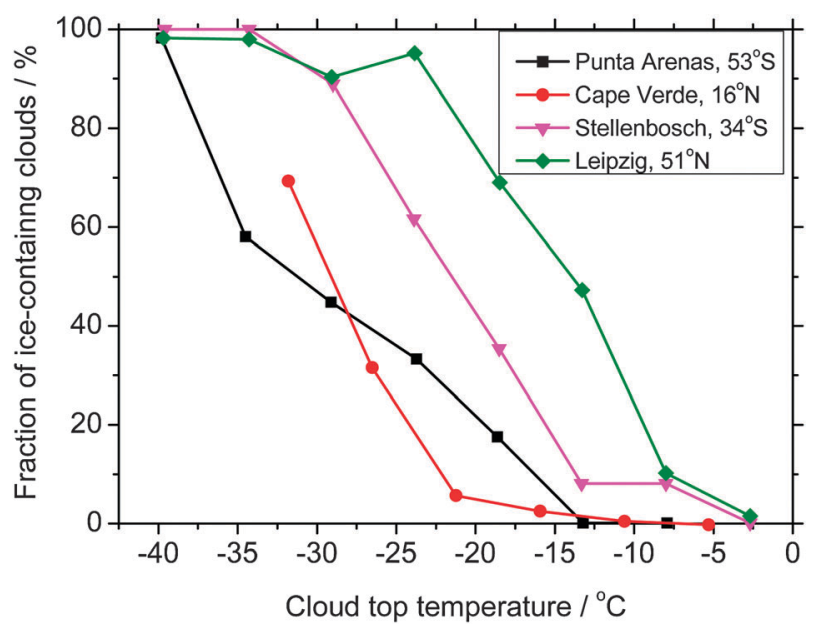

Fig. 1 The fraction of mid-level stratus clouds which contained ice determined using polarization lidar in a number of locations. This data is taken from Kanitz et $a l^{41}$ and is further discussed in other articles. ${ }^{37,39}$ The clouds examined in this work were mainly within the altitude range $2-8 \mathrm{~km}$ and were mostly less than $1 \mathrm{~km}$ thick with small optical depths.

This is remarkable considering its location in the path of dust emissions flowing from Africa. ${ }^{25,42}$ This is a similar finding to that of Ansmann et al. ${ }^{36}$ who showed that clouds above Morocco remained in a supercooled state down to $-18{ }^{\circ} \mathrm{C}$ despite being colocated with Saharan dust. In contrast, Sassen et $a .^{43}$ report that Saharan dust is capable of glaciating altocumulus clouds at temperatures between -5 and $-9{ }^{\circ} \mathrm{C}$.

The global distribution of the fraction of clouds containing supercooled water has been measured by satellite based LIDAR (a technique comparable to RADAR, but using laser light). ${ }^{35,40}$ These results highlight the regional and seasonal variability of the occurrence of supercooled water in the atmosphere. Based on this data Choi et al. ${ }^{40}$ suggest that the presence of dust leads to a significant reduction in cloud albedo, counteracting the direct effect of the dust.

\subsection{Consequences of ice nucleation in supercooled clouds}

Despite their rarity, IN have a substantial impact on the properties of mixed phase clouds. In part this is because IN are rare in comparison to particles capable of serving as $\mathrm{CCN}$, but it is also related to the fact that a liquid cloud below $0{ }^{\circ} \mathrm{C}$ is thermodynamically unstable. In many systems, including clouds, a transition to a more thermodynamically stable state can happen promptly despite the system having previously persisted in a metastable state for a long period of time. ${ }^{44}$ Ice nucleation in a small fraction of cloud droplets can trigger a transformation in the whole cloud and substantially modify its properties. Since ice is more stable than supercooled water below $0{ }^{\circ} \mathrm{C}$, ice crystals have a lower equilibrium vapour pressure. ${ }^{45}$ This causes a water vapour concentration gradient to form between the air around ice crystals and the supercooled water droplets, leading to growth of the ice crystals at the expense of the supercooled droplets. This is known as the Bergeron-Findeisen (sometimes referred to as the WegenerBergeron-Findeisen) process. ${ }^{7,46}$ The timescale for glaciation through this process depends on temperature and pressure and in the middle troposphere at $-20{ }^{\circ} \mathrm{C}$ the timescale is on the order of minutes. This process is thought to be critical in many low- and mid-level clouds, resulting in a cloud containing large ice crystals of a considerably lower concentration than the original liquid droplet concentration. In vigorous convective systems a supersaturation with respect to liquid water may be maintained, even in the presence of ice particles and under these conditions both ice and supercooled droplets will grow. ${ }^{47,48}$ If sufficiently large ice crystals form, they can collide with supercooled droplets, which freeze on contact in a process referred to as riming. This collision coalescence process is an important mechanism in the formation of rain and hail.

Cloud glaciation is further complicated by ice multiplication mechanisms (also termed secondary ice production processes). The mechanism which has received most attention is the Hallett-Mossop process ${ }^{49}$ in which riming at around -3 to $-8{ }^{\circ} \mathrm{C}$ (most effective at $-5{ }^{\circ} \mathrm{C}$ ) leads to ice splinters being ejected, yielding ice crystal concentrations that are orders of magnitude higher than IN concentrations. ${ }^{29,50-52}$ This process requires supercooled water droplets with a diameter greater than $24 \mu \mathrm{m}$ and relative impact velocities need to be greater than $1.4 \mathrm{~m} \mathrm{~s}^{-1} \cdot{ }^{49,53}$ Pruppacher and Klett ${ }^{7}$ present data which suggests ice multiplication mechanisms are important above about $-20{ }^{\circ} \mathrm{C}$, which is significantly below the temperature range where the Hallett-Mossop process is known to be active. This is thought to be due to the break-up of fragile dendrites which can form in this temperature range, ${ }^{7,54}$ but ice multiplication mechanisms remain an area of significant uncertainty. From the point of view of ice nucleation, any IN active in a regime relevant for ice multiplication will have a disproportionate impact on cloud glaciation.

\subsection{Modes of ice nucleation in mixed phase clouds}

There are a number of ways in which aerosol particles are thought to trigger ice nucleation in the atmosphere. These are: (i) deposition nucleation, which occurs when vapour directly deposits onto a solid surface as ice. (ii) Immersion freezing, which happens when ice nucleates on a solid particle immersed within a supercooled liquid droplet. (iii) Condensation freezing, which occurs when water vapour condenses on a solid particle, possibly due to the presence of some hygroscopic material, and then freezes (this is sometimes referred to as deliquescence freezing ${ }^{55}$ and is sometimes classed together with immersion freezing ${ }^{31}$ or deposition freezing ${ }^{56,57}$ ). (iv) Contact freezing, in which a solid particle collides with a supercooled liquid droplet, resulting in ice nucleation. ${ }^{7,58}$ In addition to these standard modes of nucleation, an 'inside-out' nucleation process has been identified in which solid particles immersed within a droplet come into contact with the air-water interface and only then initiate freezing. ${ }^{59-61}$ It has been proposed that this may occur while a droplet evaporates. ${ }^{59}$

In many situations field data and modelling studies indicate that liquid water droplets are a prerequisite for ice formation. This implies that deposition nucleation plays a secondary role under mixed phase cloud conditions. Westbrook and Illingworth ${ }^{62}$ used radar and lidar measurements to show that $95 \%$ of ice particles which formed at temperatures above $-20{ }^{\circ} \mathrm{C}$ originate within supercooled clouds. In a study of altocumulus 
clouds over Cape Verde Ansmann et al. ${ }^{37}$ found that $99 \%$ of clouds they probed had a liquid layer at their tops. They concluded from this observation that deposition and condensation ice nucleation are not important mechanisms in these clouds. In the majority of cases above $-30{ }^{\circ} \mathrm{C}$ at high latitudes de Boer et $\mathrm{al}^{57}$ showed that for ice to form a liquid cloud was required to form first. Ice supersaturated haze layers are observed in these regions with no apparent ice formation, suggesting that deposition and condensation (below water saturation) nucleation is not important. ${ }^{57}$ In modelling mountain lee wave clouds Field et al. ${ }^{31}$ concluded that ice formation required liquid water to form first. Based on the same field study, Twohy et al. ${ }^{33}$ stated that deposition nucleation in ice-supersaturated, but water-subsaturated, conditions was not observed and that there was no evidence for contact nucleation in the evaporating cloud. In contrast, Sassen and Khvorostyanov ${ }^{63}$ concluded that ice formed below water saturation in the formation of altocumulus clouds impacted by smoke in Alaska. Nevertheless, most studies conclude that water saturation is a prerequisite for ice formation in lowand mid-level clouds and therefore either contact or immersion freezing dominate. Phillips et al. ${ }^{64}$ suggest that contact mode nucleation is of secondary importance because thermophoretic effects (force exerted by a temperature gradient) favour contact nucleation only in evaporating droplets, but these droplets tend to disappear before they can freeze.

\subsection{What makes an effective ice nucleating particle?}

Pruppacher and $\mathrm{Klett}^{7}$ list a number of requirements for a particle to be an effective IN. These are: (i) insolubility, water absorption may cause the substrate to disintegrate; (ii) size, a correlation between the number of 'larger' aerosol particles and IN has been reported; $;^{7,21}$ (iii) chemical bond requirement, water must be able to make chemical bonds with the IN surface; and (iv) crystallographic, a good IN should template ice. These requirements might be met either on a particular crystallographic face of a nucleant or at specific active sites such as cracks or defects.

These criteria were set out in part to help the community establish which atmospheric materials are likely to serve as IN, but these criteria are perhaps too narrow. For example, it has been shown that crystalline soluble salts such as ammonium sulphate ${ }^{65}$ and oxalic acid ${ }^{66}$ nucleate ice in the immersion mode (in saturated solution droplets). These results suggest that the insolubility requirement of IN should be rephrased to be a 'solid' requirement, although this would not include ice nucleation by ordered surfactants ${ }^{67}$ Hygroscopic solutions in a glassy state, ${ }^{11,68}$ atmospheric organic aerosol, ${ }^{69}$ and secondary organic aerosol $^{70}$ have also been shown to nucleate ice despite their amorphous (non-crystalline) nature which challenges the concept of a lattice match. Soot is also a poorly ordered solid material which is known to catalyse ice formation. ${ }^{56,71,72}$ In the early literature ice nucleation by the clay mineral kaolinite was ascribed to its lattice match with ice, which is thought to template ice. ${ }^{7}$ However, more recent computational work indicates that this is not the case, suggesting kaolinite nucleates ice for a different reason, possibly due to defects in the crystal structure. ${ }^{73-75}$ In summary, these commonly cited guidelines need to be taken with caution since our basic understanding of what makes an effective ice nucleating material remains limited. At present the only way of determining if a particular material is effective at nucleating ice is by quantitative experimentation.

\subsection{Impact of ice nucleation in mixed phase clouds on climate: aerosol indirect effects involving ice formation}

There have been substantial changes in the amount and composition of aerosol particles in the Earth's atmosphere since pre-industrial times. ${ }^{1}$ In the present day atmosphere the number of aerosol particles over the continental regions is greatly enhanced due to human activity. ${ }^{1,76}$ It has been suggested that in pre-industrial times, $\mathrm{CCN}$ loading in the continental regions was of the same order of magnitude as in oceanic regions $\left(100-300 \mathrm{~cm}^{-3}\right.$, in the absence of dust storms or fires). ${ }^{20,77,78}$ Andreae et $a l^{20}$ state that primary and secondary biogenic sources dominated in the pre-industrial era. In contrast, the present continental aerosol loading is orders of magnitude larger than that over oceans due to proximity to significant anthropogenic sources. The dramatic changes in aerosol loading of the atmosphere from pre-industrial to present day are illustrated in Fig. 2. In the pre-industrial atmosphere aerosol concentrations were much more homogeneous between maritime and continental regions than they are in the present atmosphere, which illustrates the anthropogenic impact on global aerosol concentrations. ${ }^{77}$ Using modelled global distributions such as this it is possible to estimate the impact humankind has had on CCN concentrations, ${ }^{76,77}$ but it is not known how the number of IN has changed due to human activity. Hence, assessing the anthropogenic impact on cloud glaciation remains a significant challenge.

In this section we discuss a number of potential indirect effects involving ice in mixed phase clouds. Let us start with a description of a cloud forming under 'clean' conditions, where 'clean' is defined as a natural aerosol loading in the absence of dust storms, fires or volcanic activity. With the relatively few $\mathrm{CCN}$ the resulting number of cloud droplets tends to be low and these droplets tend to grow to larger sizes. For example, Rosenfeld et al..$^{79}$ reported droplet sizes in marine clouds in excess of $40 \mu \mathrm{m}$ (effective diameter). In such clouds ice-free warm rain processes, in which droplets grow large enough to sediment, are feasible. ${ }^{79}$ During sedimentation, they can coalesce with more water droplets and with sufficient time precipitation forms. This leads to removal of liquid water from the cloud, which has the effect of removing latent heat that would otherwise be released if ice formation occurred and would lead to a higher and colder cloud top. If IN are present ice crystals may form, and if this occurs in the temperature regime required for the Hallett-Mossop process ${ }^{49,53}$ even a very small concentration of IN may lead to rapid cloud glaciation. ${ }^{79,80}$ Clouds are clearly sensitive to the number of ice nuclei, but they are also sensitive to the number of aerosol particles which can serve as $\mathrm{CCN}$ as well as the ratio of CCN to IN. We will now consider a range of cases with contrasting ratios of $\mathrm{CCN}$ to IN.

(i) Increased $C C N$ and low $I N$ : This might come about if the overall aerosol concentration increases, through an additional source of soluble aerosol particles, but where the number of IN remain constant. In this case a greater number of $\mathrm{CCN}$ leads to more, but smaller cloud droplets. In shallow clouds 
a)

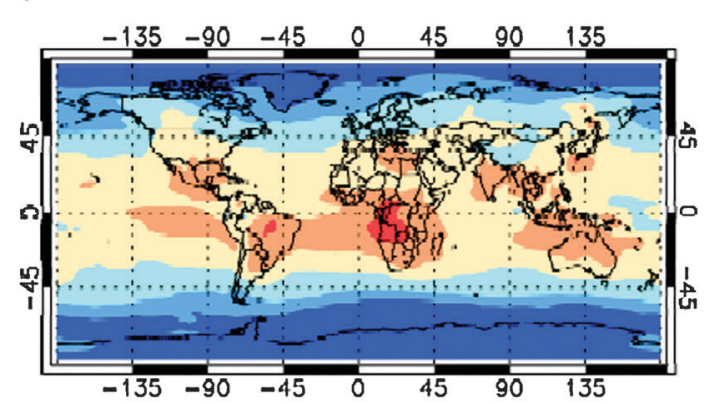

b)

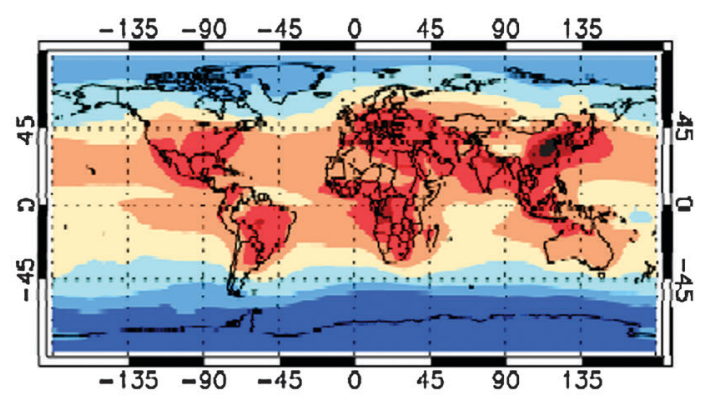

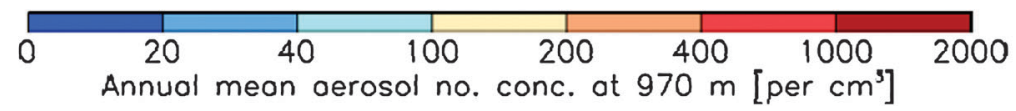

Fig. 2 Modelled global distribution of annual mean aerosol particle concentrations at low-cloud altitudes in the pre-industrial and present day atmosphere (personal communication from Anja Schmidt and adapted from Schmidt et al. ${ }^{77}$ ). The aerosol particle concentration is equal to the concentration of aerosol particles with a dry diameter larger than $70 \mathrm{~nm}$ (including sea salt, sulphate, black carbon, organic carbon and dust) which contain a soluble component and therefore will potentially serve as CCN. Hence, any insoluble material in these droplets will potentially serve as immersion mode ice nuclei.

this leads to a decrease in precipitation via the warm rain process. ${ }^{78}$ In contrast, for convective clouds this inhibits the warm rain process, allowing more water to arrive at the freezing level and more latent heat to be released, leading to a more vigorous updraft. This has a number of effects including increased transport of water, particles and trace gases into the mid and upper troposphere (and sometimes the stratosphere), altering atmospheric dynamics and creating more intense precipitation in convective systems. ${ }^{81-85}$ The latent heat released during droplet and ice formation is consumed when the hydrometeors evaporate, but when condensed water is removed via precipitation the heat is retained in the atmosphere which energises convection and atmospheric circulation. ${ }^{78}$ Andreae et $a l .{ }^{81}$ reported that the hail which developed in a smoke-impacted cloud in the Amazon was so large that it dented the nose of an aircraft, which is striking as no hail was observed in clouds not impacted by smoke. Increasing $\mathrm{CCN}$ in cumulus clouds has been shown to decrease or eliminate precipitation through reduced droplet size and consequently reduced efficiency of ice multiplication and warm rain processes. ${ }^{48,52}$ Clouds with an increased number of smaller droplets scatter more incoming solar radiation and it is this effect which is accounted for in the IPCC's assessment of radiative forcing. ${ }^{1}$ In addition they also tend to have a longer lifetime. Clouds with smaller droplets tend to have a lower glaciation temperature (hence a higher glaciation altitude) since droplets are not large enough for secondary ice multiplication processes (see Section 1.4). Rosenfeld et al. ${ }^{79}$ reported convective clouds forming in a smoke plume over China with droplet sizes of only $10-15 \mu \mathrm{m}$ (effective radius) and glaciation only occurring below $-33^{\circ} \mathrm{C}$. In this case, the smoke aerosol particles did not serve as an effective IN, but did serve as $\mathrm{CCN}$.

(ii) Increased $C C N$ and $I N$ : DeMott et al. ${ }^{21}$ reported that the concentration of IN in a number of locations is related to the number of aerosol particles larger than $0.5 \mu \mathrm{m}$ as well as temperature. Hence, an increase in the number of larger aerosol particles is generally associated with increased IN number densities. As in case (i), increased CCN concentrations suppresses the warm rain process. However, Rosenfeld et al. ${ }^{79}$ suggested that enhanced IN could then trigger glaciation in convective clouds which will enhance precipitation through the Bergeron-Findeisen process. Hence, suppression of the warm rain process by enhanced $\mathrm{CCN}$ may be counteracted by the enhanced precipitation from IN formation.

(iii) Increased IN and low CCN: As discussed in Section 1.2, concentrations of $\mathrm{CCN}$ are usually far greater than for IN. If particles which are not only $\mathrm{CCN}$ but are also efficient IN are introduced, the total IN number will increase substantially with a minimal increase in $\mathrm{CCN}$ number. In this situation one might not expect a dramatic change in cloud droplet size, hence warm rain and also the Hallet-Mossop process may remain active. Increased IN and increased glaciation temperature would be particularly important if the initiation of freezing were shifted into the regime important for secondary ice production. However, Rosenfeld et al. ${ }^{79}$ suggest that even very small concentrations of IN can effectively glaciate a convective cloud formed with few $\mathrm{CCN}$ (due to secondary ice production) and that these clouds may therefore not be particularly sensitive to increased IN.

There have been a limited number of studies at the global scale investigating the impact of ice nucleation in mixed phase clouds. Lohmann and Diehl ${ }^{86}$ explored the impact of mineral dusts and black carbon as ice nuclei on mixed phase clouds. They show that the lifetime of clouds is reduced due to ice nucleation enhancing precipitation, resulting in a substantial warming due to reduced cloud cover. Their sensitivity study shows that ice nucleation by mineral dust (using ice nucleation parameterisations, ${ }^{87}$ based on laboratory data lacking any quantification for surface area ${ }^{87-89}$ ) had a radiative forcing of up to $2.1 \mathrm{~W} \mathrm{~m}^{-2}$. This significantly counteracts the impact of increased $\mathrm{CCN}$ and similar results have been obtained in other studies. ${ }^{90,91}$ In a later study, Storelvmo et al. ${ }^{92}$ assessed the impact of increased ice particle concentrations from increased IN and showed that this created more reflective clouds. This effect largely counteracted the positive radiative 
forcing from decreased cloud lifetime. In summary, the icerelated aerosol indirect effects are complex and research in this area is still in its infancy. There are many uncertainties in our understanding of clouds and the lack of a quantitative understanding of heterogeneous ice nucleation by atmospheric aerosol is a severe limitation.

\section{Classical nucleation theory (CNT)}

Classical nucleation theory has been applied in a wide range of fields in which a new phase nucleates from the parent metastable phase. ${ }^{93,94}$ One of its strengths is that it makes use of readily available macroscopic quantities to estimate the rate at which the new phase nucleates. Although simplifying assumptions are made in CNT, it does a remarkably good job at reproducing observed trends (e.g. see ref. 17, 93, and 95). This theory can be applied to the nucleation of ice from supercooled water or from a supersaturated water vapour as well as to the nucleation of amorphous materials (e.g. liquid) from vapours. The equations set out below are written in a general form that could be applied to any situation in which a new phase nucleates from a metastable phase, but our focus here is on ice nucleating in supercooled water.

\subsection{Homogeneous classical nucleation theory}

In pure water, clusters form and dissipate through the addition and removal of water molecules.

$$
\mathrm{H}_{2} \mathrm{O}+\left(\mathrm{H}_{2} \mathrm{O}\right)_{n-1} \leftrightarrows\left(\mathrm{H}_{2} \mathrm{O}\right)_{n}
$$

The size distribution of clusters is related to their stability as well as temperature, but cluster formation above $0{ }^{\circ} \mathrm{C}$ is always a thermodynamically unfavourable process. In supercooled water ice growth occurs spontaneously if the cluster is above a critical size. Below the critical size the addition of a new water molecule is an endothermic process, but above this size it becomes exothermic and crystal growth can then occur. The Gibbs free energy of forming a cluster, $\Delta G_{\mathrm{cl}}$, is the sum of the Gibbs energy associated with making an interface ( $\Delta G_{\mathrm{s}}$, always positive, i.e. unfavourable) and the Gibbs energy associated with forming bonds between water molecules within the bulk of the cluster $\left(\Delta G_{\mathrm{v}}\right.$, negative if $S$, the saturation ratio with respect to a specific condensed phase, is greater than 1$):{ }^{94}$

$$
\Delta G_{\mathrm{cl}}=\Delta G_{\mathrm{s}}+\Delta G_{\mathrm{v}}
$$

It can be shown that

$$
\Delta G_{\mathrm{cl}}=-\frac{4 \pi r_{\mathrm{i}}^{3}}{3 \nu} k T \ln S+4 \pi r_{\mathrm{i}}^{2} \gamma
$$

for a spherical cluster of radius $r$ (containing i molecules), where $k$ is the Boltzmann constant, $\gamma$ is the energy of the interface between the new and parent phases (sometime referred to as surface tension or surface forming energy), and $\nu$ is the molecular volume of the condensed phase ( $\nu=m / \rho$; where $m$ is the molecular mass of the substance and $\rho$ is its density). ${ }^{94}$ For ice nucleating from supercooled water, $S$ can be conveniently derived from the ratio of vapour pressures of liquid water and ice $\left(P_{1} / P_{\text {ice }}\right)$ which are available in the literature. ${ }^{45}$
The radius of the critical cluster $\left(r_{\mathrm{g}}\right)$ is $r_{\mathrm{i}}$ where $\mathrm{d} \Delta G_{\mathrm{cl}} / \mathrm{d} r_{\mathrm{i}}=0$, hence, the critical radius is

$$
r_{\mathrm{g}}=\frac{2 \gamma \nu}{k T \ln S}
$$

By substituting the expression for $r_{\mathrm{g}}$ into eqn (3) an expression for the Gibbs energy of formation of the critical cluster can be written:

$$
\Delta G^{*}=\frac{16 \pi \gamma^{3} \nu^{2}}{3(k T \ln S)^{2}}
$$

This expression highlights the very strong dependence of the nucleation energy barrier on interfacial energy. This provides a physical explanation for Ostwald's law of stages which states that a metastable phase crystallises in preference to the stable phase which has a greater interfacial energy. ${ }^{94,96}$ In the case of homogeneous nucleation of ice in water it has been shown that a metastable phase of ice with a smaller interfacial energy nucleates in preference to the stable hexagonal phase ${ }^{17,95,97}$ (the structure of ice which initially crystallises is discussed in more detail in Section 3). This also provides an explanation for why liquid water droplets nucleate from the vapour phase in preference to ice even below $-73{ }^{\circ} \mathrm{C}$, since liquid water has a lower interfacial energy. ${ }^{98-101}$

It should be noted that classical nucleation theory has a number of weaknesses. A significant issue is the assumption that parameters such as interfacial energy, density and saturation ratio are the same for a nanometre sized cluster of molecules as they are for a macroscopic well defined material. For example, it is thought that the interfacial energy is size dependent. ${ }^{102}$ In addition, the assumption that the initial cluster is spherical may be incorrect. Nevertheless, classical theory does provide a theoretical framework with which to understand nucleation and is capable of reproducing experimental observations.

The rate coefficient $(J$, nucleation events per unit volume per unit time) at which ice crystals appear in supercooled water is related to the Gibbs energy required to form a critical cluster in an Arrhenius form:

$$
J=A \exp \left(-\frac{\Delta G^{*}}{k T}\right)
$$

On combining eqn (5) and (6) we can write: ${ }^{94}$

$$
\ln J=\ln A-\frac{16 \pi \gamma^{3} \nu^{2}}{3 k^{3} T^{3}(\ln S)^{2}}
$$

Fitting this equation to experimental data requires an estimate of $A$ and expressions for this exist in the literature for supercooled water. ${ }^{17,95}$ However, the expressions rely on quantities such as viscosity which are poorly constrained. Another approach is to assume the variables are only weakly dependent on temperature, which is valid over a typical experimental temperature range of a few degrees. This allows one to plot $\ln J$ vs. $T^{-3}(\ln S)^{-2}$ and the resulting straight line has an intercept of $\ln A$ and slope

$$
M=-\frac{16 \pi \gamma^{3} \nu^{2}}{3 k^{3}}
$$

Since $\nu$ is known for ice, ${ }^{100}$ this provides a convenient way of determining $\gamma$ without the need to calculate $A \cdot{ }^{17,103,104}$ 


\subsection{Heterogeneous classical nucleation theory}

A suitable surface in contact with supercooled water can reduce the energy barrier to nucleation and therefore catalyse ice formation. The Arrhenius equation for homogeneous nucleation can be adapted for the heterogeneous nucleation coefficient $\left(J_{\text {het }} / \mathrm{cm}^{-2} \mathrm{~s}^{-1}\right)$ :

$$
J_{\text {het }}(T)=A_{\text {het }} \exp \left(-\frac{\Delta G^{*} \varphi}{k T}\right)
$$

where $A_{\text {het }}$ is a pre-exponential factor in units of $\mathrm{cm}^{-2} \mathrm{~s}^{-1}$ and $\varphi$ is the factor by which the presence of a solid surface reduces the height of the energy barrier relative to homogeneous nucleation. This factor is often expressed in terms of an ice nucleating efficiency parameter, $m$ :

$$
\varphi=\frac{(2+m)(1-m)^{2}}{4}
$$

The parameter $m$ is equal to $\cos \theta$, where $\theta$ is the contact angle of a spherical ice nucleus in contact with a flat surface. While this concept is useful in terms of deriving simple equations, its physical significance is unclear since a critical ice cluster may not adopt a hemispherical form. Hence, values of $\theta$ reported in the literature should be regarded as a semi-empirical measure of how well a material catalyses ice nucleation. A value of $m=1$ (i.e. $\theta=0^{\circ}$ ) would correspond to a perfect ice nucleus $(\varphi=0)$, whereas a value of $-1\left(\right.$ i.e. $\left.\theta=180^{\circ}\right)$ would indicate that a surface does not nucleate ice $(\varphi=1)$. Combining the above we can see that the heterogeneous nucleation rate can be expressed as: $:^{94,103,104}$

$$
\ln J=\ln A_{\text {het }}-\frac{16 \pi \gamma^{3} \nu^{2}}{3 k^{3} T^{3}(\ln S)^{2}} \frac{(2+m)(1-m)^{2}}{4}
$$

Hence, over a narrow range of temperatures a plot of $\ln J$ verses $T^{-3}(\ln S)^{-2}$ yields a linear plot with slope

$$
M=-\frac{16 \pi \gamma^{3} \nu^{2}}{3 k^{3}} \frac{(2+m)(1-m)^{2}}{4}
$$

thus providing a means of determining $m$ if $\gamma$ is known, without the need to estimate $A_{\text {het }}{ }^{103,105}$ As with homogeneous nucleation, one has to make assumptions about which phase nucleates. Unfortunately, this is not straightforward, as is discussed in Section 3.

\section{The structure of ice which nucleates and grows}

In many studies it is implicitly assumed that that stable hexagonal phase of ice nucleates and grows when atmospheric water droplets freeze. This is perhaps reasonable given older literature (e.g. see Hobbs ${ }^{106}$ ), which indicate a metastable phase of ice only exists below about $-70{ }^{\circ} \mathrm{C}$. However, it is well known that in many systems a metastable phase will nucleate and crystallise in preference to a stable phase and will only later recrystallise to the stable phase at some finite rate; this is known as Ostwald's law of stages. ${ }^{94,96}$ In a recent study Malkin et al. ${ }^{97}$ showed that pure water droplets of $0.9 \mu \mathrm{m}$ diameter exclusively crystallised to a metastable form of ice at about $-40{ }^{\circ} \mathrm{C}$, consistent with Ostwald's law of stages.
This supports the hypothesis that crystallisation of water always proceeds through a metastable phase.

Let us now discuss the metastable phases of ice which might form when water freezes. Out of the 15 crystalline phases of ice that are known only ice I can form at atmospheric pressure. ${ }^{107}$ Traditionally it was thought that ice I came in two distinct forms: the stable hexagonal phase (ice $I_{h}$ ) and the metastable cubic phase (ice $I_{c}$ ). Both of these phases are made up of water molecules arranged in layers consisting of puckered sixmembered rings. In ice $I_{h}$ each layer is a mirror image of the previous layer, whereas in ice $I_{c}$ each successive layer is shifted a distance of half of the diameter of the hexagonal ring. However, diffraction data show that ice which forms from pure water droplets is neither of these phases. ${ }^{97}$ In fact, Malkin et al. ${ }^{97}$ show that this ice is fully stacking disordered, i.e. it is composed of randomly stacked layers of cubic and hexagonal sequences. This ice is named stacking disordered ice (ice $\mathrm{I}_{\mathrm{sd}}$ ) ${ }^{97}$ Furthermore, ice which was previously identified as ice $I_{c}$ was in fact stacking disordered ice. ${ }^{97,108,109}$

The diffraction work of Malkin et al. ${ }^{97}$ showed that water droplets crystallised to a stacking disordered ice, but it is important to bear in mind that we do not know from experiments which phase nucleated (i.e. the phase of the critical nucleus). This is important because parameterisations based on classical theory require some knowledge of the phase of the critical nucleus. Usually it is implicitly assumed that ice $\mathrm{I}_{\mathrm{h}}$ forms, ${ }^{110,111}$ but others have suggested the metastable ice $I_{c}$ may form. ${ }^{17,95,105}$ Homogeneous nucleation rates are more consistent with a substantially lower interfacial energy of ice $\mathrm{I}_{\mathrm{c}},{ }^{17,95,101}$ but direct observational evidence of the nucleating phase is lacking. However, computational studies indicate stacking disorder is present to scales approaching that of the critical cluster, ${ }^{97,112-115}$ and it is possible the critical cluster does not have a well-defined structure. In summary, the crystallisation of an atmospheric droplet is a poorly understood process and it is clear that the assumption that ice $I_{h}$ nucleates and initially grows may not be correct.

\section{Descriptions of experimental ice nucleation data}

In order to quantify ice nucleation in models and also to be able to quantitatively state which materials are the most import IN in the atmosphere we need a means of quantifying how efficiently a particular material nucleates ice. In the early days of ice nucleation research it was common to quote the threshold temperature or relative humidity at which ice was observed to form under a particular set of conditions (for example see Mason ${ }^{22}$ and Pruppacher and $\mathrm{Klett}^{7}$ ). While a threshold value might be useful when comparing different materials within the context of a single experimental design, it is much less useful when comparing results from different experiments or attempting to estimate the number of ice particles which will form under a given set of atmospheric conditions. For example, on injecting kaolinite aerosol particles into a chamber containing supercooled droplets Mason and Maybank ${ }^{116}$ reported a threshold temperature of $-9{ }^{\circ} \mathrm{C}$, whereas Hoffer ${ }^{88}$ reported a very different freezing temperature for $100 \mu \mathrm{m}$ diameter droplets, containing an unspecified quantity of kaolinite, of $-32{ }^{\circ} \mathrm{C}$. Given this data alone it is impossible to assess the impact of glaciation by this material in clouds. 
The variation in freezing temperatures measured in these early experiments most likely stems from differences in both the amount of material in the droplets and the mode of nucleation. In order to quantitatively compare ice nucleation by different materials in laboratory studies it is essential to quantify how much material is available for nucleation and to design the experiment in a manner such that the mode of nucleation is unambiguous.

There are two primary motivations for wanting to describe heterogeneous ice nucleation. The first motivation is to attempt to understand and describe ice nucleation from a fundamental perspective, whereas the second is to describe ice nucleation by complex natural materials in a way which captures the dominant ice nucleating properties of natural aerosol in a relatively simple way.

Nucleation is a stochastic process, meaning the probability of nucleation occurring is dependent on time as well as the amount of heterogeneous nucleating material. This is clear in the classical theory described above. In some idealised laboratory experiments the sample being investigated was uniform with each particle having much the same ice nucleating probability as the next. ${ }^{105,117-119}$ In contrast, natural atmospheric aerosol tend to be much more complex, primarily for the reason that natural aerosol is made up of a wide range of different materials each with its own ice nucleating characteristics. For example, droplets containing relatively pure kaolinite froze over just a few degrees and freezing systematically shifted to higher temperatures as the amount of kaolinite in the droplets was increased or cooling rate was reduced; this data fitted a simple stochastic model. ${ }^{105}$ In contrast, droplets containing a dust more representative of natural atmospheric mineral dust composed of a range of minerals nucleated ice over a much broader temperature range and required a much more complex model to describe the data. ${ }^{120-122}$ In order to simplify this complex behaviour it has been suggested that the time dependence, or stochastic behaviour, of ice nucleation can be neglected, which has given rise to the singular description. In the following sections we discuss the stochastic and singular approaches.

\subsection{The stochastic description}

In this discussion we will consider an array of droplets each containing material which could nucleate ice. The stochastic model is often implicitly assumed to refer to a situation in which each droplet in an array contains exactly the same material and therefore has the same probability of freezing. This case has been referred to as the single component stochastic description, with 'single component' referring to the uniformity of droplets, i.e. the freezing of all droplets can be described by a single probability. ${ }^{105,120}$ The condition of droplet uniformity often does not always hold and droplets may contain different amounts of material or different particle types. This heterogeneity leads to some droplets having a greater probability of freezing at a given temperature and freezing of the whole population of droplets cannot be described by the single component stochastic description. Instead each droplet will have a temperature and time dependent probability of freezing and can then be described by a stochastic model which includes multiple nucleating components to account for the droplet to droplet inhomogeneity. This section begins with a discussion of the single component stochastic description and then expands to describe the how various authors have developed this description to cope with multiple ice nucleating components.

4.1.1 Single component stochastic (SCS) description. The probability of a critical cluster forming increases with larger IN surface areas and with longer periods of time. This is valid for particles on which water vapour deposits as ice or droplets in which immersed particles catalyse ice formation. In the case of deposition mode nucleation, $J_{\text {het }}$ should be derived as a function of relative humidity and temperature, whereas for immersion freezing $J_{\text {het }}$ should be derived as a function of temperature (since the temperature of pure water defines the supersaturation). Given the topic of this review article, we focus on immersion freezing.

The rate $(R)$ at which droplets freeze to form ice particles can be defined as:

$$
R=\frac{\mathrm{d} N}{\mathrm{~d} t}=-J_{\mathrm{het}} s N
$$

where $\mathrm{d} N$ is the number of ice free liquid droplets containing nucleant surface area $s$, which activate to ice in time $t$. It is assumed that a single nucleation event will lead to a droplet freezing.

In a time interval from $t_{1}$ to $t_{2}$, the number of droplets which are liquid will decrease from $N_{1}$ to $N_{2}$ :

$$
\int_{N_{1}}^{N_{2}} \frac{\mathrm{d} N}{N}=\int_{t_{1}}^{t_{2}}-J_{\text {het }} s \mathrm{~d} t
$$

This integration yields

$$
N_{2}=N_{1} \exp \left(-J_{\text {het }} s \Delta t\right)
$$

where $\Delta t=t_{2}-t_{1}$. Since the number of droplets which freeze $\left(\Delta n_{\text {ice }}\right)$ in a time increment is equal to $N_{1}-N_{2}$, the fraction of droplets frozen in $\Delta t$ can be expressed:

$$
\frac{\Delta n_{\text {ice }}}{N_{1}}=1-\exp \left(-J_{\text {het }} s \Delta t\right)
$$

In this model the probability of droplets with the same nucleant surface area remaining liquid $\left(P=N_{2} / N_{1}\right)$ is equal (i.e. droplet uniformity) and a population of identical ice-free droplets will decay with time in a manner analogous to the radioactive decay of atoms, i.e. the number of liquid droplets should decay exponentially. This has clearly been shown to be the case for pure water droplets freezing homogeneously, where the condition of droplet uniformity is met. ${ }^{120,123} \mathrm{It}$ has also been shown to be the case for droplets of water containing kaolinite (see Fig. 3a). ${ }^{105}$ The repetitive freezing of droplets containing silver iodide also produces a single exponential decay of the probability of the droplet remaining liquid with time (Fig. 3a). ${ }^{117-119}$

Some care needs to be taken in justifying the assumption of droplet uniformity required to apply the SCS model. It is not possible to decide if this approximation holds when only a single population of droplets are cooled under a specific 
a) Single component stochastic

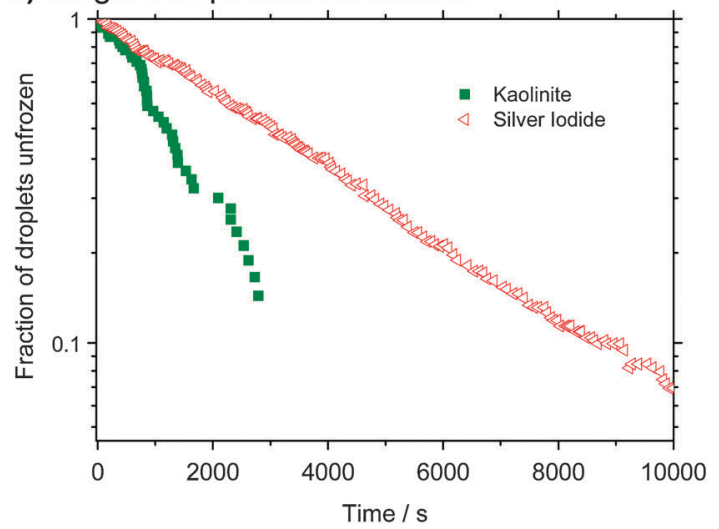

b) Multiple component stochastic

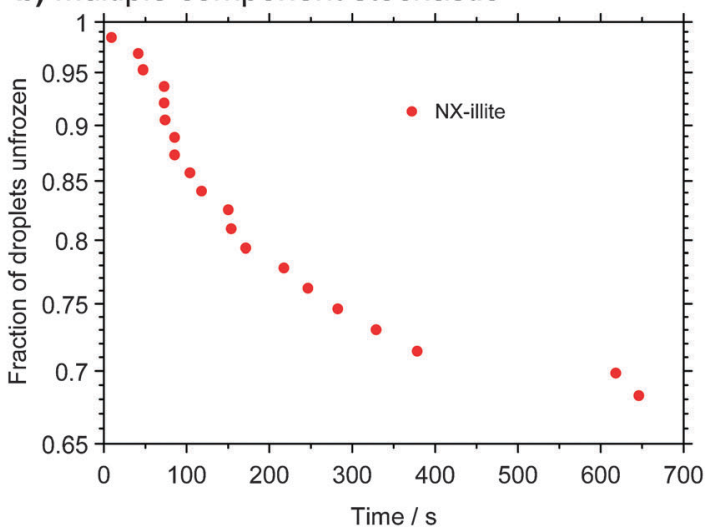

Fig. 3 Decay of liquid droplets with time under isothermal conditions. (a) Data are shown for kaolinite ${ }^{105}$ and also silver iodide; ${ }^{118,119}$ note that the surface area and temperature were different in the two experiments. The kaolinite experiment was done with multiple kaolinite containing droplets supported on a hydrophobic surface and freezing was monitored over time at $-29{ }^{\circ} \mathrm{C}$. The silver iodide experiment was done by repeatedly cooling to $-4.9^{\circ} \mathrm{C}$, waiting for freezing, and thawing a droplet containing a silver iodide crystal. Each point represents the time it took for the droplet to freeze in one experiment. Freezing by material in both of these experiments is consistent with a single component stochastic model since the decays are approximately exponential. However, multiple experiments would be needed to assess particle-to-particle variability in the case of the silver iodide particles. (b) Data for an array of droplets held at $-30{ }^{\circ} \mathrm{C}$ containing a dust which is made up of numerous minerals (NX-illite). Each droplet has a different probability of freezing at this temperature which is consistent with the multiple component stochastic model. Note that the axes displaying the fraction of droplets unfrozen are plotted on a log scale in both panels a and b (although this is difficult to see by eye in panel b).

set of conditions; other experiments are required. ${ }^{120,124}$ One approach is to test the time dependence of nucleation under isothermal conditions. A uniform population of liquid droplets will decay exponentially with time as discussed above. The case where the decay is not exponential is discussed in the next section. Another test is to repeat the experiments at different cooling rates. Results from an ice nucleation study by a relatively pure kaolinite particles immersed in a population of droplets were well described by the SCS model for experiments with a wide range of cooling rates. ${ }^{105}$ Hence, freezing by this kaolinite sample is consistent with the SCS model. A contrasting study is that of Broadley et al. ${ }^{120}$ who studied an illite rich sample containing many minerals. They show that single data sets (from a single population cooled at a constant rate) can be parameterised with the SCS model. However, when they compared their results for experiments at different cooling rates the SCS model failed, indicating that the assumption of droplet uniformity did not hold for this material. Instead the description of ice nucleation by this complex mixture of minerals must reflect droplet heterogeneity (i.e. different droplets have a different probability of freezing).

4.1.2 Multiple component stochastic (MCS) description. In many ice nucleating materials there is a mixture of particle types, each with its own ice nucleating ability. In a given sample of such a material, some particles would be expected to initiate freezing sooner and at higher temperatures than others. Accordingly, a plot of the number of ice free droplets would not be exponential. An example of this is given in Fig. 3b, where a dust composed of many minerals, and hence many nucleation sites, was immersed in water droplets. In this example the decay was clearly not exponential and only $30 \%$ of the droplets froze over the course of the 650 second long experiment. In this case the SCS description cannot be used and instead the distribution of particle types must be accounted for. We refer to this as the multiple component stochastic (MCS) description.

There are a number of methods discussed in the literature which we place under the general heading of MCS descriptions. ${ }^{105,120-122,124-128}$ In general these methods sum the effect of many different ice nucleating particles. Murray et al. ${ }^{105}$ express the fraction of droplets which activate to ice in a time interval where the droplets have a distribution of ice nucleating abilities as:

$$
\frac{\Delta n_{\text {ice }}}{N}=1-\exp \left(-\sum_{\mathrm{i}} J_{\mathrm{i}} s_{\mathrm{i}} \Delta t\right)
$$

Ice nucleation by each ice nucleus of type i can be described by a temperature dependent nucleation rate coefficient, $J_{\mathrm{i}}$. Murray et al. ${ }^{105}$ suggest determining $J_{\mathrm{i}}$ for each major atmospheric nucleus type in the atmosphere which would allow us to calculate the ice activation spectrum for any atmospheric situation if the aerosol composition were known. Alternatively, others have characterised a continuous distribution of $J_{\mathrm{i}}$. This has been done by defining a distribution of contact angles in the context of classical nucleation theory. ${ }^{121,125-127}$ For example, Marcolli et al. ${ }^{121}$ described ice nucleation by Arizona Test Dust by fitting a lognormal distribution of contact angles to describe particle to particle variability. This was similar to Stoyanova et al. ${ }^{125}$ who used only three contact angles to describe ice nucleation by their urban aerosol sample. Welti et al. ${ }^{128}$ found that a kaolinite sample from the Fluka chemical supplier, which exhibited time dependence, was also best described with a distribution of contact angles in the context of classical theory. This is in contrast to Murray et $a l .{ }^{105}$ who showed that ice nucleation by a kaolinite sample from the Clay Mineral Society fitted well to a single component 
stochastic model (i.e. a single contact angle). The difference between the results of Murray et al. and Welti et al. is most likely the source and purity of the clay samples used. Niedermeier et al. ${ }^{122}$ proposed a model in which IN were described with a conceptual soccer ball, with each panel of the ball having an associated nucleation temperature dependent probability of freezing. The freezing probability associated with each panel was described using classical theory and controlled by a distribution of contact angles. Broadley et al. ${ }^{120}$ demonstrated that the lack of cooling rate dependence of freezing by their illite rich sample (containing a range of minerals) could not be described using classical theory. They found that the nucleation rate coefficient was not sufficiently steep to reproduce the observed cooling rate independence when using the contact angle approach. Instead they modelled their data with $J_{\mathrm{i}}$ defined by a linear equation in which the parameters could be adjusted. Barahona ${ }^{124}$ recently proposed a stochastic formulation which encapsulates particle variability and time dependence in a form more suitable for modelling studies. At present this description is for deposition nucleation, but Barahona ${ }^{124}$ suggests it could be extended to immersion freezing.

\subsection{The singular description}

An alternative way of dealing with the complexity of the particle to particle variability is to make the assumption that the time dependence of nucleation is of secondary importance in comparison to the distribution of ice nuclei types. This has given rise to the singular description. ${ }^{7,129,130} \mathrm{~A}$ result of this assumption is that nucleation will occur at a particular site at a characteristic set of conditions. Immersion mode freezing by a particular IN type will occur at a characteristic temperature, $T_{\mathrm{c}}$, above which ice nucleation cannot occur. The temperature at which an IN containing multiple nucleation sites activates to ice is determined by the nucleation site with the highest $T_{\mathrm{c}}$. A similar statement can be made about the deposition mode, but where there are two variables: temperature and relative humidity.

Let us consider the case where there is an array of droplets where the ice-nucleating ability of the particles dispersed through the droplets population is heterogeneous (i.e. different droplets have nucleation sites with different $T_{\mathrm{c}}$ in them). In this case freezing would occur over a range of temperatures, i.e. a spectrum of ice activation temperatures. On cooling, the fraction of droplets that freeze by temperature $T, f_{\text {ice }}(T)$, can be described by: ${ }^{105,120,131-133}$

$$
f_{\text {ice }}(T)=\frac{n_{\text {ice }}(T)}{N_{\text {tot }}}=1-\exp \left(-n_{\mathrm{s}}(T) s\right)
$$

where $n_{\text {ice }}(T)$ is the cumulative number of frozen droplets at temperature $T$ and $n_{\mathrm{s}}(T)$, the active site density, is the cumulative number of nucleation sites per surface area that are active between the ice melting temperature $\left(0{ }^{\circ} \mathrm{C}\right.$ for pure water) and temperature $T$.

The density of surface sites that become active per unit temperature, $k(T)$, is formally related to $n_{\mathrm{s}}(T)$ by:

$$
n_{\mathrm{s}}(T)=-\int_{T_{0}}^{T} k(T) \mathrm{d} T
$$

where $T_{0}$ is the melting point (for pure water: $0{ }^{\circ} \mathrm{C}$ ).
Vali ${ }^{134}$ defined similar quantities, but rather than expressing the cumulative nucleation sites per unit surface area, it was expressed per unit volume and was termed the cumulative nucleus spectrum $K(T)$ :

$$
\frac{n_{\text {ice }}(T)}{N_{\text {tot }}}=1-\exp (-K(T) V)
$$

If the mass concentration ( $C_{\mathrm{m}}$, mass per volume of liquid) and specific surface area $\left(s_{\mathrm{sp}}\right.$, surface area per unit mass) of the material in the sample is known that $K$ can be related to $n_{\mathrm{s}}$.

$$
K=n_{\mathrm{s}} s_{\mathrm{sp}} C_{\mathrm{m}}
$$

Another approach is to express the cumulative number of ice active sites per unit dry mass ( $n_{\mathrm{m}}$, per unit mass):

$$
K=n_{\mathrm{m}} C_{\mathrm{m}}
$$

When there are discrete ice nucleating particles, such as bacterial cells, it is useful to express the cumulative number of ice active sites per particle $\left(n_{\mathrm{n}}\right.$, per cell, grain, etc.) where the number concentration of particles in water is $C_{\mathrm{n}}$ :

$$
K=n_{\mathrm{n}} C_{\mathrm{n}}
$$

The above expression for $n_{\mathrm{s}}$ can be simplified for situations where $f_{\text {ice }}<0.1:^{135}$

$$
n_{\mathrm{s}}(T)=\frac{n_{\text {ice }}}{s_{\text {tot }}}
$$

where $s_{\text {tot }}$ is the total surface area available for nucleation. ${ }^{135,136}$

\subsection{Modified singular description}

In order to test the assumption of time independence, Vali ${ }^{130}$ conducted a sequence of experiments to study the repeatability of freezing individual water droplets and found that the same droplets tended to freeze within a few degrees on repeated temperature cycling, although differences of up to $5{ }^{\circ} \mathrm{C}$ were occasionally observed. According to the standard singular description, if the same droplet is cooled and warmed repeatedly it will always freeze at the same temperature. In comparison with the broad spectrum of freezing temperatures $\left(-5\right.$ to $\left.-24{ }^{\circ} \mathrm{C}\right)$ this variability on repeated freezing is relatively small, but nevertheless indicates that there is a non-negligible stochastic element to freezing. The time dependent nature of nucleation was illustrated by an observed $0.4{ }^{\circ} \mathrm{C}$ shift in freezing temperatures when the cooling rate was increased by a factor of six. In an earlier study Vali and Stansbury ${ }^{137}$ observed a $0.2{ }^{\circ} \mathrm{C}$ change in mean freezing temperature with a factor of two change in cooling rate for the heterogeneous freezing of distilled water droplets. This observation led Vali ${ }^{129}$ to propose a modification to the singular approximation, presented here in terms of surface area rather than droplet volume: ${ }^{105}$

$$
f_{\text {ice }}(T)=\frac{n_{\text {ice }}(T)}{N}=1-\exp \left(-n_{\mathrm{s}}(T-\alpha) s\right)
$$

The variable $\alpha$ is the offset in temperature from a freezing spectrum recorded at a cooling rate of $1{ }^{\circ} \mathrm{C} \mathrm{min}^{-1}$ and is related to the cooling rate $(r)$ with an empirical parameter $\beta$ :

$$
\alpha=\beta \log (|r|)
$$


Vali $^{129}$ calculated $\beta$ to be 0.66 based on earlier observations ${ }^{137}$ of a $0.2{ }^{\circ} \mathrm{C}$ change in mean freezing temperature with a factor of two change in cooling rate for the freezing of distilled water droplets. Murray et al. ${ }^{105}$ found a stronger dependence on cooling rate for droplets containing kaolinite, with a $\beta$ of 2.01 . This results in a $2{ }^{\circ} \mathrm{C}$ decrease in freezing temperature on increasing cooling rate from 1 to $10{ }^{\circ} \mathrm{C} \mathrm{min}^{-1}$.

\section{Methodologies for quantifying ice nucleation by particles immersed in supercooled water}

The experimental techniques for the investigation of immersion mode ice nucleation can be conveniently classified into two broad categories where droplets are: suspended in gas (e.g. an aerosol of liquid droplets) or immobilised on a surface or in oil.

\subsection{Droplets suspended in gas}

Cloud expansion chambers are large temperature and humidity controlled vessels which are used to quantify deposition, immersion and condensation mode ice nucleation. ${ }^{71,135,138} \mathrm{~A}$ typical experiment involves expanding the gas in the chamber via pumping, resulting in a reduction of temperature and enhanced saturation ratio. In order to observe immersion mode freezing in a cloud chamber it is first necessary to increase the humidity to water saturation to activate aerosol particles as liquid droplets. If the sample nucleates ice below water saturation this may not be possible. On continued cooling, freezing can then be quantified by the appearance of ice crystals.

Continuous Flow Diffusion Chambers (CFDCs) are commonly employed in the laboratory and field for quantification of the concentration of IN in air samples. ${ }^{21,139-143}$ In order to determine the IN concentration, aerosol particles are passed into the chamber where the humidity is controlled by two ice coated plates set at different temperatures. ${ }^{143}$ Particles which nucleate ice in the time the aerosol spends in the supersaturated region are counted as they exit the chamber. A range of relative humidities are accessible in these instruments which allows studies of ice formation below water saturation and also in aerosol particles which have activated to droplets at or above water saturation. Another approach is to activate aerosol to droplets in advance of admitting them to the CFDC, which ensures that only the immersion mode is studied. ${ }^{126}$

Other techniques: Wind tunnels can be used to suspend single droplets in a flow of gas at controlled temperature and freezing probabilities are established as a function of temperature through observations with many droplets. ${ }^{89,144,145}$ Laminar flow chambers generate a supersaturation by mixing a cool dry flow containing aerosol with warmer more humid air. ${ }^{132,146}$ The proportion of aerosol which activated to ice under varying conditions is then determined down-stream. Free falling droplet systems have also been used to quantify freezing in micron sized water and solution droplets. ${ }^{147}$ Streams of droplets are allowed to fall into a well characterised cold chamber and freezing detected using a polarised laser system. Electrodynamic levitation of micron sized droplets has been used to study homogeneous nucleation of water, ${ }^{123}$ and could also be used for heterogeneous studies. Aerosol flow tubes have been used to study freezing by size selected nanometer scaled solid particles immersed in solution droplets of know composition. $^{148}$

\subsection{Droplets immobilised on a surface or in oil}

Supporting droplets on a hydrophobic surface and subsequent cooling is a common method of determining the efficiency with which any suspended particles nucleate ice. ${ }^{149}$ The droplets used range from microlitre down to picolitre sizes, with advantages at both ends of the range. Microlitre (millimetre sized) droplets are better suited to detection of rare, but highly efficient ice nuclei. A disadvantage is that droplets without any added nucleating material can freeze tens of degrees above the homogeneous limit, probably due to contamination in the droplets or on the supporting surfaces. ${ }^{149}$ In order to access the full range of atmospheric temperatures, i.e. down to homogeneous freezing, it is necessary to finely divide the droplets which, substantially reduces the probability of finding a contaminating particle in any one droplet. Division of droplets into picolitre volumes (microns in scale - similar to cloud droplets) and working with carefully prepared hydrophobic surfaces has been used to quantify heterogeneous freezing down to $\sim-37^{\circ} \mathrm{C} .{ }^{17,105}$

Immersing droplets in oil is another method of immobilising droplets for freezing studies. Droplets containing ice nuclei can be supported between two immiscible oil layers, ${ }^{88}$ or in an oil emulsion with a surfactant to stabilise the suspension. ${ }^{121,150,151}$ Droplets supported on hydrophobic substrates have also been immersed by oil which blocks mass transfer between supercooled water and ice crystals. ${ }^{105,120}$ This technique has the advantage that the time dependence of nucleation can be quantified by exposing droplets to a well-defined set of conditions for periods of hours (rather than seconds or minutes which are possible in CFDCs or cloud chambers). ${ }^{105,120}$ Freezing has commonly been monitored using microscopy, ${ }^{88,120}$ or differential scanning calorimetry. ${ }^{121,151}$ Microfluidic techniques have also been applied to heterogeneous freezing in which droplets were carried in a liquid fluorocarbon over a temperature controlled stage, with freezing detected optically. ${ }^{152}$

\section{Classes of ice nucleating aerosol}

\subsection{Mineral dusts}

Large quantities of mineral dust are aerosolised into the atmosphere from a range of sources, most notably from arid regions in Africa, the Middle East and Asia, referred to as the Dust Belt. ${ }^{42}$ Mineral dusts of varying types were shown to serve as effective ice nuclei decades ago. ${ }^{7,22}$ Nevertheless, it is only in recent years that quantitative measurements have been made on their ice nucleation efficiency in the immersion mode.

6.1.1 Mineral dust particles as important atmospheric ice nuclei. Early electron microscope work on individual snow crystals revealed that mineral dust particles were often found in their centre. ${ }^{153}$ This was consistent with laboratory fog chamber experiments in which various mineral dusts were found to effectively catalyse ice formation. ${ }^{7,22}$ More modern instrumentation, capable of in situ detection and characterisation of ice nuclei, confirm that mineral dust is an important ice nucleus, usually accounting for tens of per cents 


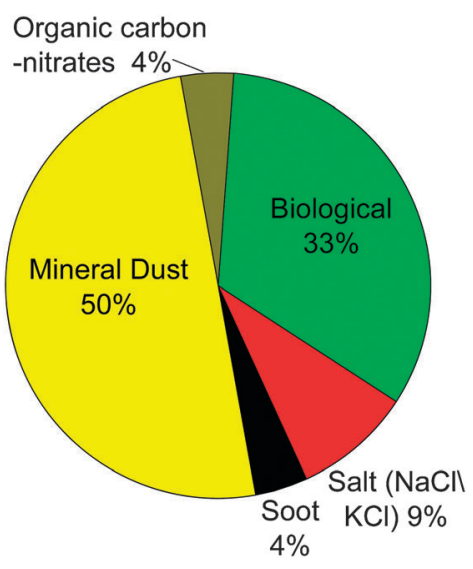

Fig. 4 Relative contributions of different particle types in ice residual particles sampled (46 were sampled) in a wave cloud $\sim 8 \mathrm{~km}$ above Wyoming as determined by aerosol time of flight mass spectrometry (ATOFMS). This is an example from a single flight and there was significant variability between different flights. Data taken from Pratt et al. ${ }^{156}$

of the total number of atmospheric ice nuclei. ${ }^{154-156}$ An example of the contribution of different particle types to the residues of ice crystals (assumed to be the ice nuclei) in a wave cloud over Wyoming is shown in Fig. 4; in this case $50 \%$ of the residues were mineral dust. ${ }^{156}$

The importance of mineral dusts as ice nuclei is also supported by studies within the modelling community. In 2004, Diehl and Wurzler ${ }^{87}$ produced parameterisations for illite, kaolinite and montmorillonite based on experiments by Hoffer ${ }^{88}$ and Pitter and Pruppacher. ${ }^{89}$ Unfortunately the experimental reports did not contain details of how much solid material was inside the droplets and the resulting parameterisations were therefore independent of the surface area of ice nucleating material. These parameterisations were used by Lohmann and Diehl ${ }^{86}$ in a general circulation model sensitivity study on mixed phase stratiform clouds and showed that the different mineral parameterisations had a significant effect upon the simulation (these simulations are discussed in Section 1.7). A parameterisation based on observations of ice nuclei using a CFDC has been produced by Phillips et al., ${ }^{157}$ who determined that mineral dusts and metallic particles were responsible for a large proportion of IN throughout the atmosphere. Further supporting this conclusion, recent simulations using a global climate model by Hoose et al. ${ }^{110}$ found that mineral dusts accounted for $77 \%$ of IN active between 0 and $-38{ }^{\circ} \mathrm{C}$.

6.1.2 The sources of mineral dust. Mineral dust aerosols are primarily eroded crustal rock which has been lifted into the atmosphere by wind and turbulence. Rates of dust uplift are dependent upon several different factors, such as wind speed and land surface conditions; ${ }^{158}$ arid areas with little vegetation, such as deserts, are important source regions. ${ }^{42,159}$ It has been estimated that 1000 to $3000 \mathrm{Tg}$ of mineral dust is aerosolised each year ${ }^{160}$ and up to $50 \%$ of this may be related to anthropogenic activity primarily through land usage changes such as desertification and deforestation. ${ }^{161,162}$

Mineral dust concentrations vary greatly on spatial and temporal scales depending on the uplift process and distance of transportation. Smaller scale features, such as dust devils of $1-10 \mathrm{~m}$ in size and lasting seconds to minutes, ${ }^{163}$ are responsible for the uplift of significant amounts of dust. ${ }^{164}$ Large scale convective systems and atmospheric circulations occur in the hour-month and $0.1-1000 \mathrm{~km}$ scales and are able to transport dust in the continental to global scale. ${ }^{165}$ For example, it has been estimated that $50 \mathrm{Tg}$ of dust is transported annually from Africa to the Amazon basin. ${ }^{166}$ Surface measurements, which at some locations have been on-going for several decades, show large variations in dust concentration depending upon location and season. ${ }^{159,167}$

As the nucleating efficiency of individual minerals differs (see Section 6.1.4), knowledge of bulk dust concentration alone is insufficient to understand the dust glaciation effect. Proportional mineralogy of bulk powder samples can be retrieved by X-ray Diffraction (XRD), however the lower limit of detection for most minerals using XRD is typically $0.5-1 \%{ }^{168}$ Electron microscopy can also be used to determine mineralogy in much smaller masses of material. ${ }^{169}$ Fig. 5 provides a comparison of observations of atmospheric dust mineralogies retrieved via XRD analysis, with the average observed composition shown in Fig. 6. Atmospheric dust is primarily composed of clay minerals (47\%), quartz (29\%) and feldspar minerals $(13 \%)$ with other minerals making up the remainder. Dust mineralogy is determined by laboratory analysis of filter samples collected either at the surface or from aircraft. Some details can be retrieved by in situ mass spectrometry, ${ }^{155}$ but many minerals have chemically similar compositions and mineralogy is not typically reported.

Global dust distributions can be retrieved using satellite products (see for example Schepanski et al., ${ }^{170}$ ). Progress has been made towards improving these retrievals to identify individual minerals. ${ }^{171}$ This would enable the study of how the composition of a dust plume changes with time and, in combination with laboratory studies, would enable a more accurate estimation of global mineral dust IN concentrations.

6.1.3 Dust mineralogy. Minerals are naturally occurring crystalline solid substances with a specified chemical composition and specific crystal structure. Silicates are the most abundant mineral type, of which the feldspar group is one of the most common. ${ }^{172}$ Most minerals fall into two broad categories: primary and secondary. Primary minerals are igneous in origin and are chemically and structurally unchanged since formation; notable examples include quartz and the feldspars. Secondary minerals are components of metamorphic and sedimentary rock, usually formed via processing of minerals and include the clay minerals. An example of a primary to secondary conversion process is acid weathering, such as that of potassium feldspar to form illite or kaolinite. ${ }^{173}$

The group of minerals most frequently observed in the atmosphere are the clays. Clays are part of the phyllosilicate group which are secondary minerals with a highly laminated (layered) structure. In the majority of clays, this structure is made up of repeating layers of silicon dioxide tetrahedrals and aluminium oxide octahedrals, with clays categorised by the numbers of each type of layer within the repeating structure. For example, the structure of kaolinite features single silicon 


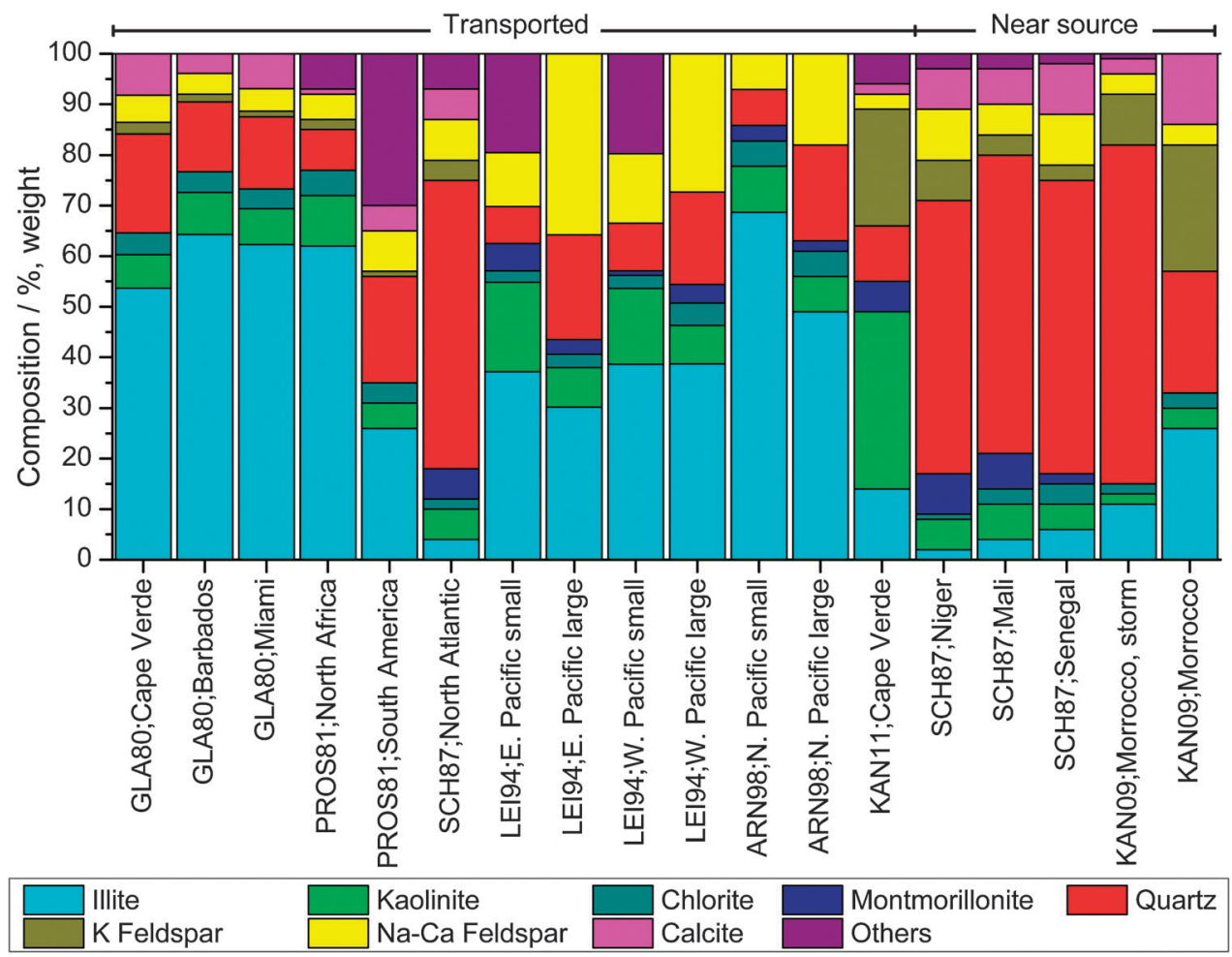

Fig. 5 A summary of atmospheric mineral dust compositions from XRD analyses. The data are split into mineral dust which was sampled near the source region (generally continental locations) and at locations a large distance from the source region (generally in marine locations). Dust sampled close to source was richer in materials associated with the coarse fractions, whereas the clay minerals were relatively enhanced in samples in remote locations. 'Others' includes materials such as gypsum, goethite, haematite, palygorskite and halite which were also identified in some studies. In addition, for the LEI94 study the 'other' category also includes material which could not be identified with X-ray diffraction. From left to right, GLA80: Glaccum and Prospero, ${ }^{331}$ PROS81: Prospero et al.; ${ }^{332}$ SCH87: Schütz and Sebert; ${ }^{176}$ LEI94: Leinen et al., ${ }^{333}$ small is particles $<2 \mu \mathrm{m}$, large between $2 \mu \mathrm{m}$ and $20 \mu \mathrm{m}$; ARN98: Arnold et al. ${ }^{334}$ sizes as in LEI94; KAN09: Kandler et al.; ${ }^{335}$ KAN11: Kandler et al. ${ }^{336}$

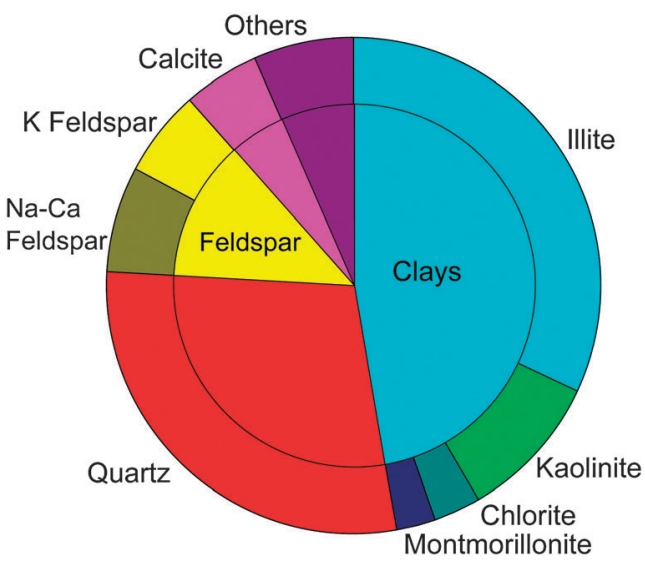

Fig. 6 Average of atmospheric dust compositions shown in Fig. 5. Averaging is done without any weighting. Where mineralogy of different particle size bins are provided in a particular study only the smaller size is included. 'Others' is defined in the caption for Fig. 5.

and aluminium layers repeating and is referred to as a $1: 1$ clay mineral (see Fig. 7B). In montmorillonite, the aluminium layer is sandwiched between silicon layers and is referred to as a 2 : 1 clay mineral (Fig. 8). Within these layers, ion substitutions frequently occur, such as $\mathrm{Al}^{3+}$ for $\mathrm{Si}^{4+}$ and $\mathrm{Mg}^{2+}$ for $\mathrm{Al}^{3+}$. Any resulting charge imbalances caused by these substitutions are balanced by cations located within the inter-layer region.
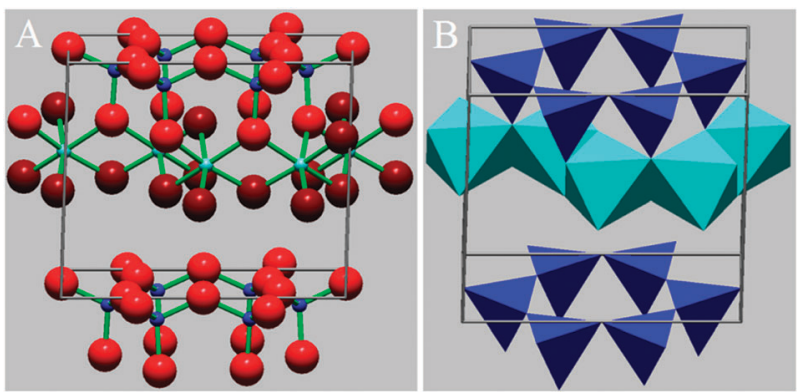

Fig. 7 Representations of the structure of kaolinite, a $1: 1$ clay mineral (see Section 6.1.3). Fig. 7A (left) is a ball and stick structure, explicitly showing the location of all atoms within the structure. Light blue $-\mathrm{Al}^{3+}$, dark blue $-\mathrm{Si}^{4+}$, red (large) $-\mathrm{O}^{2-}$, dark red (large) $-\mathrm{OH}^{-}$. Fig. 7B is a polygonal representation: Light blue octagons represent $\mathrm{AlO}_{0.5}(\mathrm{OH})_{2}$, dark blue tetrahedra representing $\mathrm{SiO}_{2}$. In each polygon, the cation position is in the centre, with the anions on the points. The $\mathrm{OH}$ groups, as shown in the spherical representation, occupy the lower side of the $\mathrm{Al}$ layer, and the positions on the upper side of the $\mathrm{Al}$ layer in the centre of the Si tetrahedral hexagons. Crystal structures are drawn using XtalDraw. ${ }^{337}$

The layered structure of the clay minerals introduces weakness and all have a Mohs hardness of less than 3 (on this scale diamond has a value of 10 and talc has a value of 1$).{ }^{172}$ Consequentially the clays readily break up into small, thin, 


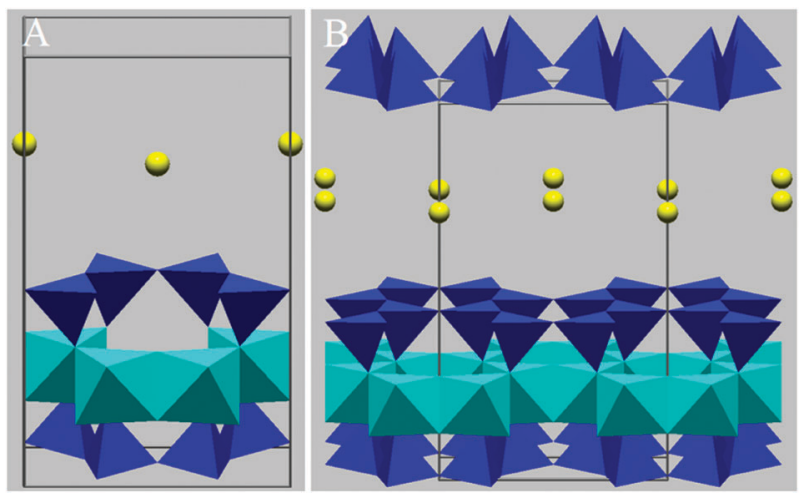

Fig. 8 Polygonal representations of montmorillonite. Panel A (left) displays the unit cell, and B (right) displays an expansion of the structure, highlighting the layering and hexagonal arrangements within the structure. As in Fig. 7, light blue octahedrals represent aluminium, specifically $\mathrm{AlO}(\mathrm{OH})$, and dark blue tetrahedrals represent $\mathrm{SiO}_{2}$. Yellow spheres represent interlayer $\mathrm{Ca}^{2+}$ cations. All polygon points represent $\mathrm{O}$, except on $\mathrm{Al}$ polygons where any point not connecting to a silicon tetrahedral represents an $\mathrm{OH}$ group.

plate-like particles with a higher surface to volume ratio and greater asphericity than most other minerals.

6.1.3.1 Clay minerals: kaolinite. Kaolinite has the simplest structure of the clay minerals commonly found in the atmosphere. It is a common component of soil and has a density of approximately $2.65 \mathrm{~g} \mathrm{~cm}^{-3}$. With repeating aluminium and silicon layers, as shown in Fig. 7, kaolinite is a $1: 1$ clay mineral. The chemical composition of kaolinite is $\mathrm{Al}_{4} \mathrm{Si}_{4}(\mathrm{OH})_{4} \mathrm{O}_{10}$. Ion substitutions within kaolinite are infrequent, with hydrogen bonds providing inter-layer attraction. The relatively high strength of these inter-layer attractions prevents ions or molecules such as water from entering this region. ${ }^{172}$

6.1.3.2 Clay minerals: montmorillonite. Montmorillonite is a common mineral of the smectite group, with an average density of $2.35 \mathrm{~g} \mathrm{~cm}^{-3}$. It has a $2: 1$ layered structure (see Fig. 8), with frequent substitutions of $\mathrm{Mg}^{2+}$ for $\mathrm{Al}^{3+}$ within the octahedral layer. The resulting charge imbalance is usually countered by the presence of $\mathrm{Ca}^{2+}$ or $\mathrm{Na}^{+}$ions within the interlayer region and the chemical composition of montmorillonite is $(\mathrm{Na}, \mathrm{Ca})_{0.7}(\mathrm{Al}, \mathrm{Mg})_{4} \mathrm{Si}_{8} \mathrm{O}_{20}(\mathrm{OH})_{4} \cdot n\left(\mathrm{H}_{2} \mathrm{O}\right) .{ }^{172}$ The size of these ions combined with their distance from the negatively charged inner layer results in weakly bound layers. ${ }^{173}$ The consequence of this is the easy infiltration of the interlayer regions by ions and polar molecules (especially water) and as a result montmorillonite is a swelling clay with a high capacity for ion exchange. ${ }^{173,174}$ This swelling characteristic can make identification of montmorillonite difficult via XRD as the layer separation, and therefore the diffraction pattern, varies with humidity. ${ }^{172}$

6.1.3.3 Clay Minerals: illite. Illite is the prevalent mineral found in the atmosphere (see Fig. 6) and has an average density of $2.75 \mathrm{~g} \mathrm{~cm}^{-3}$. It has a $2: 1$ structure similar to that of montmorillonite, with frequent ion substitutions especially of aluminium for silicon (see Fig. 9A). ${ }^{172}$ This results in a higher layer charge than in montmorillonite and consequently stronger interlayer bonding and a non-swelling structure. ${ }^{173}$

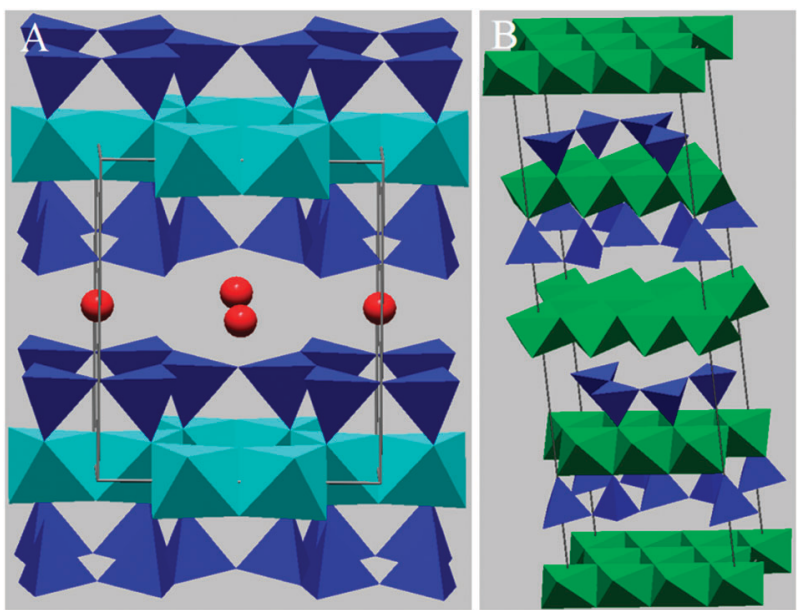

Fig. 9 Polygonal representations of illite (panel A) and chlorite (panel B). Panel A includes the unit cell of illite and has the same colour coding as montmorillonite (Fig. 8), but with red spheres representing $\mathrm{K}$. Note the much smaller separation of illite layers $v s$. montmorillonite layers. Panel B is the unit cell for chlorite with green octahedra represent metal ions, typically $\mathrm{Mg}^{2+}, \mathrm{Fe}^{2+}$ or $\mathrm{Al}^{3+}$, blue tetrahedra represent $\mathrm{SiO}_{2}$. The majority of octahedral polygon points in chlorite represent $\mathrm{OH}^{-}$groups, with those constituting part of $\mathrm{Si}$ tetrahedrals representing $\mathrm{O}^{2-}$.

This layer charge is compensated by the addition of potassium and hydronium ions between the repeating layers, resulting in a general chemical composition of $\mathrm{K}_{1.5} \mathrm{Al}_{4}(\mathrm{Si}, \mathrm{Al})_{8} \mathrm{O}_{20}(\mathrm{OH})_{4}{ }^{172}$

6.1.3.4 Clay Minerals: chlorite. While chlorite is not always classified as a true clay, ${ }^{172}$ it is often treated as a clay since it is a phyllosilicate (layered structure) and can exist in the same size range as typical clays (i.e. typically less than $2 \mu \mathrm{m}$ ). ${ }^{173,175,176}$ Chlorite refers to a group of minerals with a layer structure which is similar to a $2: 1$ clay, but with some important differences. Ion substitutions are similar to illite, but are generally more frequent. Also, unlike illite the interlayer cations are replaced by a layer of hydroxide octahedrals resulting in a $2: 1: 1$ structure (see Fig. 9B). This structure is strongly bound and non-swelling. Members of the chlorite group are classified by the primary non-aluminium or silicon ion present, such as clinochlore (magnesium, $\left.\left(\mathrm{Mg}_{10} \mathrm{Al}_{2}\right)\left(\mathrm{Al}_{2} \mathrm{Si}_{6}\right) \mathrm{O}_{20}(\mathrm{OH})_{16}\right)$ and chamosite (iron(II), $\left.\left(\mathrm{Fe}^{2+}{ }_{10} \mathrm{Al}_{2}\right)\left(\mathrm{Al}_{2} \mathrm{Si}_{6}\right) \mathrm{O}_{20}(\mathrm{OH})_{16}\right)$, with densities in the range of $2.6-3.3 \mathrm{~g} \mathrm{~cm}^{-3} .{ }^{172,173}$

6.1.3.5 Quartz. Quartz is a primary mineral which is present in most igneous rocks. Unlike the clay minerals, the structure of quartz is formed by a framework exclusively of silicon dioxide tetrahedrals, creating a compact arrangement of six membered loops (see Fig. 10A). This results in a very strong (Mohs hardness of 7), chemically resistant crystal structure which has a density of $2.65 \mathrm{~g} \mathrm{~cm}^{-3}$ and a tendency to break up into granular particles with a lower surface area to volume ratio than the clays. Also in contrast to the softer clay minerals, this hardness results in a resistance to erosion; quartz is found in most sedimentary rocks, including clay formations. ${ }^{172}$

6.1.3.6 Feldspar. The feldspar group of minerals are the most common crustal minerals. They are primary minerals usually of igneous origin, found in most volcanic ashes, and constitute 


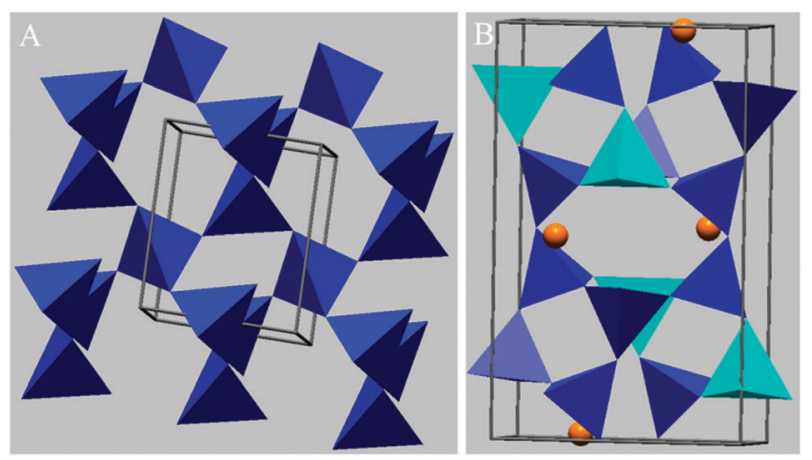

Fig. 10 Polygonal representations of quartz (panel A) and feldspar (panel B). Panel A shows quartz which consists of $\mathrm{SiO}_{2}$ tetrahedra arranged in six membered loops. Panel $\mathrm{B}$ shows the feldspar albite, with dark blue tetrahedra representing $\mathrm{SiO}_{2}$ and light blue tetrahedral representing $\mathrm{AlO}_{2}{ }^{-}$, arranged in loops of 4 . Orange spheres represent $\mathrm{Na}^{+}$, which balances the $\mathrm{AlO}_{2}{ }^{-}$charge. All tetrahedral points are occupied by $\mathrm{O}^{2-}$.

a large proportion of common rocks such as granite. Similar to quartz, the feldspars are composed of a framework of tetrahedrals, except with the replacement of some silicon by aluminium with the resulting negative charges balanced by the addition of a cation (potassium and sodium feldspars have $\mathrm{Al}: \mathrm{Si}$ ratios of $1: 3$, for calcium feldspar this is $1: 1$ ). The structure of the sodium feldspar albite is shown in Fig. 10B. The hardness of the feldspars (6-6.5 on the Mohs scale) means they are resistant to physical erosion. ${ }^{172}$ Plagioclase feldspars (those containing a mixture of calcium and sodium) form kaolinite when weathered by acids, whereas potassium feldspar tends to form illite as well as other clays. ${ }^{172,173}$ The feldspar minerals all have densities around $2.5-2.7 \mathrm{~g} \mathrm{~cm}^{-3}$. The chemical compositions of the feldspars are $\mathrm{CaAl}_{2} \mathrm{Si}_{2} \mathrm{O}_{8}$ (anorthite plagioclase), $\mathrm{NaAlSi}_{3} \mathrm{O}_{8}$ (albite plagioclase) and $\mathrm{KAlSi}_{3} \mathrm{O}_{8}$ (orthoclase/microcline). The plagioclase feldspars form a series of minerals composed of a mixture of anorthite and albite. ${ }^{172}$

6.1.3.7 Calcite. Calcite $\left(\mathrm{CaCO}_{3}\right)$ is a common carbonate mineral and is the principle component of a number of common sedimentary rocks including limestone and chalk. Its structure is similar to ionic substances such as $\mathrm{NaCl}$ (see Fig. 11), and due to its weakness (Mohs hardness of 3) easily

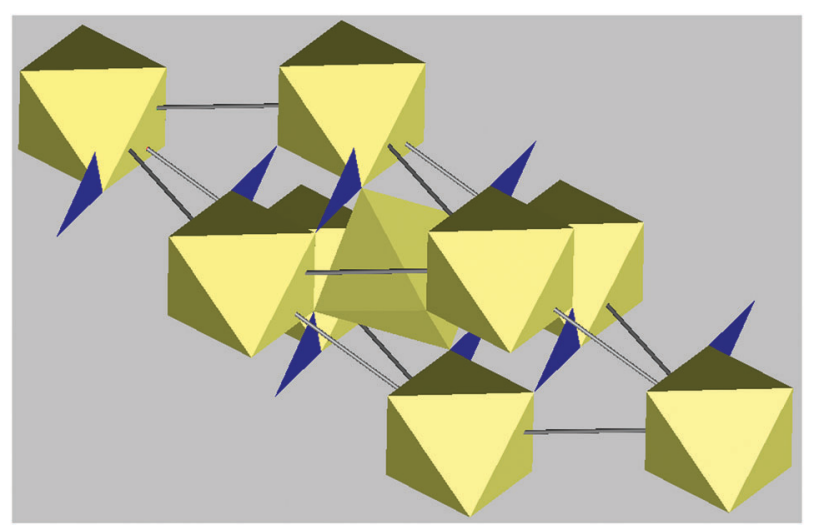

Fig. 11 Calcite, with yellow octahedrals representing $\mathrm{Ca}^{2+}$ and blue triangles representing $\mathrm{CO}_{3}{ }^{2-}$. All polygon points are occupied by $\mathrm{O}^{2-}$. breaks up into cubic grains. ${ }^{172}$ It reacts readily with acids, and via reactions with atmospheric sulphuric acid can be processed into gypsum. ${ }^{177}$ It has a density of $2.7 \mathrm{~g} \mathrm{~cm}^{-3} .{ }^{172}$

6.1.4 Laboratory-based investigations of ice nucleation by mineral dusts. There is a large body of older literature data, ${ }^{7,22}$ which demonstrates mineral dusts are capable of nucleating ice, but it is difficult to interpret this data quantitatively. In many of these experiments, specifically those in which a cloud of supercooled droplets (fog) was generated and then exposed to aerosolised mineral dusts, the mode of nucleation was not clear. $^{22}$ In some other experiments, in which the mode of ice nucleation was clearly immersion, the quantity of mineral dust per droplet was not quantified. ${ }^{88,89}$ In the past decade new instrumental approaches have been applied to the quantification of ice nucleation by mineral dusts in the immersion mode; the results from these studies are reviewed here. We split this discussion into three sections: the first in which ice nucleation by natural dusts are examined, the second in which well characterised single minerals are discussed and in the third we review the available data for proxies of natural dusts for laboratory studies.

6.1.4.1 Ice nucleation by natural mineral dusts. The active site densities determined for natural minerals dusts from several sources are shown in Fig. 12. The natural mineral dust samples that have been analysed are typically dusts collected from desert surfaces. Dust from non-arid regions contains significant components of biological material which can dominate ice nucleation, ${ }^{178}$ but we focus here on mineral dusts relevant for arid source regions which dominate mineral dust loadings. ${ }^{42}$ Connolly et al. ${ }^{131}$ acquired and tested dust samples from Asia and the Sahara at the AIDA expansion chamber in Karlsruhe. In these experiments dust was aerosolised and then exposed to a supersaturation sufficient for the condensation of water onto the particles. On expansive cooling the mineral dust particles were observed to act as IN and the fraction of

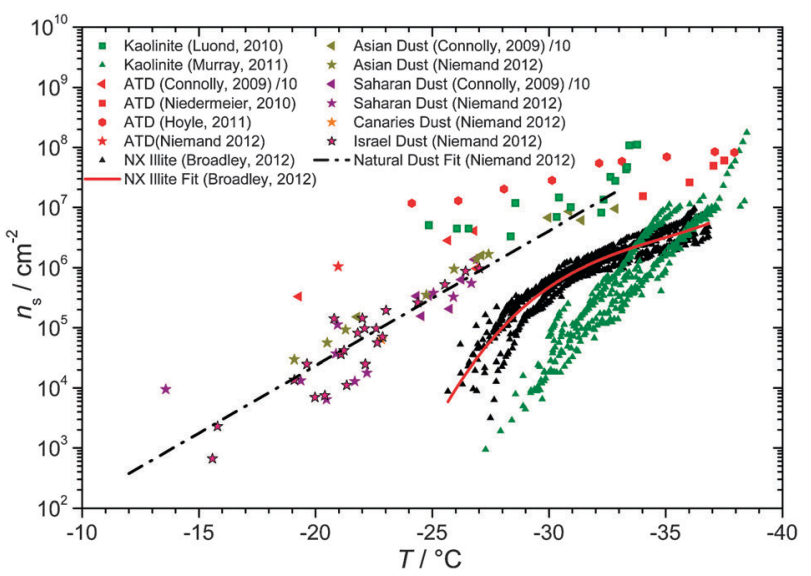

Fig. 12 A summary of mineral dust $n_{\mathrm{s}}$ values from Connolly et al., ${ }^{131}$ Niemand et al., ${ }^{135}$ Murray et al., ${ }^{105}$ Lüönd et al., ${ }^{126}$ Hoyle et al., ${ }^{181}$ Niedermeier et al., ${ }^{132}$ and Broadley et al. ${ }^{120}$ Values from Connolly et al. have been adjusted down by a factor of 10 , as per Niemand et al. ${ }^{135}$ in order to correct an earlier error in the data presented by Connolly et al. ${ }^{131}$ Details of included parameterisations can be found in Table 2. 
aerosol which catalysed freezing was determined. Combining this information with the size distribution of the mineral dust aerosol they were able to determine the cumulative ice nucleus spectrum in the form of the active site densities $\left(n_{\mathrm{s}}(T)\right)$. The $n_{\mathrm{s}}$ values reported by Connolly et al. ${ }^{131}$ have since been adjusted down by one order of magnitude. ${ }^{135}$ In a later study, Niemand et $a l .{ }^{135}$ expanded the AIDA study to dusts from Asia, the Sahara, the Canary Isles and Israel. A striking result from the AIDA studies is that mineral dusts from all sources appear to have similar ice nucleating efficiency and can be fitted with a single parameterisation (see Fig. 12). It seems that there is a common component of all these studied natural mineral dusts which causes it to nucleate ice, but unfortunately no mineralogical information was supplied by the authors.

In a study using emulsified droplets containing mineral dusts, Pinti et al. ${ }^{151}$ used differential scanning calorimetry (DSC) to study ice nucleation by dust from the Hoggar Mountains in the Sahara. Although they reported a freezing onset temperature of around $-26{ }^{\circ} \mathrm{C}$, it is non-trivial to estimate $n_{\mathrm{s}}$ values from the data provided. In order to estimate $n_{\mathrm{s}}$ values the fraction of droplets frozen as a function of temperature is required; unfortunately this information is not readily available from DSC data.

6.1.4.2 Ice nucleation by dusts composed of single minerals. There are very few ice nucleation studies of single minerals where the composition of the mineral dust was specified. Natural mineral powders sold as single minerals invariably contain finite quantities of other minerals and it is therefore never completely unambiguous which component causes ice nucleation. Natural minerals are never pure because secondary minerals, such as clays and carbonates, usually originate from sedimentary rock formations and frequently include quantities of other minerals which might survive weathering processes, such as quartz and feldspar. ${ }^{172}$ Due to the similar densities of all the aluminosilicate minerals, it is often impractical to remove such impurities. This must be borne in mind when interpreting ice nucleation results reporting to be for a particular mineral. In this section we review immersion mode ice nucleation studies in which it was reported that a single mineral was introduced to the droplets.

Illite is the most common mineral type in the atmosphere (Fig. 6), but immersion mode ice nucleation by this mineral has only been studied by Hoffer. ${ }^{88}$ In this study droplets were supported by an oil surface on a cold stage and a median freezing temperature of $-24{ }^{\circ} \mathrm{C}$ for an unknown concentration of illite was reported ( $n_{\mathrm{s}}$ values are not determined here because the amount of material per droplet is unknown). Details of the exact mineral composition were not provided, which is a concern since illite samples can contain substantial impurities. For example, Broadley et al. report ice nucleation by a mineral dust marketed as NX-illite, but showed it was made of a mixture of many minerals of which illite was one component (Broadley et al. ${ }^{120}$ suggest that this mineral dust is a good proxy for natural dusts which have been subject to long range transport, which is supported in this study - see Fig. 19).

Kaolinite, despite being a smaller component of natural atmospheric dust (Fig. 6), has been studied more intensively.
Early work by Hoffer ${ }^{88}$ and Pitter and Pruppacher ${ }^{89}$ (using a wind tunnel based system) found median freezing temperatures of -33 and $-25{ }^{\circ} \mathrm{C}$, respectively. Unfortunately, the amount of material per droplet was not reported in either of these studies and we therefore cannot estimate $n_{\mathrm{s}}$ values.

More recently, Lüönd et al. ${ }^{126}$ used a continuous flow diffusion chamber to investigate particles of 200 to $800 \mathrm{~nm}$ diameter of a commercial kaolinite (from Fluka; no more details, such as composition, were provided). They reported median freezing temperatures of -35 to $-33{ }^{\circ} \mathrm{C}$. A different kaolinite, of known mineralogy, was investigated by Murray et al. ${ }^{105}$ using a cold stage with droplets supported on a hydrophobic surface. This resulted in median freezing temperatures in close agreement with Lüönd et al. ${ }^{126}$ although the surface site densities $\left(n_{\mathrm{s}}\right.$, see Fig. 12) determined for these two studies are substantially different, with the results from Murray et al. ${ }^{105}$ up to three orders of magnitude smaller at $-27{ }^{\circ} \mathrm{C}$. Lüönd et al. ${ }^{126}$ report mobility diameters from which we determined a surface area assuming the particles were spherical. In combination with the reported fraction of droplets frozen we determine temperature dependent $n_{\mathrm{s}}$ values. In contrast Murray et al. ${ }^{105}$ used the $\mathrm{N}_{2}$ gas adsorption method to determine surface area. For the $800 \mathrm{~nm}$ particles used by Lüönd et al. ${ }^{126}$ we estimate that the gas adsorption surface area would produce an $n_{\mathrm{s}}$ value about four times smaller. This suggests that the discrepancies between Murray et al. and Lüönd et al. ${ }^{126}$ cannot be simply put down to differences in the method of determining surface area. It may be that there is an intrinsic difference between the kaolinite used in the two studies, since they are from two different sources. Alternatively, ice nucleation in one or both studies may have been dominated by a different mineral present in the samples. The clay mineral society kaolinite (KGa-1b) is a well characterised and documented material with $4 \%$ impurity of anatase (titanium dioxide) and crandallite (hydrated phosphate) with traces of dickite (another polymorph of kaolinite) and quartz. ${ }^{179}$ Unfortunately, the mineralogical make up of Fluke kaolinite used by Lüönd et al. ${ }^{126}$ is unknown. The enhanced ability of Fluka kaolinite over KGa-1b to nucleate ice was also recently confirmed by Pinti et al. ${ }^{151}$ in a calorimetry study.

Montmorillonite has been studied by several groups. Hoffer $^{88}$ and Pitter and Pruppacher ${ }^{89}$ reported median freezing temperatures of -24 and $-21{ }^{\circ} \mathrm{C}$ respectively. Details of sample mineralogy and concentrations were not reported. Conen et al. ${ }^{178}$ performed droplet freezing experiments using a commercial montmorillonite in $50 \mu \mathrm{L}$ droplets, with freezing beginning at $-10{ }^{\circ} \mathrm{C}$. Whilst Conen et al. provided values of $n_{\mathrm{m}}$ (ice nucleation sites per mass), they did not provide sufficient information to estimate $n_{\mathrm{s}}$. Pinti et al. ${ }^{151}$ provided DSC data for four different montmorillonites, of which two were sourced from the Clay Mineral Society (SWy-2 and STx-1b) and two commercially (two acid treated samples from Sigma Aldrich). Significant differences were evident between the samples, with three samples initiating freezing in a small proportion of droplets up to $10{ }^{\circ} \mathrm{C}$ higher due to a second, more effective, minor component. All four samples exhibited a freezing onset at -34 to $-37{ }^{\circ} \mathrm{C}$. None of the discussed montmorillonite experiments provided sufficient information to enable the inclusion of $n_{\mathrm{s}}$ values in Fig. 12. 
6.1.4.3 Ice nucleation by proxies for natural atmospheric mineral dust. Using laboratory proxies for natural mineral dust provides the benefits of allowing different groups with different instrumentation to benchmark their equipment and also explore a wide range of conditions with a well characterised material. A good proxy would have a well characterised particle size, surface area, and also mineralogy. To date, two commercial dusts have been suggested as proxies: Arizona Test Dust (ATD) and NX illite.

ATD is a dust supplied by Powder Technology Inc., USA, and has been the subject of numerous studies. It is made of material which has been milled to produce particles with a specific range of sizes and is sold on a commercial basis for testing the efficiency of filters. It is attractive for ice nucleation experiments because it has a well-defined particle size and is available in large quantities. As well as elemental compositions provided by Vlasenko et al., ${ }^{180}$ mineralogical composition has been provided by Broadley et al. ${ }^{120}$ In Fig. 12 we summarise and compare ice active site densities for a number of experiments performed in the immersion mode with ATD. Connolly et al. ${ }^{131}$ explored ice nucleation by ATD in the AIDA chamber during experiments similar to those described above for natural dusts. Their results are in good agreement with the later study by Niemand et al. ${ }^{135}$ which also made use of the AIDA chamber (also discussed above). Niedermeier et al. ${ }^{132}$ report $n_{\mathrm{s}}$ values for ATD determined with the LACIS (Leipzig Aerosol Cloud Interaction Simulator) chamber which is a temperature controlled laminar flow tube, allowing the activated fraction of aerosol particles to be determined under specific conditions. In addition, Hoyle et al. ${ }^{181}$ activated individual size-selected ATD particles to droplets and then measured the ice nucleating fraction using a continuous flow diffusion chamber. We have estimated the surface area based on a spherical assumption in conjunction with the reported fraction frozen data in order to derive $n_{\mathrm{s}}$ values. Ice nucleation in the immersion mode was also studied by Marcolli et al. ${ }^{121}$ using a DSC with emulsified micrometer sized droplets, but it is non-trivial to determine $n_{\mathrm{s}}$ values from this data since the fraction of droplets frozen was not reported. The $n_{\mathrm{s}}$ values for all four of the studies in which values were derived or reported are consistent with one another (see Fig. 12), which indicates ATD is a useful material for benchmarking and validating instrumentation.

The values of $n_{\mathrm{s}}$ for ATD are higher than those for the natural dusts shown in Fig. 12, which indicates that ATD is significantly more efficient at nucleating ice than natural dusts. This is also consistent with differential calorimetry studies which show ATD nucleates ice at higher temperatures than natural samples. ${ }^{121,151}$ The greater efficiency of ATD may be related to the milling process that ATD is subjected to in its manufacture, but it could also be related to its mineralogy which is significantly different to natural dusts (see Fig. 13).

A second dust called NX illite, produced by $\mathrm{B}+\mathrm{M}$ Nottenkaempe, Germany, has been proposed as a suitable proxy for natural dust. ${ }^{120}$ The efficiency of ice nucleation has been quantified for this material using a cold stage with micron sized droplets containing NX-illite supported on a hydrophobic surface. ${ }^{120}$ The justification for adopting this dust as
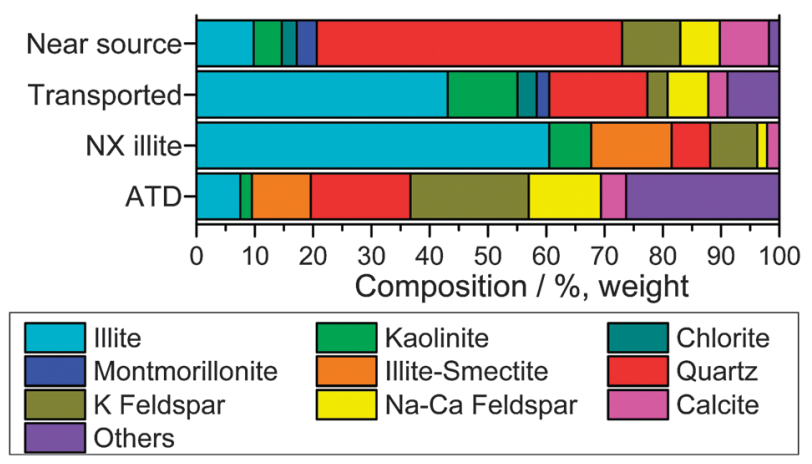

Fig. 13 Relative compositions of proxies of atmospheric mineral dust (NX-illite and Arizona Test Dust), in comparison with mineral dust sampled in the atmosphere. The natural atmospheric dust is classified as those near source regions (i.e. continental) and those transported some distance from the source (sampled over the oceans) - see Fig. 5 for classification of individual samples. The illite-smectite group is a mixed layer clay which has been distinguished in the X-ray diffraction patterns of bulk samples of the two proxy dusts. The illite-smectite component is identified on the basis of a weak feature in the diffraction pattern, hence it is not routinely reported in natural samples where signal to noise is limited by small sample sizes. The 'other' category for the natural material is defined in the caption for Fig. 5. For ATD the 'other' category also includes a substantial proportion of unusual mixed layer clays. ${ }^{120}$ Mineralogy of ATD and NX-illite are from Broadley et al. ${ }^{120}$

a proxy for natural dust which have been subject to long range transport (i.e. dust captured over oceans) is on the basis of its mineralogy. A comparison of the mineralogy of the proxy dusts is provided in Fig. 13 and shows that the mineralogical make up of NX illite and ATD are very different.

On a mineralogical basis, NX-illite is a closer match to transported natural dusts than ATD, which is greatly enhanced in minerals generally associated with the coarse mode (i.e. quartz and feldspars). However, the ice nucleating efficiency, expressed as $n_{\mathrm{s}}$ values, for NX illite is substantially smaller than the natural dusts (Fig. 12), but there is a caveat which needs to be considered when comparing these results. The methodologies used to derive surface area across these studies differed. For the natural dusts tested in the AIDA chamber experiments, surface areas were estimated assuming the particles were spheres of radii determined using mobility measurements. ${ }^{131,135}$ In contrast, the surface area of NX illite particles was based upon gas adsorption measurements in combination with the mass of dust per droplet. ${ }^{120}$

In a gas adsorption measurement the number of gas molecules, usually $\mathrm{N}_{2}$, required to make a monolayer coverage on the surface is determined and therefore a specific surface area (surface area per mass of solid) can be estimated if an assumption is made about how much space each molecule takes up on the surface. ${ }^{182}$ Surface areas for various kaolinites measured with atomic force microscopy and gas adsorption techniques agree to within $3 \%,{ }^{105,183}$ which increases confidence in the gas adsorption technique. Electron microscopy ${ }^{120,169,184}$ and atomic force microscopy ${ }^{183}$ of dust grains reveals that particles with geometric sizes of greater than 100s of nanometers are often made up of many grains of only 10 s of nanometers in size. Hence, mineral dust grains tend to have 
a true surface area significantly greater than the surface area of a sphere of equivalent size.

As a consequence of the different methods of estimating surface area, the way in which $n_{\mathrm{s}}$ is calculated in a particular experiment needs to be taken into consideration when using this data in estimating the number of ice crystals which could nucleate in the atmosphere. It seems sensible that if a spherical approximation has been made in the laboratory, then this assumption should also be made for atmospheric aerosol if they are of a similar size; whereas if a specific surface area has been used then a similar estimate should be made for the atmospheric counterpart. This is illustrated later in this review (Section 6 and Fig. 19) where it is shown that the prediction of concentration of potential ice nuclei using $n_{\mathrm{s}}$ values from the natural dusts and NX-illite are consistent with one another in the temperature range where they overlap. This further indicates that NX-illite is a good proxy for natural dusts which have been subject to long range transport.

\subsection{Biological material}

Although it has been known for more than 40 years that biological particles can act as efficient ice nuclei, their role in ice formation within supercooled clouds remains poorly understood. Primary biological aerosol particles, or PBAPs, encompass all airborne solid particles that are, or were derived from, living organisms. ${ }^{185}$ Aerosolisation of biological particles occurs as a result of both active and passive processes. ${ }^{186-188} \mathrm{~A}$ diverse array of biological entities are found in atmospheric aerosol including fragments of plants and animals, pollen, fungal spores, bacteria and virions (virus particles). ${ }^{185,189,190}$ Discussions on the potential impacts of biological aerosols upon ice formation processes in the atmosphere have featured in several previous reviews. ${ }^{5,8,157,187,190-192}$ In the next section, a brief summary of recent evidence from field observations and model studies implicating PBAPs as potentially important atmospheric IN will be introduced. Following this overview, a more detailed discussion on the characteristics of biological ice nuclei derived from laboratory studies is presented.

6.2.1 Atmospheric primary biological aerosol particles (PBAPs). Over recent years, estimates of the amount of PBAP emissions to the atmosphere have increased substantially. ${ }^{193}$ Based on observed concentrations, the strength of other sources and atmospheric residence times, Jaenicke et al. ${ }^{194,195}$ estimate that PBAP emissions may be on the order of $1000 \mathrm{Tg}$ per year. Numerous studies across a variety of sampling sites have found PBAPs constitute $\sim 20 \%$ by number $(d>0.4 \mu \mathrm{m})$ of the total aerosol. ${ }^{185,196-199}$ Clearly, ice nucleation by PBAPs in the atmosphere should be considered.

Although the extent to which PBAPs act as atmospheric IN has yet to be quantified, evidence has emerged to suggest that they are significant. In a study examining the nature of IN in precipitation collected from locations around the globe, Christner et al. ${ }^{200}$ found that for IN active at temperatures $\geq-9{ }^{\circ} \mathrm{C}$, on average $95 \%$ were deactivated by heat treatment ( $95{ }^{\circ} \mathrm{C}$ for $10 \mathrm{~min}$ ) which is consistent with the disruption of the membrane-bound proteins bacteria rely on for their IN activity. The authors also examined the effect of lysozyme (which catalyzes the hydrolysis of peptidoglycan in bacterial cells walls, and thereby disrupts the membranes) on the freezing behaviour and found that on average, $42 \%$ of the high temperature ice nuclei were inactivated across all the samples. Recently, Pratt and co-workers ${ }^{156}$ have also presented evidence that biological materials play a significant role in atmospheric ice nucleation processes. During an investigation into the composition of ice crystal residues sampled from a wave cloud above Wyoming, they used Aerosol Time of Flight Mass Spectrometry (ATOFMS) to show that biological particles and mineral dusts accounted for $33 \%$ and $50 \%$ respectively of the residues sampled in one particular cloud (Fig. 4). ${ }^{156}$ The potential importance of biological IN on a regional scale has also been highlighted by Prenni et al. ${ }^{201}$ during a field campaign investigating IN in aerosols sampled above the canopy at a site in the Amazon basin. By employing transmission electron microscopy and energy-dispersive X-ray diffraction, IN-active aerosol particles were shown to be primarily composed of mineral dust and carbonaceous materials. On the basis of ultraviolet aerodynamic particle sizer (UV-APS) measurements (which provides size resolved number concentrations of total and biological aerosol particles) the authors were able to infer that the carbonaceous fraction of IN was dominated by biological particles.

Bacteria, a single constituent of the biological aerosol, have gained considerable attention from atmospheric researchers interested in ice nucleation. Certain bacteria, designated $\mathrm{Ice}^{+}$, are amongst the most effective ice nucleators currently known, possessing the ability to nucleate ice at temperatures as high as $-2{ }^{\circ} \mathrm{C} .{ }^{202}$ Airborne bacteria are ubiquitous over land, with cell densities typically exceeding $10^{-2} \mathrm{~cm}^{-3} \cdot{ }^{203}$ On a global scale, inferring the proportions of airborne bacteria which possess the Ice ${ }^{+}$phenotype is a difficult task given available data. An early study published by Maki and Willoughby, ${ }^{204}$ found that in snow $15.4 \%$ of the bacteria isolated exhibited the Ice ${ }^{+}$ phenotype, while of the limited number (only five) of isolates in rainwater, none were similarly active. During the 1980s, Lindemann et al. ${ }^{205}$ sampled air from above a variety of canopies over plants including corn, wheat, alfalfa and pea and found that, at most, $3.9 \%$ of the bacterial colony forming units (CFUs) were active as IN above $-10{ }^{\circ} \mathrm{C}$. In a recent study of cloud water collected at two mountain sites in the Hebrides (UK), Ahern et al. ${ }^{206}$ showed that none of the Pseudomonad isolates, which dominated the samples, were $\mathrm{Ice}^{+}$strains. Of late, questions have been raised over how representative bacterial communities in freshly fallen precipitation or aerosol particles sampled in close proximity to the Earth's surface are of those typically found in mixed-phase clouds. ${ }^{207,208}$ Clearly, the bacterial community composition in cloud water is a topic which will require further study before firm conclusions can be drawn on the prevalence of Ice ${ }^{+}$ bacteria in the atmosphere.

While field studies suggest that biological IN may be involved in atmospheric ice formation at least on a regional/ seasonal scale, model studies have demonstrated mixed results on the net impacts of PBAPs in atmospheric ice formation processes. Diehl and Wurzler ${ }^{209}$ have examined the effects of bacterial IN in the immersion mode compared with other 
known ice nucleating particles such as mineral dust and soot using air parcel model simulations of a convective cloud. They used freezing parameterisations developed in previous studies. ${ }^{87,209,210}$ The authors found that the impacts of bacterial IN on ice formation in convective clouds were substantially less than that of mineral dusts. However, they assumed that 20 to $25 \%$ of the cloud droplets contained mineral dust particles, which seems high when mineral dust typically only makes up a small proportion of atmospheric aerosol. ${ }^{155}$ In comparison, the assumed fraction of cloud droplets containing bacterial IN was only $1 \times 10^{-8}$ to $0.01 \%$, hence it is not surprising that bacteria played a minor role in their modelling study. Phillips et al. ${ }^{211}$ examined the potential impacts from elevated bioaerosol concentrations on continental cloud ensembles, using a cloud-system resolving model. Ice nucleation by biological participles (termed 'insoluble organic' by Phillips et al. ${ }^{211}$ ) was parameterised using a scheme based on published laboratory data. ${ }^{157}$ During the simulations, concentrations were raised up to 100 times those typically seen at continental regions; a plausible factor given past observations of the PBAP variability. ${ }^{205}$ Cloud micro- and macrophysical properties, including average numbers and sizes of ice crystals and droplets in the clouds, horizontal cloud coverage and precipitation were demonstrated by the authors to be sensitive to the allowed variations in PBAP concentrations. In contrast, Hoose and co-workers ${ }^{110,212}$ found that the average contributions of bacteria, pollen and fungal spores to the global ice nucleation rate were minimal. Using immersion freezing parameterisations based on classical nucleation theory and laboratory measurements, less than $10^{-5} \%$ of heterogeneous ice nucleation in mixed-phase clouds was found to be due to the PBAPs included in the simulations. In contrast, $77 \%$ of the simulated heterogeneous nucleation was found to be initiated by mineral dust particles and $23 \%$ by soot. However, as noted by the authors the assumed IN active fraction of biological materials in the atmosphere remains uncertain, and further research is necessary to better constrain current estimates.

\subsubsection{Laboratory investigations of PBAPs}

6.2.2.1 Bacterial ice nuclei. Owing in part to their roles in the frost injury of plants, bacteria are the most intensively studied biological ice nucleators. Early indications that biological materials may exhibit ice nucleation activity (INA) emerged during the early 1970's when Schnell and Vali ${ }^{213,214}$ discovered that decaying leaves contained a source of highly active ice nuclei. Within a short period of time the causative agent was identified as Pseudomonas syringae, ${ }^{215}$ an epiphytic (leaf dwelling) bacterium. Although $P$. syringae may be the most abundant and widely distributed Ice $^{+}$bacteria identified to date, ${ }^{205,216,217}$ numerous other species of highly IN active bacteria have been identified, most of which have been isolated from the phyllosphere (leaf surfaces) and are Gram-negative (Gram staining is a technique to differentiate bacteria into one of two major groups, which differ in their cell wall structure). These include other pseudomonads such as strains of P. Aluorescens, ${ }^{218} P$. viridiflava ${ }^{219}$ and $P$. antarctica, ${ }^{220}$ along with a number of other Gram-negative bacteria including Pantoea agglomerans, Pantoea ananas ${ }^{221}$ and Xanthomonas campestris pv. translucens. ${ }^{222}$
Laboratory studies quantifying the ice-nucleating activity of Ice $^{+}$bacteria have required careful consideration of both the nature and source of the bacteria under examination, along with the characteristics of the nucleating sites. The ability of certain bacteria to nucleate ice at exceptionally small supercoolings has been localised to a membrane bound protein around $120-180 \mathrm{kDa}$ in size which is proposed to provide an epitaxial fit to ice. ${ }^{223-225}$ Disruption of the cell membrane, by either physical or chemical means, can lead to a reduction in the activity of Ice $^{+}$bacteria. $^{204,215,224,226}$ Conversely, bacteria do not necessarily need to be viable (able divide and form offspring) in order to express IN activity. For example, Maki and Galyan ${ }^{215}$ demonstrated that $P$. syringae remained IN active even after the cells were killed with the antibiotic polymyxin B. For some bacteria, IN activity is not necessarily constrained to the cells themselves; certain strains of $P$. agglomerans have been observed to shed membrane vesicles $50-200 \mathrm{~nm}$ in diameter which retain the nucleating capabilities of the parent cell. ${ }^{227}$ Within a given population of bacteria, distinct sub-populations of bacteria with varying IN activities exist. While for the most active cells (type I), ice nucleation activity is expressed at temperatures between -2 to $-5{ }^{\circ} \mathrm{C}$, other cells termed type II and III are only active at lower temperatures $\left(-5\right.$ to $-7{ }^{\circ} \mathrm{C}$ and -7 to $-10{ }^{\circ} \mathrm{C}$ respectively; using a microliter drop freezing assay). ${ }^{228}$ Differences between the nucleating sites are believed to be related to the degree of post-translational glycosylation in the $\mathrm{N}$ - and C-terminal regions of the protein and the degree of multimerisation of proteins in the outer membrane. ${ }^{229-231}$

The extent to which INA is exhibited by individual bacterial cells has been found to be dependent on a wide variety of factors. When grown in vitro for laboratory studies, expression of the Ice ${ }^{+}$phenotype is found to be dependent on culture conditions, such as the medium composition, ${ }^{232,233}$ water activity, ${ }^{234}$ and temperature ${ }^{235,236}$ along with the growth stage during which ice nucleation is assayed (an assay is an analysis done to determine a property of a system and is a term common in the biological ice nucleation community). ${ }^{228}$ Amongst strains of $P$. syringae the number of cells active as ice nuclei at $-5{ }^{\circ} \mathrm{C}$ ranges from most cells of some strains, to less than 1 in $10^{7}$ for others (for an illustration of the range of IN activities exhibited by bacteria see Fig. 14). ${ }^{237}$ In nature, the frequency of occurrence for IN active $P$. syringae strains varies with the environment of origin. In a study examining the abundance of $P$. syringae across a wide variety of potential habitats, Morris et al. ${ }^{217}$ found that while all strains isolated from snow samples were IN active, the proportion of $\mathrm{Ice}^{+}$ strains found on wild plants and epilithic biofilms (on the surface of rocks) were significantly lower. In addition O'Brien and Lindow have found that the IN activities of $P$. syringae strains are generally higher when grown on plants than in vitro and under these conditions, ice nucleation activity is controlled by complex and strongly interacting factors such as the host plant species along with environmental variables such as light intensity and relative humidity. ${ }^{238}$

When present in cloud waters, the effects of relevant environmental conditions on the INA of Ice $^{+}$bacteria must also be considered. Recently, Attard et al. ${ }^{239}$ have examined how acidic $\mathrm{pH}$ levels, exposure to UV-A and to reactive gases such 


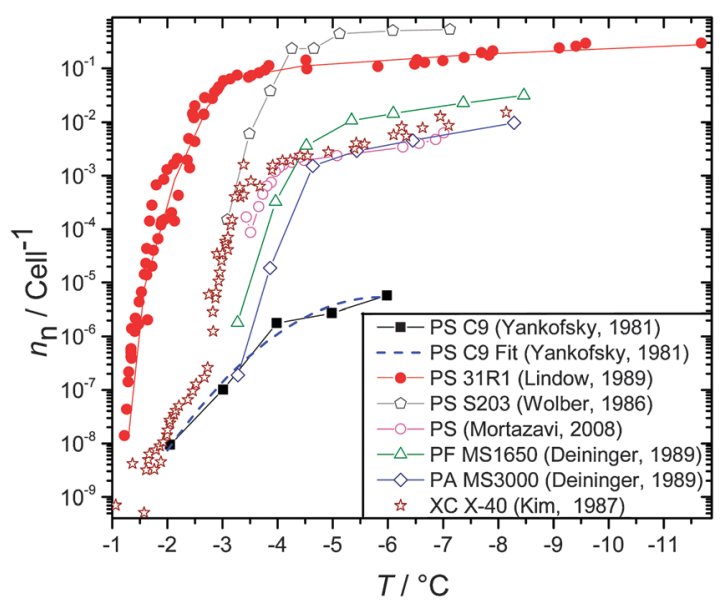

Fig. 14 Ice nucleating efficiency for a range of bacteria expressed as nucleation sites per cell $\left(n_{\mathrm{n}}\right)$. Included are data on various strains of Pseudomonas syringae (PS), ${ }^{22,225,244,338}$ along with Pseudomonas fluorescens (PF), ${ }^{233}$ Pantoea agglomerans $(\mathrm{PA})^{233}$ and Xanthomonas campestris (XC). ${ }^{339}$ See Section 6.2.2.1 for a discussion on the factors underlying the observed variability in activity for ice nucleating bacteria.

as $\mathrm{NO}_{2}$ and $\mathrm{O}_{3}$ impact the INA of $\mathrm{Ice}^{+}$bacteria. In agreement with previous reports, ${ }^{231,240,241}$ the authors demonstrated that increasing acidity had a deleterious effect on the INA of Ice ${ }^{+}$ Pseudomonads. Exposure to UV-A was shown to lead to a significant loss in cell viability, but only minor decreases in INA were observed. Variable results were found on exposure to the reactive pollutants $\mathrm{NO}_{2}$ and $\mathrm{O}_{3}$; while exposure did not significantly reduce INA for two strains of $P$. syringae isolated from cloud water, the effect on a third strain isolated from leaf surfaces varied between replicates, indicating that as-yet unidentified parameters were causing differences between the tests.

Many of the past studies on the freezing behaviour of bacterial suspensions have involved variants of the dropfreezing assay where a sample is split into many drops. These subunits are cooled and freezing is usually detected by visual inspection or by thermoanalytical techniques such as differential scanning calorimetry. ${ }^{149}$ By assuming that the timedependence of nucleation is a second order effect, results from the drop-freezing assay can be interpreted in terms of the cumulative nucleus spectrum $K(T)$, which describes the number of nuclei active per unit volume at temperatures higher than $T$ (see Section 4.2) ${ }^{149}$ Expressed per unit volume of water, the cumulative nucleus spectrum can readily be determined from the fraction of droplets frozen, $f_{\text {ice }}(T)$, at a given temperature using the formula: ${ }^{134,242}$

$$
K(T)=\frac{-\ln \left(1-f_{\text {ice }}(T)\right)}{V}
$$

where $V$ is the volume of a drop in the assay. If the number of cells (or other particles) per unit volume of water $\left(C_{\mathrm{n}}\right)$ is known then the cumulative ice active sites per particle $\left(n_{\mathrm{n}}\right)$ can be determined (see Section 4.2):

$$
\eta_{\mathrm{n}}(T)=\frac{-\ln \left(1-f_{\text {ice }}(T)\right)}{V C_{\mathrm{n}}}
$$

Although drop freezing assays have provided a wealth of information on $\mathrm{Ice}^{+}$bacteria, the common use of microliter sized droplets restricts the temperature range throughout which activity can be assessed. Under such conditions, ultrapure water generated via means commonly available within laboratories is frequently found to freeze at temperatures of $-25{ }^{\circ} \mathrm{C}$ or higher, ${ }^{206,207,243,244}$ presumably due to nucleation from the supporting substrate or contamination by foreign particles.

To date, relatively few experiments have examined the activity of bacteria using techniques validated to be free from potential interference such as nucleation by substrates (i.e. using techniques where homogeneous nucleation is achievable in bacteria free droplets). Using droplets in free-fall, Wood et al. ${ }^{147}$ examined the IN activity of Snowmax ${ }^{\mathrm{TM}}$, a freeze-dried and sterilized bionucleant manufactured from $P$. syringae strain R31 grown under proprietary conditions. ${ }^{245}$ Given the conditions under which this material is produced, its atmospheric relevance is questionable. In this technique, nanolitre sized falling droplets are frozen under the influence of a vertical temperature gradient maintained within a hollow cylinder. Freezing is detected by illuminating the falling droplets with a linear polarized laser and monitoring the depolarization of the backscattered light. With this setup, the authors were able to successfully demonstrate both homogeneous freezing of water droplets $\left(T_{\text {freeze }} \sim-37{ }^{\circ} \mathrm{C}, d_{\text {droplet }}<70 \mu \mathrm{m}\right)$, and show that Snowmax ${ }^{\mathrm{TM}}$ nucleated ice at temperatures $\left(-10<T_{\text {freeze }}<-6{ }^{\circ} \mathrm{C}, d_{\text {droplet }}<70 \mu \mathrm{m}\right)$ similar to those obtained previously by Maki et al., ${ }^{215}$ for unfiltered, sonically disrupted cells of $P$. syringae. In contrast, Junge and Swanson $^{246}$ employed the same technique to determine the ice nucleating properties of Polar sea ice bacteria. Of the 15 isolates investigated, freezing temperatures for all samples were found to be within two degrees of those observed for the homogeneous freezing of the artificial seawater medium $\left(-42.2 \pm 0.3{ }^{\circ} \mathrm{C}\right)$.

Other laboratory techniques used to investigate the IN activity of $\mathrm{Ice}^{+}$bacteria have included the use of wind tunnels ${ }^{247}$ and cloud chambers. ${ }^{245,248}$ During the early 1980s, Levin and Yankovsky ${ }^{247}$ examined the applicability of desiccated and pulverised $\mathrm{Ice}^{+}$bacteria isolated from citrus as an artificial IN for weather modification using a vertical wind tunnel. The dry bacterial powder used during the experiments (termed bacterium M1 by the authors) was later identified as $P$. agglomerans. ${ }^{249}$ Immersion mode measurements were made by suspending individual bacteria-containing droplets of 440-720 $\mu \mathrm{m}$ diameter in a wind tunnel. ${ }^{247}$ The work confirmed the conclusions of past researchers that disrupted bacteria can still act as high temperature IN, thereby demonstrating their potential as cloud seeding agents. Studies on the potential of bacterial IN as cloud seeding agents were also conducted by Ward and DeMott ${ }^{248}$ using a dynamic cloud chamber. By expansion-cooling a dispersion of Snowmax ${ }^{\mathrm{TM}}$ powder in air, both the $\mathrm{CCN}$ and IN activities of the bacterial particles were investigated. The propensity of IN activities to be centred at narrow temperature ranges was noted by the authors, consistent with the activation of distinct nucleating sites. During isothermal chamber experiments, the authors further demonstrated that the yields of ice crystals per gram of Snowmax ${ }^{\mathrm{TM}}$ 
nucleant added exceeded that of silver iodide at temperatures greater than $-5{ }^{\circ} \mathrm{C}$.

Recently, Möhler et al. ${ }^{245}$ have examined ice nucleation by several live Ice $^{+}$bacteria including strains of $P$. viridiflava, $P$. syringae and $P$. agglomerans in both the immersion and condensation modes. Bacterial suspensions were aerosolised and introduced into the cloud chamber where two styles of experiment were conducted. Standard expansion experiments were performed where the supersaturation was controlled by reducing pressure in the chamber in a controlled manner. In the other series of experiments, ice nucleation was probed as the aqueous suspension was nebulised into the chamber. In these so-called "spray experiments" droplets cooled to the surrounding conditions before all the liquid water evaporated and immersion mode ice nucleation was observed. From the number of ice particles, measured using optical particle counters, the authors calculated the fraction of IN active cells from the ratio of the number density of ice particles to that of bacterial cells. Interestingly, when Möhler et al. ${ }^{245}$ compared the results taken from the cloud chamber to those determined using a popular variant of the drop freezing assay introduced by Lindow, ${ }^{242}$ lower than expected IN active fractions were found for the latter. While the authors had insufficient evidence to definitively conclude that a systematic difference between the techniques existed, the result highlights the need for further inter-comparison studies on the techniques employed to quantify bacterial IN activity.

Not all bacterial ice nucleators induce freezing at the higher temperatures characteristic of $\mathrm{Ice}^{+}$bacteria. During recent investigations into the IN activity of bacteria isolated from snow samples collected at ground level, Mortazavi et al. ${ }^{244}$ found that an intermediate range of activity within bacteria was also possible. While none of the bacteria isolated belonged to the Pseudomonas or Pantoea genera, most of the isolates nucleated ice at temperatures below $-16^{\circ} \mathrm{C}$. Similarly, Ponder et al. ${ }^{250}$ have presented evidence suggesting that a Grampositive bacterium may also have limited activity as an ice nuclei. These observations raise the fascinating possibility that bacterial ice nucleation may not be restricted to a limited number of Ice $^{+}$bacteria, but may in fact be a more widespread phenomenon at lower temperatures.

Despite the large number of lab-based studies which have characterised Ice ${ }^{+}$bacteria, questions on the efficacy of bacteria as atmospheric ice nuclei remain. Translating the current body of knowledge to an atmospheric context represents a considerable task. Determining how environmental conditions affects the expression of INA, both before and after bacteria become airborne, will necessitate carefully controlled studies only possible in the laboratory.

6.2.2.2 Fungal and lichen ice nuclei. Although Ice ${ }^{+}$bacteria have been the most intensively studied biological ice nucleators to date, similar IN activities have been documented in both lichens (symbiotic organisms composed of a fungus and a photosynthetic partner, either an alga or cyanobacterium) and in certain free-living fungi. ${ }^{251-254}$ Despite these observations, it is currently difficult to establish whether these biological IN play a relevant role in atmospheric ice formation processes. Estimates of lichen biomass, and consequently concentrations of lichen-derived aerosol particles are difficult. ${ }^{190,243}$ Margulis ${ }^{255}$ has estimated that biomass on rock surfaces alone is in the region of $10^{17} \mathrm{~kg}$ globally, while Henderson-Begg et al. ${ }^{243}$ have suggested that the canopy lichen biomass in temperate forests is similar to leaf biomass and that if lichen particles become airborne, an impact on cloud glaciation is at least plausible. Similarly, the amount of hyphal fragments (the filamentous structures of fungi which collectively constitute the mycelium, or vegatative body) in the atmospheric biological aerosol has yet to be firmly established, but number concentrations of up to $10^{-3} \mathrm{~cm}^{-3}$ in air over vegetated regions have been reported near the surface. ${ }^{256}$

INA in lichens was first reported by Kieft ${ }^{251}$ in 1988, who examined 15 different lichen partnerships collected from a variety of different substrates (rocks, plants and soil) using a drop freezing assay. Of the 15 lichens examined, onset freezing temperatures varied from between $-8{ }^{\circ} \mathrm{C}$ for the least active lichen partnership to $-2.3{ }^{\circ} \mathrm{C}$ for the lichen Rhizoplaca chrysoleuca, with threshold temperatures for freezing generally higher in lichens collected from the surface of rocks. Kieft and Ahmadjian $^{252}$ further examined the INA of pure cultures of lichen fungi (mycobionts) along with lichen algae and cyanobacteria (photobionts) and found that only the fungi could nucleate ice at $T \geq-5{ }^{\circ} \mathrm{C}$.

Several authors have reported warm temperature INA associated with the mycelia of non-lichenised fungi, all of which belonging to the genus Fusarium. 253,254,257 Pouleur et $a .^{253}$ examined the INA of mycelial mats from fungi spanning 20 different genera, and found that strains of $F$. acuminatum and $F$. avenaceum had cumulative nucleus spectra similar to those found for $\mathrm{Ice}^{+}$bacteria on a per unit mass basis.

While the nucleating sites in lichen and Fusarium IN have been identified as proteinaceous, they exhibit several key differences to those found in their Ice ${ }^{+}$bacterial counterparts. Activity in both lichen and Fusariam ice nucleators are found to be insensitive to $\mathrm{pH}$; the freezing behaviour of extracts prepared by grinding samples of either Rhizoplaca chrysoleuca or $F$. avenaceum remained constant throughout the $\mathrm{pH}$ range $1-12 .^{253,258}$ Similarly, while in Ice ${ }^{+}$bacteria INA is lost after incubation above $40{ }^{\circ} \mathrm{C},{ }^{204}$ lichen and Fusarium derived IN maintain their activity after incubation at or above $60{ }^{\circ} \mathrm{C}$. Perhaps the most striking difference between bacterial and lichen/fungal IN is the ability of the latter to pass through $0.22 \mu \mathrm{m}$ filters, indicating the presence of IN in the absence of cells. $^{253,258}$

In addition to fungal fragments, spores from fungi also have the potential to affect atmospheric ice formation processes. Fungal spores alone are thought to account for $23 \%$ by mass of the total primary emissions of organic aerosol, ${ }^{259}$ with typical number concentrations of $10^{-3}-10^{-2} \mathrm{~cm}^{-3}$ observed in the continental boundary layer. ${ }^{259-261}$ These reproductive units of fungi, which are ejected either passively or actively, have typical diameters which lie in the coarse mode of atmospheric aerosol; spore diameters are most frequently found to be in the range $2-10 \mu \mathrm{m} .^{260-262}$ Despite having number densities similar to those found for bacteria, currently few studies have examined the IN activities of fungal spores. 
During their survey of biogenic IN sampled from an aircraft above the Arctic, Jayaweera and Flanagan ${ }^{263}$ found that certain fungal spores exhibited varying ice nucleating efficiencies in drop freezing assays. The IN activity of the fungal spores, reported by the authors as the temperature required to observe an active fraction of 0.03 , varied from up to $-10{ }^{\circ} \mathrm{C}$ for spores of Penicillium digitatum, down to $-23{ }^{\circ} \mathrm{C}$ for spores of Rhizopus stolonifera. Recently, Iannone et al..$^{264}$ examined the immersion mode IN activity of spores from Cladosporium species, one of the most abundant types of fungal spore found in the atmosphere. Using a temperature-controlled flow cell coupled to an optical microscope, the authors demonstrated the spores to be relatively inefficient IN, with only $10^{-3}$ spores demonstrating IN activity by $-28{ }^{\circ} \mathrm{C}$.

6.2.2.3 Pollen ice nuclei. Number densities of pollen in the atmosphere are influenced by a variety of factors including meteorology, location, season and even time of day. ${ }^{186,190}$ Estimates of typical annual average number densities of pollen over continents are in the range $10^{-6}$ to $10^{-5} \mathrm{~cm}^{-3},{ }^{110}$ although episodic pollen counts of up to $10^{-3} \mathrm{~cm}^{-3}$ can occur. ${ }^{265}$ Typical diameters of pollen grains range from $10-100 \mu \mathrm{m}$, leading to short atmospheric residence times. However, elevated pollen number densities observed in inversion layers ${ }^{266}$ have prompted suggestions that pollen may be temporarily suspended in the atmosphere at concentrations comparable to those of other atmospheric ice nuclei. ${ }^{190,267}$

Laboratory experiments examining the IN activity of pollen in the immersion mode have shown that pollen grains can induce freezing of droplets at temperatures as high as $-9{ }^{\circ} \mathrm{C}$. Using a vertical wind tunnel, Diehl et al. ${ }^{145}$ and von Blohn et $a .^{268}$ examined the freezing behaviour of freely suspended droplets $(d=500-760 \mu \mathrm{m})$ containing pollen grains. Throughout these experiments, the authors surveyed the IN activities of eight types of pollen including four deciduous tree pollen, three grass pollen types and one conifer pollen. Pollens with small grain diameters $(<30 \mu \mathrm{m})$, and hence lower settling velocities, were chosen for the studies. Of the eight pollen types investigated, all exhibited ice nucleating abilities at temperatures of $-15{ }^{\circ} \mathrm{C}$ or higher, with some, such as alder (Alnus incana) pollen demonstrating active fractions approaching 1.0 by $-20{ }^{\circ} \mathrm{C}$ (Fig. 15).

Recently, Pummer et al. ${ }^{150}$ examined ice nucleation induced by a range of birch and conifer pollens in water droplets $\left(V_{\text {median }} \sim 22 \mathrm{pL}\right)$ in an oil and surfactant matrix. Median freezing temperatures ranging from -33 to $-19{ }^{\circ} \mathrm{C}$ were reported by the authors, largely in agreement with previous reports. ${ }^{145,268}$ The authors went on to show that when the pollen grains were separated from the suspension, ice nucleation in the remaining water proceeded as efficiently as in the suspensions containing the grains. In contrast to the proteinaceous active sites in bacterial and fungal ice nucleators, the extractible IN from pollen were found to be stable to compounds which degrade proteins, such as proteases and $6 \mathrm{M}$ guanidinium chloride. Ice activity was only lost after exposure to $5 \mathrm{M}$ sulfuric acid, leading the authors to propose that the responsible species may be a polysaccharide. As evident from Fig. 15, the cumulative nucleus spectrum for the more active pollens, such as birch, indicate that the extractible IN from

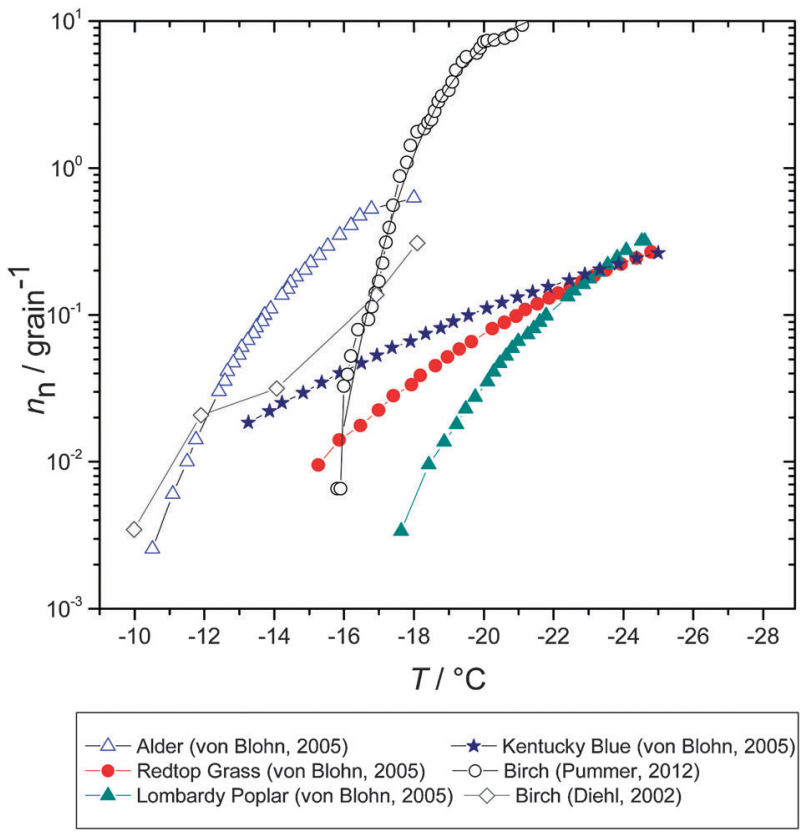

Fig. 15 Ice nucleating efficiency for pollens expressed as nucleation sites per pollen grain $\left(n_{\mathrm{n}}\right)$. Calculated from Diehl et al., ${ }^{145}$ von Blohn et al. ${ }^{268}$ and Pummer et al., ${ }^{150}$ assuming pollen grains are spherical and have a density of $0.8 \mathrm{~g} \mathrm{ml}^{-1}$.

one pollen grain can potentially nucleate ice in more than one water drop. On the basis of their results, the authors argued that the macromolecular IN associated with pollen could be distributed independently in the atmosphere from the grains themselves, perhaps released via the bursting of pollen grains by rain; a process which can discharge allergens and sugars from the bulk. ${ }^{269,270}$

6.2.2.4 Plankton ice nuclei. The majority of past research examining biological ice nuclei has focused on those with continental sources, with few studies examining potential marine sources of biological ice nuclei. As recently discussed by Burrows et al., ${ }^{193}$ evidence from in situ, ship-based measurements over the past 40 years suggests that in remote, biologically active regions of the ocean, background atmospheric IN levels are linked to sea spray production and local marine biological activity. In early laboratory studies examining laboratory cultured marine phytoplankton, Schnel1 ${ }^{271}$ demonstrated that cultures of the marine dinoflagellate Heterocapsa niei exhibited remarkably high IN activities. However, a decade later, Fall and Schnell ${ }^{272}$ identified the IN active species in the mixed algal cultures (which also contained bacteria) as a bacterium, phenotypically similar to Pseudomonas fluorescens biotype G.

Recently, IN activity has been explicitly identified by Knopf and co-workers ${ }^{273-275}$ in two microalgae, Thalassiosira pseudonana and Nannochloris atomus. IN activity of the two phytoplankters, which were grown in unialgal, axenic (i.e. free of other organisms) cultures was investigated as a function of water activity in aqueous sodium chloride droplets which were conditioned in a humidity-controlled chamber. These two microalgae possess remarkably different cell wall structures; the diatom T. pseudonana has a silaceous cell wall, while $N$. atomus, 
a chlorophyte, has only an organic layered cell wall composed of cellulose and other polysaccharides. ${ }^{276}$ At water activities approaching unity, freezing in droplets containing T. pseudonana or $N$. atomus $\left(a_{\mathrm{w}}=0.98\right.$ and 0.99 respectively) proceeded at median temperatures $\sim 10{ }^{\circ} \mathrm{C}$ above the homogeneous freezing limit. $^{277}$ In contrast, Emiliania huxleyi, a coccolithophore with an outer wall of calcitic plates was shown by the authors to have negligible IN activity. While future laboratory studies employing techniques which can assess IN activity down to the homogeneous limit will be required to properly constrain source strengths of planktonic ice nuclei, these studies highlight that biogenic particles of marine origin may also play a role in atmospheric ice production.

\subsection{Carbonaceous combustion aerosol}

There have been dramatic increases in the amount of carbonaceous combustion aerosol released into the atmosphere due to human activity. ${ }^{1,278}$ Ito and Penner ${ }^{278}$ estimate that the amount of black carbon emitted globally has increased from $2.1 \mathrm{Tg}$ per year in 1870 to $8.2 \mathrm{Tg}$ per year in 2000. Much of the increase comes from fossil fuel combustion. Combustion aerosol can account for a significant fraction of atmospheric aerosol; for example, one study concluded that $33 \%$ of particles sampled in the North American free troposphere were identified as biomass burning particles. ${ }^{279}$ This material may have a significant impact on cloud properties. In a global model study Spracklen et al. ${ }^{76}$ estimate that carbonaceous combustion aerosol account for more than half of global $\mathrm{CCN}$ and the majority of $\mathrm{CCN}$ in polluted regions. The presence of carbonaceous combustion aerosol in cloud droplets supports Lohmann's ${ }^{280}$ hypothesis of a 'glaciation indirect effect', a phrase coined to distinguish the ice nucleation potential of anthropogenic aerosol from the well-known liquid cloud indirect effects.

6.3.1 What is carbonaceous combustion aerosol?. Aerosol particles resulting from combustion are complex and highly variable, ranging from elemental carbon through to complex mixtures of organic and inorganic materials. ${ }^{281-284}$ In part, this reflects the varied sources of combustion aerosol, with contributions from fossil fuel burning as well as biomass burning for domestic use and in wildfires. The terminology associated with combustion aerosol is at times confusing in the literature, but here we use the terms defined by Andreae and Gelencsér. ${ }^{281}$ The fine particulate material produced during combustion which has a black or brown colour is termed soot. Soot particles are made up of many spherical particles of only $\sim 10 \mathrm{~s} n$ in size which are arranged in a fractal-like morphology. ${ }^{285}$ The spherules are typically composed of a carbon core, which is almost pure elemental carbon, surrounded by varying amounts of organic carbon often in the form of polycyclic aromatic hydrocarbons (PAHs). ${ }^{285}$ The ratio of organic to elemental carbon depends on the fuel and the combustion conditions. ${ }^{281,284,286}$ The soot carbon cores have a high degree of $\mathrm{sp}^{2}$ hybridisation and are analogous to graphite or graphene in structure. The degree of order in the graphitic material depends on the formation process with high temperatures and longer annealing times favouring more ordered graphitic structures to form, while rapidly formed soot particles are nearly amorphous. ${ }^{281}$ These graphitic cores can clearly be seen in transmission electron microscope images. ${ }^{285,287,288}$ The term black carbon is also used extensively in the literature. This term refers to particles with optical properties similar to that of soot carbon and is used synonymously with the term soot carbon. Andreae and Gelencsér ${ }^{281}$ suggest that black carbon should only be used as a proxy for soot carbon or elemental carbon.

Another major class of particles observed in biomass burning plumes are spherical amorphous carbonaceous particles from 30 to $500 \mathrm{~nm}$, which have been termed tar balls and are thought to form via the condensation of uncombusted low volatility organic compounds. ${ }^{288-290}$ Tar balls may be a class of amorphous solid aerosol, ${ }^{291-294}$ and amorphous organic aerosol have been shown to catalyse ice formation. ${ }^{11,68,69}$

6.3.2 Field studies of the impact of carbonaceous combustion aerosol on clouds. Substantial evidence exists showing that combustion aerosol impact clouds by acting as CCN. ${ }^{76}$ The resulting cloud albedo indirect effect associated with this is substantial $\left(0.3 \mathrm{~W} \mathrm{~m}^{-2}\right){ }^{76}$ Field measurements confirm that combustion aerosol particles are frequently present within cloud droplets, ${ }^{295,296}$ giving these aerosol the potential to serve as immersion mode ice nuclei. However, the evidence that combustion aerosol can serve as IN from observational studies is contradictory. Some studies of the chemical composition of ice residues in mixed phase clouds indicated that combustion products were not major components of the ice nucleating aerosol population; Kamphus et al. ${ }^{297}$ report that soot particles were not enhanced in the ice phase compared to the background aerosol and that biomass burning aerosol was in fact depleted. In this particular study mineral dust concentration was greatly enhanced. In contrast there are a number of field studies which indicate combustion aerosol can serve as ice nuclei. Twohy et $a l .{ }^{33}$ show that there was a very strong correlation $\left(r^{2}>0.99\right)$ between the concentration of refractory black carbon particles (determined with a particle soot photometer which only detects the refractory and strongly light absorbing component, such as the elemental carbon core of a soot particle ${ }^{298}$ ) and the number of ice crystals measured in a wave cloud. The refractory black carbon measurement is a proxy for biomass burning aerosol, including soot, tar balls and other material which may be lofted with the smoke plume, and therefore the ice nucleating species is not necessarily the refractory black carbon. Soot particles have also been identified in ice crystals sampled from mixed phase clouds indicating that they can serve as IN. ${ }^{299,300}$ In one study the black carbon mass fraction was only $5 \%$ in the background aerosol, but this was enhanced to $27 \%$ in ice residues. This enrichment indicates that black carbon containing particles served as ice nuclei. ${ }^{300}$ In a lidar study of smoke influenced altocumulus clouds in Alaska, Sassen and Khvorostyanov ${ }^{63}$ showed that ice formation occurred in subsaturated (with respect to liquid water) conditions as well as in the supercooled liquid cloud. Again, it was unclear which material associated with the combustion aerosol caused cloud glaciation.

6.3.3 Laboratory studies of carbonaceous combustion ice nuclei. There are only a limited number of experimental studies of ice nucleation by carbonaceous combustion products in 
the immersion mode. There are a number of studies which focus on ice nucleation by soot particles either in the condensation or deposition mode below water saturation ${ }^{56,72,142,282,301-305}$ and also in the contact mode, ${ }^{61}$ but these are beyond the remit of this review. Most of these studies were conducted under conditions relevant for temperatures below those which mixed phase clouds can exist, but several studies ${ }^{142,301,306}$ indicate that deposition or condensation nucleation below water saturation by a range of soot particles is not important at temperatures greater than $-40{ }^{\circ} \mathrm{C}$.

6.3.3.1 Ice nucleation by soot particles. In a study using a controlled expansion cloud chamber, DeMott ${ }^{71}$ measured the ice nucleating ability of soot produced using an oxygendeficient acetylene burner. Size-selected soot particles were first exposed to a supersaturation with respect to water in order to activate the majority of soot particles as $\mathrm{CCN}$. On continued cooling, soot particles catalysed freezing below $-24{ }^{\circ} \mathrm{C}$. In experiments with the same system, very dilute solution droplets froze homogeneously below $-34{ }^{\circ} \mathrm{C},{ }^{71}$ indicating that soot nucleates ice in the immersion mode. DeMott ${ }^{71}$ investigated the ice nucleating ability of soot particles with electrical mobility diameters of 0.08 and $0.15 \mu \mathrm{m}$ and found that almost double the amount of ice crystals were nucleated for the latter. In addition DeMott changed the cooling rate by a factor of two with no significant shift in freezing temperatures, indicating that time dependence was not a significant factor for these conditions.

Diehl and Mitra ${ }^{56}$ bubbled exhaust from a kerosene burner through water and tested the freezing temperature of droplets made from this suspension using a wind tunnel apparatus. This study was focused on the impact of soot from jet aircraft and they used aviation kerosene to generate soot. The water droplets were between 344 and $818 \mu \mathrm{m}$ in diameter and were held in the wind tunnel at a specific temperature for about one minute. They showed that the droplets contaminated with exhaust fumes froze at higher temperatures than uncontaminated water droplets, with the probability of freezing increasing with droplet size. In the largest droplet size category $4 \%$ of droplets froze at $-18{ }^{\circ} \mathrm{C}$ and this increased to $70 \%$ at $-28{ }^{\circ} \mathrm{C}$, clearly indicating that there is some potential for soot to catalyse droplet freezing.

Since soot properties are highly dependent on the fuel and combustion conditions it is perhaps not a surprise to find soot of dissimilar origins can have different ice nucleating abilities. Gorbunov et al. ${ }^{307}$ studied ice nucleation by soot generated in two separate ways, which produced hydrophilic soot rich in surface hydrogen bonding sites and hydrophobic soot which was deficient in these sites. They show that both soot types could nucleate ice at -10 and $-20^{\circ} \mathrm{C}$, but the hydrophilic soot was 3-4 orders of magnitude more efficient at producing ice. However, the mode of ice nucleation in their experiments is unclear. During the experiments, the authors produced a cloud of supercooled droplets within a chamber and then introduced aerosol to this chamber. The chamber was held constant at a temperature for an unspecified period of time. The number of ice particles nucleated was counted by allowing ice crystals to settle onto a coated glass slide and then counting crystals with an optical microscope. ${ }^{308}$ Although the mode of nucleation in these experiments has been interpreted as contact nucleation in the past, ${ }^{280}$ it is not clear that this is the case. Given the experimental description, contact, deposition and immersion freezing may have taken place, hence we have not included the Gorbunov et al. data in our assessment of immersion freezing. However, their study does indicate soot can nucleate ice as high as $-10{ }^{\circ} \mathrm{C}$ and also that the ice nucleating ability of soot strongly depends on the soot particle production conditions.

Popovicheva et al. ${ }^{309}$ also present evidence that soot particles of different origin nucleate ice with different efficiencies. They study the freezing of millimetre sized droplets contaminated with a range of soots. Unfortunately their uncontaminated water droplets froze at between -7 and $-16{ }^{\circ} \mathrm{C}$ (with a median of $-11.5 \pm 2.1^{\circ} \mathrm{C}$ ), which strongly overlapped with their measured heterogeneous freezing temperatures. However, the median freezing temperatures for several soots were greater than that for uncontaminated water indicating that they may catalyse freezing at temperatures as high as about $-7{ }^{\circ} \mathrm{C}$.

In order to compare the efficiencies of ice nucleation by soot particles in the literature we have estimated $n_{\mathrm{s}}(T)$ values from the studies of DeMott ${ }^{71}$ and Diehl and Mitra. ${ }^{56}$ We selected these studies for this assessment because they provided frozen fractions as a function of temperature together with information on the size and concentration of soot particles. In the case of DeMott's data it is assumed that each droplet contained a single size selected soot particle. We then determined the surface area of the soot particles assuming they were spheres. Values of $n_{\mathrm{s}}$ were then determined using the fraction frozen data. A similar calculation was performed for the data presented by Diehl and Mitra, ${ }^{56}$ but where the total surface area per droplet was estimated from the measured soot particle size spectrum provided.

The resulting temperature dependent $n_{\mathrm{s}}$ values are plotted in Fig. 16. Despite the different sources of soot and the different experimental techniques employed there is consistency between the results from the two experiments. In the temperature range between -24 and $-28{ }^{\circ} \mathrm{C}$ the two data sets produce similar values of $n_{\mathrm{s}}$ in the temperature range in which they overlap. Unfortunately, neither set of authors characterised the soot they used in terms of elemental to organic carbon content or hygroscopicity. Clearly, further experiments are needed to quantify the ice nucleating ability of well characterised soot particles in order to make a more thorough assessment of soot's ability to serve as an IN in the atmosphere.

6.3.3.2 Ice nucleation by carbonaceous particles from biomass burning. Combustion of biomass in nature is likely to produce many aerosol species in addition to soot particles, hence measurements of ice nucleation by biomass combustion aerosol are also needed. At present we are only aware of a single laboratory study on the ice nucleating ability (at water saturation) of particles produced during biomass combustion rather than combustion of liquid fuels. Petters et al. ${ }^{310}$ used a large combustion chamber facility to generate smoke form 21 biomass fuels from Asia and the United States. A diffusion chamber was used to measure the number of ice nuclei at $-30{ }^{\circ} \mathrm{C}$ and 


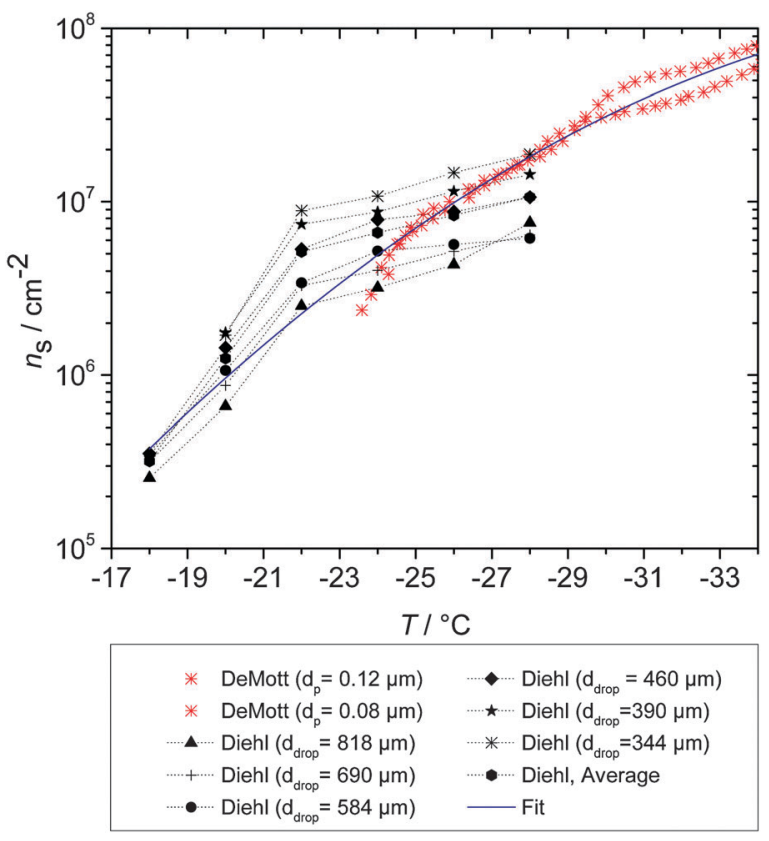

Fig. 16 Ice nucleation efficiency expressed as nucleation sites per unit area of soot particles immersed in water $\left(n_{\mathrm{s}}\right)$. Values of $n_{\mathrm{s}}$ have been estimated based on data from DeMott ${ }^{71}$ and Diehl and Mitra. ${ }^{56}$ See Section 6.3.3.1 for details.

at water saturation. Only nine of these fuels produced smokes in which there was a detectable fraction of particles (more than 1 in $10^{4}$ particles) capable of nucleating ice in the condensation or immersion mode. Furthermore, for these nine fuels, not all samples of each fuel produced detectable IN. Petters et al. ${ }^{310}$ performed a statistical analysis designed to test whether certain factors were correlated to IN emissions. The authors were able to show that organic carbon fractions were significantly lower in smoke containing IN. Petters et al. ${ }^{310}$ suggest that organic coatings may inhibit ice nucleation in much the same way as has been observed for deposition mode nucleation in a number of studies. ${ }^{302,311}$ The organic carbon content of the aerosol increased during the smouldering phase of burns and was lowest in the flaming combustion. They also report that aerosols with greater hygroscopicities or those containing water soluble inorganic ions were correlated with increased ice nucleation. Interestingly, the presence of elemental carbon was not found to be correlated with the number of IN, suggesting some other component of the biomass smokes catalysed ice nucleation.

\subsection{Volcanic ash}

Sulphur emissions from volcanoes are well known to episodically impact human health, ${ }^{312}$ as well as climate through direct $^{313}$ and indirect radiative forcings. ${ }^{77}$ Less well understood is the role volcanic emissions play in cloud glaciation. Historically, there has been some debate in the literature as to the role of volcanic activity in producing atmospheric IN. For example Isono et al $^{314}$ reported that IN were enhanced by a factor of 40 in maritime air and linked this to activity at a volcano $140 \mathrm{~km}$ from their measurement site in Tokyo. Similarly, Hobbs et al. ${ }^{315}$ observed around a 10 -fold increase in IN concentrations which they linked to volcanic eruptions. They coined the term 'ice nucleus storms' to emphasise the sporadic nature of these events. Similarly, Prenni et al. ${ }^{316}$ showed that IN were enhanced in arctic air passing close to an active volcano. In contrast Schnell and Delany ${ }^{317}$ found no significant enhancement of ice nuclei near an active volcano in Alaska in addition to evidence suggesting that effluent gases may deactivate natural IN.

The recent eruption of Eyjafjallajökull (E15) in Iceland during 2010 provided an opportunity to study the impact of volcanic ash on clouds. Lidar measurements of clouds over Germany reveal a greater propensity for clouds to glaciate within air containing volcanic ash. ${ }^{38}$ It was reported that all clouds were glaciated below $-15{ }^{\circ} \mathrm{C}$ in ash influenced clouds, whereas under clear air conditions all clouds were not glaciated until below $-25{ }^{\circ} \mathrm{C}$. Bingemer et al. ${ }^{318}$ reported that volcanic ash made up 53-68\% of the particles which served as IN below water saturation. They reported that the total ice nucleus number densities (in the deposition/condensation mode below water saturation) over Germany were much greater in ash influenced air than during intense Saharan dust storms. In addition, IN concentrations were enhanced in Tel Aviv (Israel), some $5000 \mathrm{~km}$ from Iceland. Furthermore, Bingemer et al. ${ }^{318}$ presented evidence that volcanic ash particles subjected to long range transport were substantially more efficient IN in the deposition/condensation mode than freshly emitted material. This is an intriguing finding, but at present there is no adequate explanation for these results.

While it is clear that volcanic ash can glaciate clouds, this effect is episodic and the implications for the planet's climate are limited to these sporadic events. ${ }^{319}$ A more direct and perhaps important implication of volcanic ash's ability to catalyse ice formation is its influence on volcanic clouds (i.e. the aerosol and gas produced by explosive volcanic activity $^{320}$ ). Durant et al. $^{320}$ suggest that latent heat release from water condensation and subsequent glaciation are key drivers in the dynamics of volcanic clouds. Furthermore, the Bergeron-Findeisen process is inhibited since volcanic clouds are so rich in IN and they suggest that most water freezes and subsequently the ice crystals remain small and more stable against sedimentation. Hence, ice nucleation is key in determining the dynamics of the volcanic clouds, important for factors such as injection of sulphate and water into the stratosphere as well as the dispersal of volcanic material.

6.4.1 Production and composition of atmospheric volcanic ash. Particles of a very broad range of sizes from ash to lava bombs, defined as tefra, are ejected from an erupting volcano. ${ }^{319,321}$ Volcanic ash is defined as tefra mostly under $2 \mathrm{~mm}$ in diameter and atmospheric scientists are generally interested in the fine fraction of this material. Within the field of vulcanology, 'fine' is defined as particulates smaller than $63 \mu \mathrm{m}$ rather than the value of $2.5 \mu \mathrm{m}$ adopted by aerosol and atmospheric science communities. ${ }^{321}$ Within this article the term fine ash is defined as ash particles smaller than $63 \mu \mathrm{m}$ diameter.

An important mechanism of ash production is through bubble bursting as lava depressurises and degasses. ${ }^{319,321}$ The mechanism is analogous to aerosol production by bubble bursting at the surface of oceans. ${ }^{322}$ This sort of eruption 
where ash is produced by the degassing of magma and subsequent disintegration of the 'froth' is known as a magmatic eruption. ${ }^{321}$ The morphology of ash particles depends on the eruption type and also the viscosity of the lava. In magmatic eruptions highly viscous lavas tend to produce angular fragments whereas low viscosity magmas can produce spherical ash particles. $^{321}$ Fine ash production can be enhanced if water is present during the eruption which causes violent steam eruptions in events known as phreatomagmatic eruptions. ${ }^{321}$ In addition to ash produced from magma, the surrounding rock can also be broken down by explosive forces and form part of the volcanic ash. The properties of this lithic material are dependent on the nature of the rock broken up during the eruption.

Magma is composed of a silica-rich melt with varying amounts of alumina and other metal compounds as well as some crystalline material known as phenocryst. Consequently, volcanic ash tends to a mixture of crystalline material (minerals) and a silicate rich volcanic glass. The presence of glassy (or vitreous) material in volcanic ash distinguishes it from mineral dusts which tend to have a similar mass spectrometry signature. ${ }^{316}$ The minerals in volcanic ash include some which are also present in natural mineral dust such as silicas (quartz, cristobalite and tridymite), feldspars and micas. In addition, olivines $\left((\mathrm{Mg}, \mathrm{Fe})_{2} \mathrm{SiO}_{4}\right)$, pyroxenes (typical composition ( $\mathrm{Mg}, \mathrm{Fe}, \mathrm{Ca})_{2} \mathrm{Si}_{2} \mathrm{O}_{6}$ ) and amphiboles (complex aluminosilicates with varying cations) are also present. ${ }^{319,323}$ Magmas have varying chemical composition and tend to be characterised by how much silica, iron and magnesium they contain; consequently the ashes produced vary substantially. ${ }^{321}$ Mafic magmas contain a higher proportion of magnesium and iron and this tends to be anticorrelated with the silica component. The silica component increases in the order: basaltic $\left(\begin{array}{llll}45-52 \% & \mathrm{SiO}_{2}\end{array}\right)$, andesitic $\left(\begin{array}{lll}56-59 \% & \mathrm{SiO}_{2}\end{array}\right)$ and rhyolitic $\left(63-75 \% \mathrm{SiO}_{2}\right)$ magmas. ${ }^{321}$

6.4.2 Laboratory studies of ice nucleation by volcanic ash in the immersion mode. Many of the older studies (see reviews by Durant et al. ${ }^{320}$ and Mason $^{22}$ ) in which volcanic ash was shown to nucleate ice were done in fog chamber experiments in which the mode of nucleation was unclear. Volcanic ash has been shown to nucleate ice in the deposition ${ }^{136,181,318}$ and contact ${ }^{59-61}$ modes, but we focus here on experiments conducted in the immersion mode. Indeed, the immersion mode may be most atmospherically relevant since volcanic ash tends to be associated with soluble materials such as sulphates and therefore serves as an effective condensation nucleus. ${ }^{324}$

The ice nucleating ability of large individual particles $(100 \mathrm{~s} \mu \mathrm{m})$ of volcanic ash has been investigated when immersed in water droplets. ${ }^{59-61,320}$ In these studies a single droplet was repeatedly frozen to quantify freezing probabilities as a function of temperature. Despite volcanic ash samples from a range of locations and compositions the median freezing temperature was consistently around $-20{ }^{\circ} \mathrm{C}$ when the ash particle was immersed in a water droplet. ${ }^{5-61,320}$ Fornea et al. ${ }^{61}$ give the temperature dependent probability of freezing as well as a measure of particle size (for Mount St Helens ash) which allows us to estimate the ice active site density (see Fig. 17). A striking conclusion from this style of experiment is that when the particle comes into contact with the interface, the droplets freeze at much greater temperatures. ${ }^{59-61,320}$ This inside-out contact freezing mechanism is consistent with theoretical studies which suggest heterogeneous freezing is more efficient when a particle is in contact with the droplet surface i.e. where three phases meet. ${ }^{325}$ However, Gurganus et $a{ }^{326}$ recently showed that there was no preference for nucleation at the point where three phases meet in a simplified system. Experiments to determine the importance of inside-out contact freezing with particles of atmospherically relevant size are clearly required.

Immersion mode ice nucleation from identical volcanic ash samples from the recent E15 volcanic eruption have recently been investigated by two separate groups using two different techniques. Hoyle et al. ${ }^{181}$ activated individual size-selected ash particles to droplets and then measured the ice nucleating fraction using a thermal gradient diffusion chamber set at a range of temperatures. They report a temperature dependent probability of freezing and in combination with the size distribution below $3 \mu \mathrm{m}$ diameter we estimate the active site density (see Fig. 17). It should be noted that all particles smaller than $1.8 \mu \mathrm{m}$ were placed in one size bin and this may lead to an overestimate in surface area. Steinke et al. ${ }^{136}$ used a large cloud chamber to quantify ice formation in the immersion and deposition mode. In expansions starting at and above $-20{ }^{\circ} \mathrm{C}$ no deposition mode nucleation was observed and at water saturation the ash particles activated to water droplets. On continued cooling, the ash particles catalysed freezing between about -23 and $-29{ }^{\circ} \mathrm{C}$. Using their measurement of droplet and ice number densities as a function of time together with the size distribution of volcanic ash in the chamber Steinke et al. ${ }^{136}$ estimated the temperature dependent active site density (plotted in Fig. 17).

Comparison of the active site densities derived from the three sets of experiments discussed above (Fig. 17) yields a surprisingly self-consistent picture of ice nucleation by volcanic ash. The large surface area of the ash particles $(250-300 \mu \mathrm{m}$ diameter) used by Fornea et $a l^{61}$ means that they were

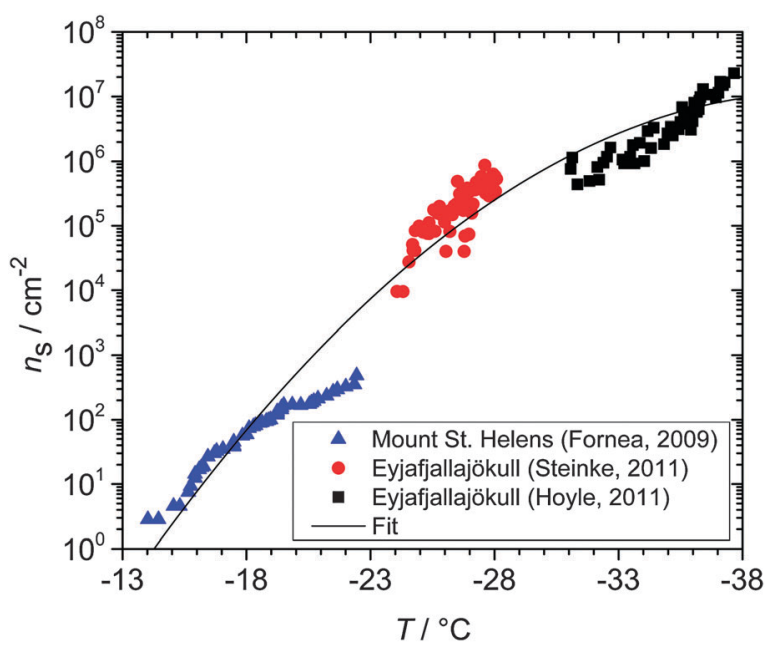

Fig. 17 Ice nucleating efficiency for volcanic ash samples expressed as nucleation sites per unit area. Values of $n_{\mathrm{s}}$ have been estimated based on data from Steinke et al., ${ }^{136}$ Hoyle et al. ${ }^{181}$ and Fornea et al. ${ }^{61}$ See Section 6.4 for details. 
sensitive to smaller active site densities than either of the aerosol based studies. Similarly, in their single particle aerosol system Hoyle et al. ${ }^{181}$ worked with a much smaller number of droplets than used in the cloud chamber experiments, ${ }^{136}$ and correspondingly Hoyle et al. observed the lowest freezing temperatures. When the nucleation events are normalised to immersed surface area (i.e. active site density) the data from all three studies falls on a curve $\left(r^{2}=0.96\right)$ spanning more than seven orders of magnitude. This consistency is despite the variability in experimental technique, implying that there is a characteristic ice nucleating ability of volcanic ash. However, we have only been able to characterise ash from two sources in terms of active site density. Quantitative measurements from more sources and compositions are needed in order to assess the hypothesis of Durant et al. ${ }^{320}$ that all volcanic ashes have similar ice nucleating ability.

\section{Summary and discussion of ice nucleation efficiency of heterogeneous ice nuclei}

In order to make a meaningful comparison of the ice nucleating efficiency of different materials we have estimated the cumulative ice active site density $\left(n_{\mathrm{s}}\right)$ for mineral dust, volcanic ash, soot, fungal spores, pollen grains and bacteria. Our estimates, based on the literature data discussed in the preceding sections, are presented in Fig. 18. In order to estimate $n_{\mathrm{s}}$ values we have had to make assumptions about surface areas of materials such as pollen and bacteria, due to which our estimates are prone to errors on the order of a factor of 10 . However, the $n_{\mathrm{s}}$ values presented here extend over nine orders of magnitude and hence even with these large uncertainties a comparison is still valid. Although there are caveats in the interpretation (see below), Fig. 18 provides a benchmark with which to compare various materials and also serves to highlight potential future research directions.

As discussed in Section 4.2, the singular approximation used here treats the time dependence of nucleation as a second order effect. We justify this approach on the basis that it provides a convenient first order approximation of the efficiency with which a material nucleates ice. However, it should be borne in mind that time dependence of nucleation may be important in some cloud types, ${ }^{29,105,120,128,327}$ and future studies examining the IN activities of substances should aim to quantify the importance of the stochastic nature of ice nucleation.

A further important point regarding the calculation of $n_{\mathrm{s}}$ values can be made in relation to the normalization by surface area. Surface area is quantified in different ways in different experiments. For example, some experiments use gas adsorption surface areas (which are quoted as specific surface areas, surface area per unit mass) and provide a total surface area of all the grains and other small scale features. ${ }^{105,120}$ Gas adsorption measurements for kaolinite samples are in excellent agreement with surface areas determined from atomic force microscopy measurements, ${ }^{105,183}$ which suggests that this is an accurate way of determining surface area. This approach is well suited to experiments in which a bulk suspension of solid in water is generated and subsequently finely divided. Another approach is to determine the surface area using the size of aerosolised particulates given by aerosol instrumentation such as the mobility diameter (see for example ref. 131, 132 and 184). Basing surface area on mobility size measurements is clearly a sensible approximation, but it should be borne in mind that dust particles tend to be agglomerates of many smaller particles. ${ }^{120,184}$ Hence, this assumption may lead to a substantial under-estimate of particle surface area. Broadley et al. ${ }^{120,184}$ estimated that a $500 \mathrm{~nm}$ diameter particle of

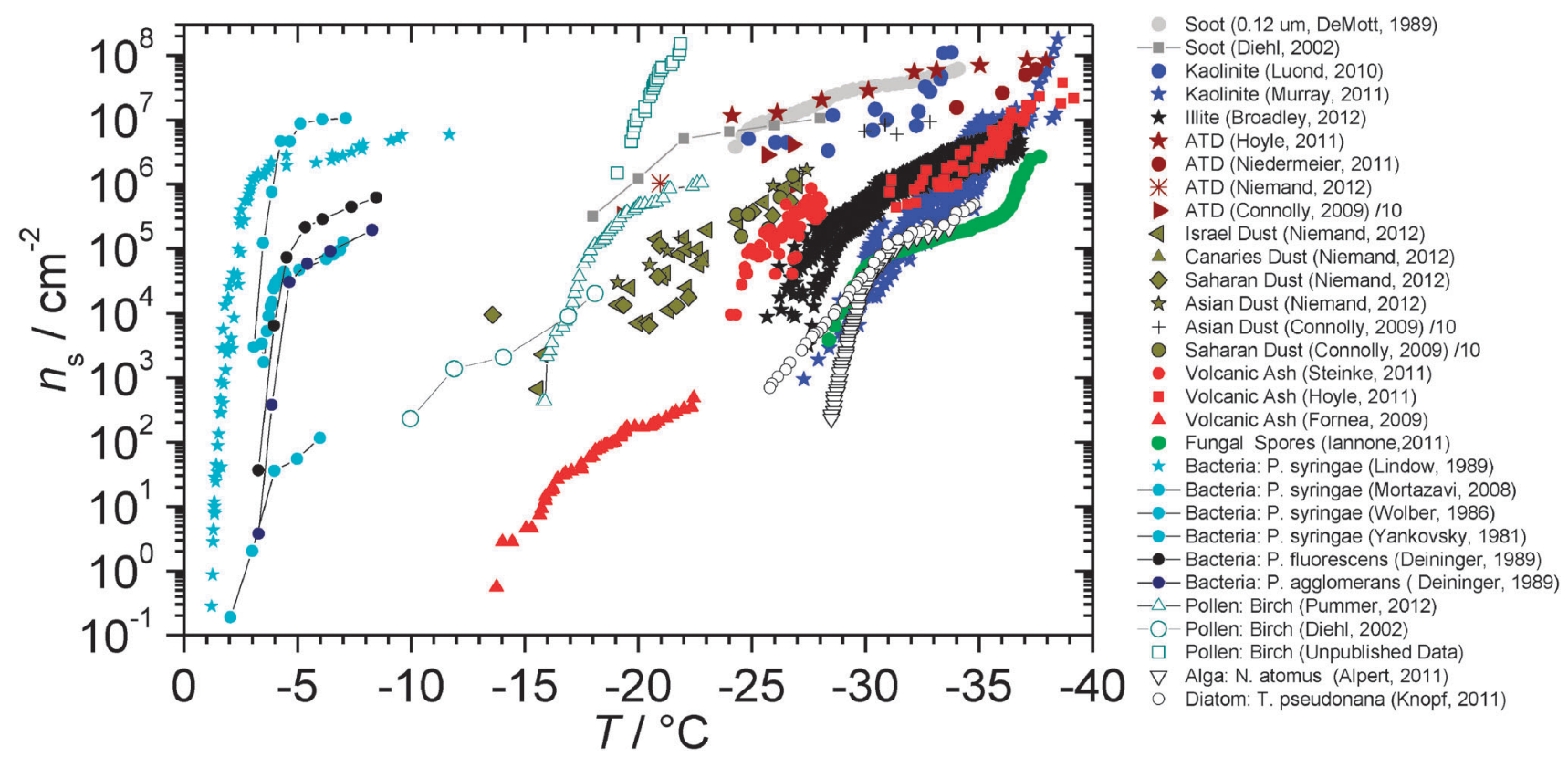

Fig. 18 Summary plot of $n_{\mathrm{s}}$ values based on literature data. The surface area of a bacteria is assumed to be $5 \mu \mathrm{m}^{2}{ }^{239}$ For birch pollen, a surface area of $1520 \mu \mathrm{m}^{2}$ is assumed $(d=22 \mu \mathrm{m})$. Note that the data of Murray et al. ${ }^{105}$ and Broadley et al. ${ }^{120}$ were determined using a gas adsorption surface area which results in a shift to smaller $n_{\mathrm{s}}$ values compared to the other mineral dust results where a spherical approximation was made (see discussion in Section 7). 


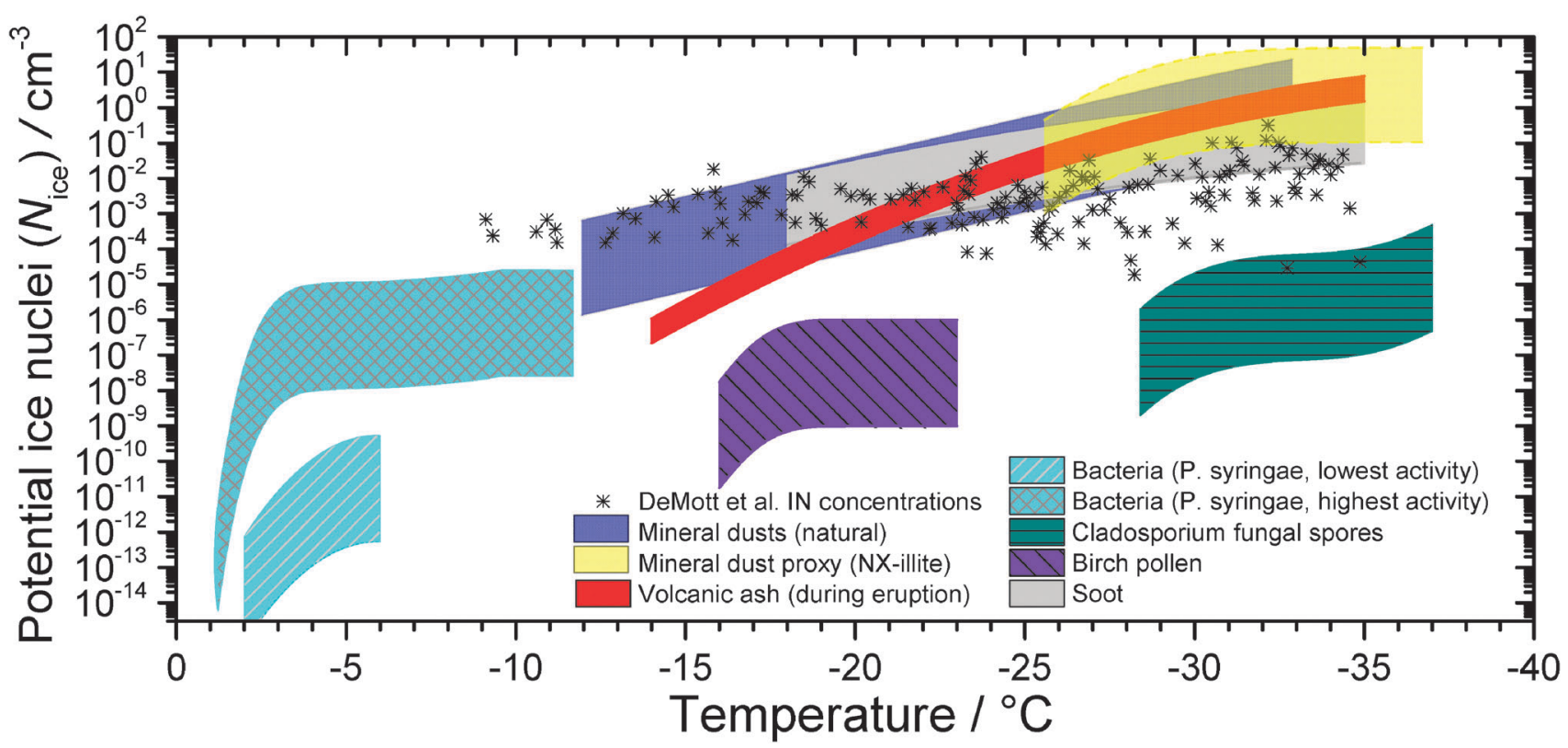

Fig. 19 Potential immersion mode ice nuclei concentrations as a function of temperature for a range of atmospheric aerosol species. Calculations performed using concentrations of different aerosol particle sypes listed in Table 1. Also provided are ice crystal number concentrations from DeMott et $a l .{ }^{21}$ for comparison, which were taken using a continuous flow diffusion chamber at water saturation within a $500 \mathrm{~m}$ altitude layer. Note that the ice crystal numbers produced for all materials are estimated using global averages of IN numbers, except for volcanic ash where the concentrations are event-based (see Table 1). For bacterial IN, it is assumed that $1 \%$ of the total number of airborne bacteria are IN active in line with Phillips et al. ${ }^{211}$

NX-illite would have a surface area more than a factor of 20 times greater if the gas adsorption surface area were used instead of a spherical approximation. This may help us understand the differences between the measurements of Niemand et al., ${ }^{135}$ of natural desert dusts, and Broadley et al., ${ }^{120}$ who used a dust with similar mineralogy to natural desert dusts. One would expect these data sets to be consistent with one another, but Niemand et al. report $n_{\mathrm{s}}$ values about one order of magnitude above that of Broadley et al. ${ }^{120}$ The difference may be that Broadley et al. used a gas adsorption surface area whereas Niemand et al. used a spherical approximation. When using these data sets to predict the number of IN in the atmosphere, it is important to consider how the surface area was determined experimentally and apply similar assumptions when determining the surface area of natural aerosol samples.

In order to estimate which materials are most important as IN in the atmosphere, $n_{\mathrm{s}}$ values are insufficient on their own, and the amount of each material present in the atmosphere needs to be accounted for. Our estimate of the concentration of potential IN $\left(N_{\text {ice }}\right)$ for various classes of aerosol particle are presented in Fig. 19. These estimates were produced using the $n_{\mathrm{s}}$ values presented in Fig. 18 (or their related $n_{\mathrm{n}}$ values) and assuming that each nucleating particle is singly immersed within one water droplet. We also compare this data to thermal gradient diffusion chamber measurements of IN densities from a range of field campaigns reported by DeMott et al. ${ }^{21}$

The determination of $N_{\text {ice }}$ values in Fig. 19 requires some explanation. These calculations were done assuming one particle per droplet. The typical upper and lower concentration of the various particle types used in this calculation are listed in Table 1 and this defines the upper and lower bounds of the estimate in Fig. 19. In the literature, the ice nucleating activities of biological materials are typically presented in the form of $n_{\mathrm{n}}$ values (i.e. active sites per particle), which allows the estimation of $N_{\text {ice }}$ via a combination of eqn (20) and (23):

$$
\frac{N_{\text {ice }}(T)}{N_{\mathrm{i}}}=1-\exp \left(-n_{\mathrm{n}}\right)
$$

Table 1 Estimated concentrations for potential ice nucleating materials used during the construction of Fig. 19. All data taken at the $600 \mathrm{~h}$ Pa level, apart from that for volcanic ash, where the lower limit is taken for the value measured by Schumann et al. ${ }^{328}$ in 2010 over Leipzig (19 May) at $598 \mathrm{~h} \mathrm{~Pa}$, and the upper limit that recorded over the North Atlantic (02 May) at $662 \mathrm{~h} \mathrm{~Pa}$. For volcanic ash, Schumann et al. ${ }^{328}$ report surface areas of ash per volume of atmosphere and we use this information directly in our calculations of $N_{\text {ice. }}$ Note that for bacteria, a value of $1 \%$ of the above numbers are assumed to be IN active

\begin{tabular}{lllll}
\hline Material & Upper limit & Lower limit & Units & Ref. \\
\hline Bacteria & $10^{-2}$ & $10^{-5}$ & $\mathrm{~cm}^{-3}$ & Hoose $(2010){ }^{110}$ Sesartic $(2011)^{340}$ \\
Pollen & $10^{-6}$ & $10^{-9}$ & $\mathrm{~cm}^{-3}$ & Hoose $(2010)^{110}$ \\
Fungal spores & $10^{-3}$ & $10^{-6}$ & $\mathrm{~cm}^{-3}$ & Hoose $(2010)^{110}$ \\
Soot $(d=0.1 \mu \mathrm{m})$ & 100 & 1 & $\mathrm{~cm}^{-3}$ & Hoose $(2010)^{110}$ \\
Dust $(d=1 \mu \mathrm{m})$ & 50 & 0.1 & $\mathrm{~cm}^{-3}$ & Hoose $(2010)^{110}$ \\
Volcanic ash & 150 & 30 & $\mu \mathrm{m}^{2} \mathrm{~cm}^{-3}$ & Schumann $(2011)^{328}$ \\
\hline
\end{tabular}


Table 2 Sources of data employed during the construction of Fig. 2, along with parameterisations of the relevant data. Note that during parameterisation of the data, temperature is in degrees Celsius. A fit for the high activity $P$. syringae is omitted, as a satisfactory polynomial fit could not be determined

\begin{tabular}{lll}
\hline Material & $n_{\mathrm{s}}(T)$ Parameterisation $\left(\mathrm{cm}^{-2}\right)$ & Data source \\
\hline Dust & $10^{-4} \times \exp (-0.517 T+8.934)$ & 135 \\
NX illite & $\exp \left(6.53043 \times 10^{4}-8.215309 \times 10^{2}(T-273.15)+\right.$ & 120 \\
Soot & $\left.3.446885376(T-273.15)^{2}-4.822268 \times 10^{-3}(T-273.15)^{3}\right)$ & 56,341 \\
Volcanic ash & $\exp \left(-0.0101 T^{2}-0.8525 T+0.7667\right)$ & $61,136,181$ \\
Birch pollen & $\exp \left(-0.02287 T^{2}-1.87203 T-22.05302\right)$ & 150 \\
Cladosporidium spores & $\exp \left(-0.0309 T^{3}-1.9893 T^{2}-42.938 T-297.26\right)$ & 264 \\
$P$. syringae (low activity) & $\exp \left(-0.02934 T^{3}-2.91415 T^{2}-96.59842 T-1056.63326\right)$ & 338 \\
$P$. syringae (high activity) & $\exp \left(-0.4325 T^{2}-5.1067 T-10.399\right)$ & 224 \\
\hline
\end{tabular}

where $N_{\mathrm{i}}$ is the number (in this case expressed as a concentration) of droplets containing potential IN of species i. For bacteria, two limiting data sets are used for the bacteria with the highest and lowest $n_{\mathrm{n}}$ values in Fig. 14. Following Phillips et al. ${ }^{157}$ and Hoose et al., ${ }^{110}$ we assumed that only 1 in 100 airborne bacteria belong to a type which is potentially ice nucleation active and applied the $n_{\mathrm{n}}$ values only to this fraction.

In the case of mineral dust and soot we use the parameterised fits of $n_{\mathrm{s}}$ to the data in Fig. 12 and 16, which are listed in Table 2. These $n_{\mathrm{s}}$ values are used in conjunction with the mean size ( 0.1 and $1.0 \mu \mathrm{m}$ for soot and dust, respectively) and number concentrations listed in Table 1. As discussed in Section 6.1.4.3 if a spherical assumption was made in determining $n_{\mathrm{s}}$ a spherical assumption should be made when determining the surface area of atmospheric dust, whereas if a specific surface area was used to determine $n_{\mathrm{s}}$ a similar assumption should be made when determining $N_{\text {ice. }}$ The appropriate calculation has been done in determining $N_{\text {ice }}$ for the proxy of transported natural dust, NX illite, (i.e. specific surface area) and also for the natural mineral dusts (i.e. spherical assumption). The agreement between the $N_{\text {ice }}$ predicted for both the natural mineral dusts and the proxy for natural dust is very good in the temperature range over which they overlap.

The $N_{\text {ice }}$ values for volcanic ash are representative of the recent Icelandic E15 eruptions in 2010. In this case Schumann et al $^{328}$ report surface areas of ash per volume of atmosphere and we use this information directly in our calculations of $N_{\text {ice }}$ rather than assuming a number concentration and size.

From the $N_{\text {ice }}$ values in Fig. 19 we can draw a number of conclusions and also draw attention to areas where our knowledge is deficient. One thing to bear in mind is that these values are based on global annual averages of aerosol particle concentrations and substantial deviations will undoubtedly occur episodically on smaller spatial and temporal scales. It should also be noted that there are significant uncertainties in the experimental data as well as approximations made in determining $N_{\text {ice }}$ that will affect its accuracy. However, these uncertainties are likely to be relatively small in comparison to the 16 orders of magnitude over which $N_{\text {ice }}$ is plotted in Fig. 19, and several conclusions can therefore be drawn from this plot.

The estimates presented in Fig. 19 suggest that cloud glaciation above about $-10{ }^{\circ} \mathrm{C}$ remains difficult to explain without the presence of IN active bacteria. However, it is also apparent that many of our community's experimental techniques for ice nucleation on mineral dust and soot may not be sufficiently sensitive to access atmospherically important $n_{\mathrm{s}}$ values at temperatures above $-15{ }^{\circ} \mathrm{C}$; this should be addressed. Crawford et $a .^{80}$ studied a mildly supercooled glaciating cumulus cloud and found that $10^{-3}$ to $10^{-4} \mathrm{~cm}^{-3}$ ice nucleus was sufficient at around $-7{ }^{\circ} \mathrm{C}$ to induce cloud glaciation via the Hallet-Mossop process. Even taking the most efficient bacteria and higher number densities for bacteria it is still difficult to explain glaciation at this warm temperature. We echo the comments of Crawford et al. ${ }^{80}$ and suggest experimental studies of ice nucleation at warm temperatures are needed.

In their studies of global ice nucleation by various species, Hoose and co-workers ${ }^{110,192,212}$ conclude that biological particles can only produce a small fraction of primary ice crystals in the Earth's atmosphere and that soot and mineral dust dominate. This is broadly consistent with our findings, however this does not exclude bacteria as being important in mildly supercooled clouds where ice multiplication may amplify their effects. The parameterisation of Phillips et al. ${ }^{157,211}$ which is based on thermal gradient diffusion chamber and laboratory studies suggest that biological aerosol (insoluble organic) are significantly more important. Clearly, more experimental work is required to constrain ice nucleation by biological particles and also to improve our understanding of how much biological material is present in the atmosphere.

In making these conclusions we are making the assumption that the materials used in experimental studies are good proxies for aerosol in the atmosphere. Given the relatively small number of studies which we are able to draw on for some materials, we recommend that more experimental efforts are made to quantify ice nucleation by a greater range of materials within these broad categories. We should also remain open to the possibility that there may be as yet uncategorised important classes of IN in the atmosphere. For example, recent work suggests secondary organic aerosol, ${ }^{69,70}$ and various aerosol species related to anthropogenic activities ${ }^{329,330}$ may be important ice nuclei. Nevertheless, we present here an up to date picture of the current paradigm of ice nucleation in the atmosphere.

\section{Conclusions}

Understanding ice nucleation by atmospheric aerosol particles is an integral part of our community's goal of quantifying the impact of natural and anthropogenic aerosol particles on clouds and climate. There are of course also many other challenges to achieving this goal including improving our 
understanding of atmospheric dynamics, aerosol composition and distribution, liquid cloud processes as well as model development. Nevertheless, our understanding of the fundamentals of ice nucleation by atmospheric aerosol particles remains a key limitation in understanding aerosol-cloud interactions. In this final section, we conclude by highlighting the key areas requiring future attention. Several of these points have been discussed in depth in previous sections, but for convenience these will be drawn together and highlighted here.

While our estimates of the potential IN concentrations presented in Fig. 19 highlight which aerosol species are important, it also highlights areas where our knowledge is lacking. It is clear that aerosol types such as soot and mineral dust are potentially important ice nuclei below about $-15^{\circ} \mathrm{C}$, however their importance at higher temperatures remains unclear. The instrumentation which has been used to probe ice nucleation by these materials is insensitive to the potentially small nucleation probabilities which may still be important at higher temperatures. At present, bacteria are the only atmospheric aerosol class which are known to be active in these warm clouds, but it is still under debate if there are sufficient bacteria in the atmosphere to have a significant impact. ${ }^{211,212}$ It should also be borne in mind that our community has so far restricted its efforts to only a small number of atmospherically relevant materials. For example, soot is a highly variable material, but data suitable for our assessment was only available for two soot types. In addition, it is conceivable that we have so far neglected an important source of ice nucleating aerosol such as SOA or various anthropogenic aerosol species. ${ }^{69,70,329,330}$

Another major challenge is how to describe ice nucleation by atmospheric aerosol. We have taken a pragmatic approach here and used a time-independent description in order to compare ice nucleation efficiencies of a range of aerosol types. However, there is evidence that the inherent time dependence of nucleation may be important in some cloud types and instruments which operate on short time scales may not always record the presence of all IN which might activate on a longer, but atmospherically relevant time scale. ${ }^{29,105,128,327}$ Further work is required to characterise time dependence of ice nucleation by the various IN types. In addition, cloud modelling studies are required to test the significance of time dependence.

Differences between experimental studies which may lead to systematic differences in measured ice nucleation efficiencies need to be explored and understood. The sources of variability discussed during this review, such as inconsistent test sample compositions between different studies and different methods of surface area determination or varying experimental conditions require further investigation.

While cooperative work within the laboratory research community will be necessary to improve our current understandings of atmospheric ice nucleation processes, interdisciplinary collaboration involving researchers in the lab, field and modelling communities is required to quantify the impact of ice nucleating aerosol particles on clouds and climate. Unravelling ever more intricate phenomena such as the impacts of environmental processing on mineral dusts, soot or biological materials will only be possible by continuing synergistic efforts across numerous disciplines.

\section{List of symbols used}

\section{Notation}

$A \quad$ Arrhenius pre-exponential factor

$C_{\mathrm{m}} \quad$ Mass concentration

$C_{\mathrm{n}} \quad$ Number of particles per unit volume of water

$f_{\text {ice }}(T)$ Fraction of droplets which freeze on cooling by temperature $T$

$\Delta G_{\mathrm{cl}} \quad$ Gibbs free energy of cluster formation

$\Delta G_{\mathrm{s}} \quad$ Surface excess free energy

$\Delta G_{\mathrm{v}} \quad$ Volume excess free energy

$J_{\text {het }} \quad$ Heterogeneous nucleation rate coefficient

$J_{\mathrm{i}} \quad$ Heterogeneous nucleation rate coefficient of ith nucleus

$k \quad$ Boltzmann constant

$k(T)$ Density of surface sites per volume that become active per unit temperature interval

$K(T) \quad$ Cumulative number of nucleation sites per unit volume (cumulative nucleus spectrum)

$m \quad$ Heterogeneous ice nucleating efficiency parameter

$N_{\text {tot }}$ Total number of droplets (or number of liquid droplets at $t=0 \mathrm{~s}$ )

$N \quad$ Number of liquid droplets at the beginning of a time interval

$N_{\mathrm{i}} \quad$ Number of liquid droplets containing potential ice nuclei species $\mathrm{i}$

$N_{\text {ice }} \quad$ Concentration of potential ice nuclei (per $\mathrm{cm}^{3}$ of air)

$n_{\text {ice }}(T) \quad$ Cumulative number of frozen droplets by temperature $T$

$n_{\mathrm{m}} \quad$ Cumulative number of nucleation sites per unit mass

$n_{\mathrm{n}} \quad$ Cumulative number of nucleation sites per unit particle

$n_{\mathrm{s}} \quad$ Cumulative number of nucleation sites per unit surface area (active site density)

$P_{\text {ice }} \quad$ Vapour pressure of ice

$P_{1} \quad$ Vapor pressure of liquid water

$R \quad$ Cooling nucleation rate (nucleation events per unit volume per unit time)

$r \quad$ Cooling rate

$r_{\mathrm{g}} \quad$ Radius of critical cluster

$r_{\mathrm{i}} \quad$ Radius of cluster containing i molecules

$S \quad$ Saturation ratio

$s \quad$ Nucleant surface area per droplet

$s_{\mathrm{i}} \quad$ Surface area of ith nucleus per droplet

$s_{\mathrm{sp}} \quad$ Specific surface area

$s_{\text {tot }} \quad$ Total surface area available for nucleation

$t \quad$ Time

$T_{\mathrm{c}} \quad$ Characteristic nucleation temperature

$V \quad$ Droplet volume

$\Delta n_{\text {ice }} \quad$ Number of droplets which freeze within a time interval

$\alpha \quad$ Modified singular temperature offset

$\beta \quad$ Modified singular empirical factor

$\gamma \quad$ Interfacial free energy

$\Phi \quad$ Heterogeneous enhancement factor

$\theta \quad$ Contact angle

$\nu \quad$ Molecular volume of condensed phase

\section{Acknowledgements}

We thank Anja Schmidt for modifying and providing a figure and gratefully acknowledge the European Research Council (FP7, 240449 ICE), and the Natural Environment Research Council (NE/I013466/1) for funding. 


\section{References}

1 P. Forster, V. Ramaswamy, P. Artaxo, T. Berntsen, R. Betts, D. W. Fahey, J. Haywood, J. Lean, D. C. Lowe, G. Myhre, J. Nganga, R. Prinn, G. Raga, M. Schulz and R. Van Dorland, in Climate Change 2007: The Physical Science Basis. Contribution of Working Group I to the Fourth assessment Report of the Intergovernmental Panel on Climate Change, ed. S. Solomon, D. M. Qin, Z. Manning, M. Chen, K. B. Marquis, M. T. Averyt and H. L. Miller, Cambridge University Press, Cambridge, 2007.

2 U. Lohmann and J. Feichter, Atmos. Chem. Phys., 2005, 5, 715-737.

3 D. L. Hartmann, M. E. Ockertbell and M. L. Michelsen, J. Clim., 1992, 5, 1281-1304.

4 W. Cantrell and A. Heymsfield, Bull. Am. Meteorol. Soc., 2005, 795-807.

5 C. Hoose and O. Möhler, Atmos. Chem. Phys. Discuss., 2012, 12, 12531-12621.

6 S. Martin, Chem. Rev., 2000, 100, 3403-3453.

7 H. R. Pruppacher and J. D. Klett, Microphysics of Clouds and Precipitation, Kluwer, Dordrecht, 1997.

8 W. Szyrmer and I. Zawadzki, Bull. Am. Meteorol. Soc., 1997, 78, 209-228.

9 T. Bartels-Rausch, V. Bergeron, J. H. E. Cartwright, R. Escribano, J. L. Finney, H. Grothe, P. J. Gutierrez, J. Haapala, W. F. Kuhs, J. B. C. Pettersson, S. D. Price, C. I. Sainz-Diaz, D. J. Stokes, G. Strazzulla, E. S. Thomson, H. Trinks and N. Uras-Aytemiz, Rev. Mod. Phys., 2012, 84, 885-944.

10 P. J. DeMott, in Cirrus, ed. D. K. Lynch, K. Sassen, D. C. Starr and G. Stephens, Oxford University Press, Oxford, 2002, pp. 102-135.

11 B. J. Murray, T. W. Wilson, S. Dobbie, Z. Q. Cui, S. Al-Jumur, O. Möhler, M. Schnaiter, R. Wagner, S. Benz, M. Niemand, H. Saathoff, V. Ebert, S. Wagner and B. Kärcher, Nat. Geosci., 2010, 3, 233-237.

12 T. Koop, Z. Physiol. Chem., 2004, 218, 1231-1258.

13 K.-T. Liou, Mon. Weather Rev., 1986, 114, 1167-1199.

14 J. R. Holton and A. Gettleman, Geophys. Res. Lett., 2001, 28, 2799-2802.

15 A. Gettelman and P. M. D. Forster, J. Meteorol. Soc. Jpn., 2002, 80, 911-924.

16 J. P. D. Abbatt, Chem. Rev., 2003, 103, 4783-4800.

17 B. J. Murray, S. L. Broadley, T. W. Wilson, S. J. Bull, R. H. Wills, H. K. Christenson and E. J. Murray, Phys. Chem. Chem. Phys., 2010, 12, 10380-10387.

18 J. H. Seinfeld and S. N. Pandis, Atmospheric Chemistry and Physics, John Wiley and Sons, New York, 1998.

19 D. V. Spracklen, K. S. Carslaw, J. Merikanto, G. W. Mann, C. L. Reddington, S. Pickering, J. A. Ogren, E. Andrews, U. Baltensperger, E. Weingartner, M. Boy, M. Kulmala, L. Laakso, H. Lihavainen, N. Kivekas, M. Komppula, N. Mihalopoulos, G. Kouvarakis, S. G. Jennings, C. O'Dowd, W. Birmili, A. Wiedensohler, R. Weller, J. Gras, P. Laj, K. Sellegri, B. Bonn, R. Krejci, A. Laaksonen, A. Hamed, A. Minikin, R. M. Harrison, R. Talbot and J. Sun, Atmos. Chem. Phys., 2010, 10, 4775-4793.

20 M. O. Andreae and D. Rosenfeld, Earth-Sci. Rev., 2008, 89, 13-41.

21 P. J. DeMott, A. J. Prenni, X. Liu, S. M. Kreidenweis, M. D. Petters, C. H. Twohy, M. S. Richardson, T. Eidhammer and D. C. Rogers, Proc. Natl. Acad. Sci. U. S. A., 2010, 107, $11217-11222$.

22 B. J. Mason, The Physics of Clouds, Clarendon Press, Oxford, 1971.

23 D. C. Rogers, P. J. DeMott, S. M. Kreidenweis and Y. L. Chen, Geophys. Res. Lett., 1998, 25, 1383-1386.

24 T. Eidhammer, P. J. DeMott and S. M. Kreidenweis, J. Geophys. Res., [Atmos.], 2009, 114, D06202.

25 P. J. DeMott, K. Sassen, M. R. Poellot, D. Baumgardner, D. C. Rogers, S. D. Brooks, A. J. Prenni and S. M. Kreidenweis, Geophys. Res. Lett., 2003, 30, 1732.

26 J. Rosinski and G. M. Morgan, J. Aerosol Sci., 1988, 19, 531-538.

27 M. P. Meyers, P. J. DeMott and W. R. Cotton, J. Appl. Meteorol., 1992, 31, 708-721.
28 B. J. Mason, Clouds, rain and rainmaking, Cambridge University Press, Cambridge, 2nd edn, 1975.

29 J. Crosier, K. N. Bower, T. W. Choularton, C. D. Westbrook, P. J. Connolly, Z. Q. Cui, I. P. Crawford, G. L. Capes, H. Coe, J. R. Dorsey, P. I. Williams, A. J. Illingworth, M. W. Gallagher and A. M. Blyth, Atmos. Chem. Phys., 2011, 11, 257-273.

$30 \mathrm{H}$. Morrison, G. de Boer, G. Feingold, J. Harrington, M. D. Shupe and K. Sulia, Nat. Geosci., 2012, 5, 11-17.

31 P. R. Field, A. J. Heymsfield, B. J. Shipway, P. J. DeMott, K. A. Pratt, D. C. Rogers, J. Stith and K. A. Prather, J. Atmos. Sci., 2012, 69, 1066-1079.

32 A. J. Heymsfield and L. M. Miloshevich, J. Atmos. Sci., 1993, 50, 2335-2353.

33 C. H. Twohy, P. J. DeMott, K. A. Pratt, R. Subramanian, G. L. Kok, S. M. Murphy, T. Lersch, A. J. Heymsfield, Z. Wang, K. A. Prather and J. H. Seinfeld, J. Atmos. Sci., 2010, 67, 2437-2450.

34 D. Rosenfeld and W. L. Woodley, Nature, 2000, 405, 440-442.

35 R. J. Hogan, M. D. Behera, E. J. O'Connor and A. J. Illingworth, Geophys. Res. Lett., 2004, 31, L05106.

36 A. Ansmann, M. Tesche, D. Althausen, D. Müller, P. Seifert, V. Freudenthaler, B. Heese, M. Wiegner, G. Pisani, P. Knippertz and O. Dubovik, J. Geophys. Res., [Atmos.], 2008, 113, D04210.

37 A. Ansmann, M. Tesche, P. Seifert, D. Althausen, R. Engelmann, J. Fruntke, U. Wandinger, I. Mattis and D. Müller, J. Geophys. Res., [Atmos.], 2009, 114, D17208.

38 P. Seifert, A. Ansmann, S. Gross, V. Freudenthaler, B. Heinold, A. Hiebsch, I. Mattis, J. Schmidt, F. Schnell, M. Tesche, U. Wandinger and M. Wiegner, J. Geophys. Res., [Atmos.], 2011, 116, D00U04.

39 P. Seifert, A. Ansmann, I. Mattis, U. Wandinger, M. Tesche, R. Engelmann, D. Müller, C. Perez and K. Haustein, J. Geophys. Res., [Atmos.], 2010, 115, D20201.

40 Y. S. Choi, R. S. Lindzen, C. H. Ho and J. Kim, Proc. Natl. Acad. Sci. U. S. A., 2010, 107, 11211-11216.

41 T. Kanitz, P. Seifert, A. Ansmann, R. Engelmann, D. Althausen, C. Casiccia and E. G. Rohwer, Geophys. Res. Lett., 2011, 38, L17802.

42 J. M. Prospero, P. Ginoux, O. Torres, S. E. Nicholson and T. E. Gill, Rev. Geophys., 2002, 40, 1002.

43 K. Sassen, P. J. DeMott, J. M. Prospero and M. R. Poellot, Geophys. Res. Lett., 2003, 30, 1633.

44 E. J. Murray, B. J. Murray and V. Sivakumar, Adv. Geotech.-Eng. Tunnelling, 2008, 553-558.

45 D. M. Murphy and T. Koop, Q. J. R. Meteorol. Soc., 2005, 131, 1539-1565.

46 A. Korolev and G. Isaac, Q. J. R. Meteorol. Soc., 2003, 129, 19-38.

47 Z. Q. Cui, K. S. Carslaw, Y. Yin and S. Davies, J. Geophys. Res., 2006, 111, D05201.

48 V. T. J. Phillips, T. W. Choularton, A. M. Blyth and J. Latham, Q. J. R. Meteorol. Soc., 2002, 128, 951-971.

49 J. Hallett and S. C. Mossop, Nature, 1974, 249, 26-28.

50 Y. Huang, A. M. Blyth, P. R. A. Brown, T. W. Choularton, P. Connolly, A. M. Gadian, H. Jones, J. Latham, Z. Cui and K. Carslaw, New J. Phys., 2008, 10, 105021.

51 Y. Huang, A. M. Blyth, P. R. A. Brown, R. Cotton, J. Crosier, K. N. Bower, M. W. Gallagher, H. Jones, A. M. Gadian, T. W. Choularton, J. Cardwell, H. Coe, S. D. Mobbs and M. Hagen, Q. J. R. Meteorol. Soc., 2011, 137, 275-286.

52 V. T. J. Phillips, A. M. Blyth, P. R. A. Brown, T. W. Choularton and J. Latham, Q. J. R. Meteorol. Soc., 2001, 127, 1513-1534.

53 S. C. Mossop, Q. J. R. Meteorol. Soc., 1976, 102, 45-57.

54 J. I. Yano and V. T. J. Phillips, J. Atmos. Sci., 2011, 68, 322-333.

55 V. I. Khvorostyanov and J. A. Curry, J. Atmos. Sci., 2004, 61, 2676-2691.

56 K. Diehl and S. K. Mitra, Atmos. Environ., 1998, 32, 3145-3151.

57 G. de Boer, H. Morrison, M. D. Shupe and R. Hildner, Geophys. Res. Lett., 2011, 38, L01803.

58 G. Vali, Bull. Am. Meteorol. Soc., 1985, 66, 1426

59 A. J. Durant and R. A. Shaw, Geophys. Res. Lett., 2005, 32, L20814.

60 R. A. Shaw, A. J. Durant and Y. Mi, J. Phys. Chem. B, 2005, 109, 9865-9868.

61 A. P. Fornea, S. D. Brooks, J. B. Dooley and A. Saha, J. Geophys. Res., 2009, 114, D13201.

62 C. D. Westbrook and A. J. Illingworth, Geophys. Res. Lett., 2011, 38, L14808. 
63 K. Sassen and V. I. Khvorostyanov, Environ. Res. Lett., 2008, 3, 025006 .

64 V. T. J. Phillips, L. J. Donner and S. T. Garner, J. Atmos. Sci., 2007, 64, 738-761.

65 B. Zuberi, A. K. Bertram, T. Koop, L. T. Molina and M. J. Molina, J. Phys. Chem. A, 2001, 105, 6458-6464.

66 R. Wagner, O. Möhler, H. Saathoff, M. Schnaiter and T. Leisner, Atmos. Chem. Phys., 2011, 11, 2083-2110.

67 D. A. Knopf and S. M. Forrester, J. Phys. Chem. A, 2011, 115, 5579-5591.

68 T. W. Wilson, B. J. Murray, R. Wagner, O. Möhler, H. Saathoff, M. Schnaiter, J. Skrotzki, H. C. Price, T. L. Malkin, S. Dobbie and S. M. R. K. Al-Jumur, Atmos. Chem. Phys. Discuss., 2012, 12, 8979-9033.

69 D. A. Knopf, B. Wang, A. Laskin, R. C. Moffet and M. K. Gilles, Geophys. Res. Lett., 2010, 37, L11803.

70 B. Wang, A. T. Lambe, P. Massoli, T. B. Onasch, P. Davidovits, D. R. Worsnop and D. A. Knopf, J. Geophys. Res., 2012, DOI: 10.1029/2012JD018063.

71 P. J. DeMott, J. Appl. Meteorol., 1990, 29, 1072-1079.

72 P. J. DeMott, Y. Chen, S. M. Kreidenweis, D. C. Rogers and D. E. Sherman, Geophys. Res. Lett., 1999, 26, 2429-2432.

73 T. Croteau, A. K. Bertram and G. N. Patey, J. Phys. Chem. A, 2010, 114, 2171-2178.

74 X. L. Hu and A. Michaelides, Surf. Sci., 2010, 604, 111-117.

75 X. L. Hu and A. Michaelides, Surf. Sci., 2007, 601, 5378-5381.

76 D. V. Spracklen, K. S. Carslaw, U. Poeschl, A. Rap and P. M. Forster, Atmos. Chem. Phys., 2011, 11, 9067-9087.

77 A. Schmidt, K. S. Carslaw, G. W. Mann, A. Rap, K. J. Pringle, D. V. Spracklen, M. Wilson and P. M. Forster, Atmos. Chem. Phys., 2012, 12, 7321-7339.

78 D. Rosenfeld, U. Lohmann, G. B. Raga, C. D. O’Dowd, M. Kulmala, S. Fuzzi, A. Reissell and M. O. Andreae, Science, 2008, 321, 1309-1313

79 D. Rosenfeld, X. Yu, G. Liu, X. Xu, Y. Zhu, Z. Yue, J. Dai, Z. Dong, Y. Dong and Y. Peng, Geophys. Res. Lett., 2011, 38, L21804.

80 I. Crawford, K. N. Bower, T. W. Choularton, C. Dearden, J. Crosier, C. Westbrook, G. Capes, H. Coe, P. J. Connolly, J. R. Dorsey, M. W. Gallagher, P. Williams, J. Trembath, Z. Cui and A. Blyth, Atmos. Chem. Phys., 2012, 12, 4963-4985.

81 M. O. Andreae, D. Rosenfeld, P. Artaxo, A. A. Costa, G. P. Frank, K. M. Longo and M. A. F. Silva-Dias, Science, 2004, 303, 1337-1342.

82 Y. Yin, K. S. Carslaw and G. Feingold, Q. J. R. Meteorol. Soc., 2005, 131, 221-245.

83 Y. Yin, K. S. Carslaw and D. J. Parker, Atmos. Chem. Phys., 2002, 2, 293-306.

84 S. S. Lee, L. J. Donner and V. T. J. Phillips, Atmos. Chem. Phys., 2009, 9, 2555-2575.

85 S. S. Lee, L. J. Donner, V. T. J. Phillips and Y. Ming, Q. J. R Meteorol. Soc., 2008, 134, 1201-1220.

86 U. Lohmann and K. Diehl, J. Atmos. Sci., 2006, 63, 968-981.

87 K. Diehl and S. Wurzler, J. Atmos. Sci., 2004, 61, 2063-2072.

88 T. E. Hoffer, J. Meteorol., 1961, 18, 766-778.

89 R. L. Pitter and H. R. Pruppacher, Q. J. R. Meteorol. Soc., 1973, 99, 540-550.

90 T. Storelvmo, J. E. Kristjansson and U. Lohmann, J. Atmos. Sci., $2008, \mathbf{6 5}, 3214-3230$.

91 C. Hoose, U. Lohmann, R. Erdin and I. Tegen, Environ. Res. Lett., 2008, 3, 025003.

92 T. Storelvmo, C. Hoose and P. Eriksson, J. Geophys. Res. [Atmos.], 2011, 116, D05207.

93 D. Kashchiev, Nucleation: Basic Theory with Applications, Butterworth-Heinemann, Oxford, 2000.

94 J. W. Mullin, Crystallization, Elsevier Butterworth-Heinemann, Oxford, Forth edn, 2001.

95 J. F. Huang and L. S. Bartell, J. Phys. Chem., 1995, 99, 3924-3931.

96 W. Ostwald, Z. Phys. Chem., 1897, 22, 289.

97 T. L. Malkin, B. J. Murray, A. V. Brukhno, J. Anwar and C. G. Salzmann, Proc. Natl. Acad. Sci. U. S. A., 2012, 109, 1041-1045.

98 J. Wolk and R. Strey, J. Phys. Chem. B, 2001, 105, 11683-11701.

99 R. C. Miller, R. J. Anderson, J. L. Kassner and D. E. Hagen, J. Chem. Phys., 1983, 78, 3204-3211.

100 B. J. Murray and E. J. Jensen, J. Atmos. Sol.-Terr. Phys., 2010, 72, 51-61.
101 A. Manka, H. Pathak, S. Tanimura, J. Wolk, R. Strey and B. E. Wyslouzil, Phys. Chem. Chem. Phys., 2012, 14, 4505-4516. 102 A. Bogdan, J. Chem. Phys., 1997, 106, 1921-1929.

103 A. Pant, M. T. Parsons and A. K. Bertram, J. Phys. Chem. A, 2006, 110, 8701-8709.

104 M. T. Parsons, J. L. Riffell and A. K. Bertram, J. Phys. Chem. A, 2006, 110, 8108-8115.

105 B. J. Murray, S. L. Broadley, T. W. Wilson, J. D. Atkinson and R. H. Wills, Atmos. Chem. Phys., 2011, 11, 4191-4207.

106 P. V. Hobbs, Ice Physics, Clarendon Press, Oxford, 1974

107 C. G. Salzmann, P. G. Radaelli, B. Slater and J. L. Finney, Phys. Chem. Chem. Phys., 2011, 13, 18468-18480.

108 T. C. Hansen, A. Falenty and W. F. Kuhs, in Physics and Chemistry of Ice, ed. W. F. Kuhs, The Royal Society of Chemistry, Cambridge, 2007, pp. 201-208.

109 E. B. Moore and V. Molinero, Phys. Chem. Chem. Phys., 2011, 13, 20008-20016.

110 C. Hoose, J. E. Kristjánsson, J. P. Chen and A. Hazra, J. Atmos. Sci., 2010, 67, 2483-2503.

111 J.-P. Chen, A. Hazra and Z. Levin, Atmos. Chem. Phys., 2008, 8, 7431-7449.

112 J. C. Johnston and V. Molinero, J. Am. Chem. Soc., 2012, 134, 6650-6659.

113 M. A. Carignano, J. Chem. Phys. C, 2006, 111, 501-504.

114 E. Pluhařov, L. Vrbka and P. Jungwirth, J. Chem. Phys. C, 2010, 114, 7831-7838.

115 P. Pirzadeh and P. G. Kusalik, J. Am. Chem. Soc., 2011, 133, 704-707.

116 B. J. Mason and J. Maybank, Q. J. R. Meteorol. Soc., 1958, 84, 235-241.

117 B. Vonnegut and M. Baldwin, J. Appl. Meteorol., 1984, 23, 486-490.

118 A. F. Heneghan, P. W. Wilson and A. D. J. Haymet, Proc. Natl. Acad. Sci. U. S. A., 2002, 99, 9631-9634.

119 A. F. Heneghan, P. W. Wilson, G. Wang and A. D. J. Haymet, J. Chem. Phys., 2001, 115, 7599-7608.

120 S. L. Broadley, B. J. Murray, R. J. Herbert, J. D. Atkinson, S. Dobbie, T. L. Malkin, E. Condliffe and L. Neve, Atmos. Chem. Phys., 2012, 12, 287-307.

121 S. Marcolli, S. Gedamke, T. Peter and B. Zobrist, Atmos. Chem. Phys., 2007, 7, 5081-5091.

122 D. Niedermeier, R. A. Shaw, S. Hartmann, H. Wex, T. Clauss, J. Voigtländer and F. Stratmann, Atmos. Chem. Phys., 2011, 11, $8767-8775$

123 B. Krämer, O. Hubner, H. Vortisch, L. Woste, T. Leisner, M. Schwell, E. Ruhl and H. Baumgartel, J. Chem. Phys., 1999, 111, 6521-6527.

124 D. Barahona, Atmos. Chem. Phys., 2012, 12, 3733-3752.

125 V. Stoyanova, D. Kashchiev and T. Kupenova, J. Aerosol Sci., 1994, 25, 867-877.

126 F. Lüönd, O. Stetzer, A. Welti and U. Lohmann, J. Geophys. Res., 2010, 115, D14201.

127 M. J. Wheeler and A. K. Bertram, Atmos. Chem. Phys., 2012, 12, $1189-1201$.

128 A. Welti, F. Lüönd, Z. A. Kanji, O. Stetzer and U. Lohmann, Atmos. Chem. Phys. Discuss., 2012, 12, 12623-12662.

129 G. Vali, J. Atmos. Sci., 1994, 51, 1843-1856.

130 G. Vali, Atmos. Chem. Phys., 2008, 8, 5017-5031.

131 P. J. Connolly, O. Möhler, P. R. Field, H. Saathoff, R. Burgess, T. Choularton and M. Gallagher, Atmos. Chem. Phys., 2009, 9, 2805-2824.

132 D. Niedermeier, S. Hartmann, R. A. Shaw, D. Covert, T. F. Mentel, J. Schneider, L. Poulain, P. Reitz, C. Spindler, T. Clauss, A. Kiselev, E. Hallbauer, H. Wex, K. Mildenberger and F. Stratmann, Atmos. Chem. Phys., 2010, 10, 3601-3614.

133 P. J. DeMott, Atmos. Res., 1995, 38, 63-99.

134 G. Vali, J. Atmos. Sci., 1971, 28, 402-409.

135 M. Niemand, O. Möhler, B. Vogel, H. Vogel, C. Hoose, P. Connolly, H. Klein, H. Bingemer, P. DeMott, J. Skrotzki and T. Leisner, J. Atmos. Sci., 2012, DOI: 10.1175/JAS-D-11-0249.1.

136 I. Steinke, O. Möhler, A. Kiselev, M. Niemand, H. Saathoff, M. Schnaiter, J. Skrotzki, C. Hoose and T. Leisner, Atmos. Chem. Phys., 2011, 11, 12945-12958.

137 G. Vali and E. J. Stansbury, Can. J. Phys., 1966, 44, 477-502.

138 P. J. Connolly, O. Möhler, P. Field, H. Saathoff, R. Burgess, T. Choularton and M. Gallagher, Atmos. Chem. Phys., 2009, 2805-2824. 
139 O. Stetzer, B. Baschek, F. Lüönd and U. Lohmann, Aerosol Sci. Technol., 2008, 42, 64-74.

140 Z. A. Kanji and J. P. D. Abbatt, Aerosol Sci. Technol., 2009, 43, $730-738$.

141 H. M. Jones, M. J. Flynn, P. J. DeMott and O. Möhler, Atmos. Chem. Phys., 2011, 11, 53-65.

142 B. Friedman, G. Kulkarni, J. Beranek, A. Zelenyuk, J. A. Thornton and D. J. Cziczo, J. Geophys. Res., [Atmos.], 2011, 116, D17203.

143 D. C. Rogers, Atmos. Res., 1988, 22, 149-181.

144 K. V. Beard and H. R. Pruppacher, J. Atmos. Sci., 1969, 26, 1066-1072.

145 K. Diehl, S. Matthias-Maser, R. Jaenicke and S. K. Mitra, Atmos. Res., 2002, 61, 125-133.

146 U. Bundke, B. Nillius, R. Jaenicke, T. Wetter, H. Klein and H. Bingemer, Atmos. Res., 2008, 90, 180-186.

147 S. E. Wood, M. B. Baker and B. D. Swanson, Rev. Sci. Instrum., 2002, 73, 3988-3996.

148 H. M. Hung, A. Malinowski and S. T. Martin, J. Phys. Chem. A, 2003, 107, 1296-1306

149 G. Vali, in Biological Ice Nucleation and Its Applications, ed. R. E. Lee, G. Warren and L. Gusta, APS press, St. Paul, Minnesota, 1995.

150 B. Pummer, H. Bauer, J. Bernardi, S. Bleicher and H. Grothe, Atmos. Chem. Phys., 2012, 12, 2541-2550.

151 V. Pinti, C. Marcolli, B. Zobrist, C. R. Hoyle and T. Peter, Atmos. Chem. Phys., 2012, 12, 5859-5878.

152 C. A. Stan, G. F. Schneider, S. S. Shevkoplyas, M. Hashimoto, M. Ibabescu, B. J. Wiley and G. M. Whitesides, Lab on a Chip, 2009, 9, 2293-2305.

153 M. Kumai, J. Meteorol., 1961, 18, 139-150.

154 D. J. Cziczo, P. J. DeMott, C. Brock, P. K. Hudson, B. Jesse, S. M. Kreidenweis, A. J. Prenni, J. Schreiner, D. S. Thomson and D. M. Murphy, Aerosol Sci. Technol., 2003, 37, 460-470.

155 P. J. DeMott, D. J. Cziczo, A. J. Prenni, D. M. Murphy, S. M. Kreidenweis, D. S. Thomson, R. Borys and D. C. Rogers, Proc. Natl. Acad. Sci. U. S. A., 2003, 100, 14655-14660.

156 K. A. Pratt, P. J. DeMott, J. R. French, Z. Wang, D. L. Westphal, A. J. Heymsfield, C. H. Twohy, A. J. Prenni and K. A. Prather, Nat. Geosci., 2009, 2, 397-400.

157 V. T. J. Phillips, P. J. DeMott and C. Andronache, J. Atmos. Sci, $2008, \mathbf{6 5}, 2757-2783$.

158 C. S. Zender, D. Newman and O. Torres, J. Geophys. Res., 2003, 108, 4543.

159 J. M. Prospero and P. J. Lamb, Science, 2003, 302, 1024-1027.

160 C. S. Zender, R. L. Miller and I. Tegen, Eos Trans. AGU, 2004, $\mathbf{8 5}, 509$.

161 I. Tegen and I. Fung, J. Geophys. Res., 1995, 100, 18707-18726.

162 I. N. Sokolik and O. B. Toon, Nature, 1996, 381, 681-683.

163 P. C. Sinclair, J. Appl. Meteorol., 1969, 8, 32-45.

164 D. A. Gillette and P. C. Sinclair, Atmos. Environ., Part A, 1990, 24, 1135-1142.

165 P. Knippertz and M. C. Todd, Rev. Geophys., 2012, 50, 28.

166 I. Koren, Y. Kaufman, J. R. Washington, M. Todd, C. Y. Rudich, J. V. Martins and D. Rosenfeld, Environ. Res. Lett., 2006, 1, 014005.

167 J. M. Prospero, J. E. Bullard and R. Hodgkins, Science, 2012, 335, 1078-1082.

168 S. Hillier, Clay Mineral Cements in Sandstones, Blackwell Publishing Ltd., 1999, pp. 213-251.

169 K. Kandler, N. Benker, U. Bundke, E. Cuevas, M. Ebert, P. Knippertz, S. Rodriguez, L. Schuetz and S. Weinbruch, Atmos. Environ., 2007, 41, 8058-8074.

170 K. Schepanski, I. Tegen, B. Laurent, B. Heinold and A. Macke, Geophys. Res. Lett., 2007, 34, L18803.

171 L. Klüser, P. Kleiber, T. Holzer-Popp and V. H. Grassian, Atmos. Environ., 2012, 54, 419-427.

172 W. A. Deer, R. A. Howie and J. Zussman, An introduction to the rock forming minerals, Addison Wesley Longman, Harlow, UK, 2nd edn, 1992.

173 A. Meunier, Clays, Springer, Berlin, Germany, 2005.

174 D. Borden and R. F. Giese, Clay Clay Miner., 2001, 49, 444-445.

175 T. Zoltai and J. H. Stout, Mineralogy concepts and principles, Burgess, Minneapolis, 1985.

176 L. Schütz and M. Sebert, J. Aerosol Sci., 1987, 18, 1-10.
177 F. Bouchelaghem, Applied Mathematical Modelling, 2010, 34, 467-480.

178 F. Conen, C. E. Morris, J. Leifeld, M. V. Yakutin and C. Alewell, Atmos. Chem. Phys., 2011, 11, 9643-9648.

179 S. J. Chipera and D. L. Bish, Clay Clay Miner., 2001, 49, 398-409.

180 A. Vlasenko, S. Sjogren, E. Weingartner, H. W. Gaggeler and M. Ammann, Aerosol Sci. Technol., 2005, 39, 452-460.

181 C. R. Hoyle, V. Pinti, A. Welti, B. Zobrist, C. Marcolli, B. Luo, Á. Höskuldsson, H. B. Mattsson, O. Stetzer, T. Thorsteinsson, G. Larsen and T. Peter, Atmos. Chem. Phys., 2011, 11, 9911-9926.

182 S. L. Gregg and K. S. W. Sing, Adsorption surface area and porosity, Academic Press, London, 1982.

183 B. R. Bickmore, K. L. Nagy, P. E. Sandlin and T. S. Crater, Am. Mineral., 2002, 87, 780-783.

184 A. Welti, F. Lüönd, O. Stetzer and U. Lohmann, Atmos. Chem. Phys., 2009, 9, 6705-6715.

185 S. Matthias-Maser and R. Jaenicke, Atmos. Res., 1995, 39, 279-286.

186 A. M. Jones and R. M. Harrison, Sci. Total Environ., 2004, 326, $151-180$.

187 A.-M. Delort, M. Vaïtilingom, P. Amato, M. Sancelme, M. Parazols, G. Mailhot, P. Laj and L. Deguillaume, Atmos. Res., 2010, 98, 249-260.

188 S. M. Burrows, T. Butler, P. Jockel, H. Tost, A. Kerkweg, U. Pöschl and M. G. Lawrence, Atmos. Chem. Phys., 2009, 9, 9281-9297.

189 L. Deguillaume, M. Leriche, P. Amato, P. A. Ariya, A. M. Delort, U. Pöschl, N. Chaumerliac, H. Bauer, A. I. Flossmann and C. E. Morris, Biogeosciences, 2008, 5, 1073-1084.

190 V. R. Després, J. A. Huffman, S. M. Burrows, C. Hoose, A. S. Safatov, G. Buryak, J. Fröhlich-Nowoisky, W. Elbert, M. O. Andreae and U. Pöschl, Tellus, Ser. B, 2012, 64, 15598.

191 O. Möhler, P. DeMott, G. Vali and Z. Levin, Biogeosciences Discuss., 2007, 4, 2559-2591.

192 C. Hoose, Nat. Geosci., 2009, 2, 385-386.

193 S. M. Burrows, C. Hoose, U. Pöschl and M. G. Lawrence, Atmos. Chem. Phys. Discuss., 2012, 12, 4373-4416.

194 R. Jaenicke, Science, 2005, 308, 73.

195 R. Jaenicke, S. Matthias-Maser and S. Gruber, Environ. Chem., 2007, 4, 217-220.

196 S. Gruber, S. Matthias-Maser and R. Jaenicke, J. Aerosol Sci., 1999, 30(Suppl. 1), S9-S10.

197 C. C. White, C. M. Kenny and S. G. Jennings, J. Aerosol Sci., 1999, 30(Suppl. 1), S809-S810.

198 B. Graham, P. Guyon, W. Maenhaut, P. E. Taylor, M. Ebert, S. Matthias-Maser, O. L. Mayol-Bracero, R. H. M. Godoi, P. Artaxo and F. X. Meixner, J. Geophys. Res., 2003, 108, 4765.

199 C. E. Morris, D. C. Sands, M. Bardin, R. Jaenicke, B. Vogel, C. Leyronas, P. A. Ariya and R. Psenner, Biogeosciences, 2011, 8, $17-25$.

200 B. C. Christner, R. Cai, C. E. Morris, K. S. McCarter, C. M. Foreman, M. L. Skidmore, S. N. Montross and D. C. Sands, Proc. Natl. Acad. Sci. U. S. A., 2008, 105, 18854.

201 A. J. Prenni, M. D. Petters, S. M. Kreidenweis, C. L. Heald, S. T. Martin, P. Artaxo, R. M. Garland, A. G. Wollny and U. Pöschl, Nat. Geosci., 2009, 2, 401-404.

202 R. Lundheim, Philos. Trans. R. Soc., B, 2002, 357, 937-943.

203 S. M. Burrows, W. Elbert, M. G. Lawrence and U. Pöschl, Atmos. Chem. Phys., 2009, 9, 9263-9280.

204 L. Maki and K. Willoughby, J. Appl. Meteorol., 1978, 17, 1049-1053.

205 J. Lindemann, H. A. Constantinidou, W. R. Barchet and C. D. Upper, Appl. Environ. Microbiol., 1982, 44, 1059-1063.

206 H. E. Ahern, K. A. Walsh, T. C. J. Hill and B. F. Moffett, Biogeosciences, 2007, 4, 115-124.

207 R. M. Bowers, C. L. Lauber, C. Wiedinmyer, M. Hamady, A. G. Hallar, R. Fall, R. Knight and N. Fierer, Appl. Environ. Microbiol., 2009, 75, 5121.

208 P. S. Kourtev, K. A. Hill, P. B. Shepson and A. Konopka, Atmos. Environ., 2011, 45, 5399-5405.

209 K. Diehl and S. Wurzler, Atmos. Environ., 2010, 44, 4622-4628.

210 K. Diehl, M. Simmel and S. Wurzler, J. Geophys. Res., 2006, 111, D07202.

211 V. T. J. Phillips, C. Andronache, B. Christner, C. E. Morris, D. C. Sands, A. Bansemer, A. Lauer, C. McNaughton and C. Seman, Biogeosciences, 2009, 6, 987-1014 
212 C. Hoose, J. Kristjánsson and S. Burrows, Environ. Res. Lett., $2010,5,024009$.

213 R. Schnell and G. Vali, Nature, 1973, 246, 212-213.

214 R. Schnell and G. Vali, Nature, 1972, 236, 163-165.

215 L. R. Maki, E. L. Galyan, M. M. Chang-Chien and D. R. Caldwell, Appl. Environ. Microbiol., 1974, 28, 456-459.

216 H. Constantinidou, S. Hirano, L. Baker and C. Upper, Phytopathology, 1990, 80, 934-937.

217 C. E. Morris, D. C. Sands, B. A. Vinatzer, C. Glaux, C. Guilbaud, A. Buffiere, S. C. Yan, H. Dominguez and B. M. Thompson, ISME J., 2008, 2, 321-334.

218 H. Obata, Y. Saeki, J. Tanishita, T. Tokuyama, H. Hori and Y. Higashi, Agric. Biol. Chem., 1987, 51, 1761-1766.

219 H. Obata, T. Nakai, J. Tanishita and T. Tokuyama, J. Ferment. Bioeng., 1989, 67, 143-147.

220 H. Obata, N. Muryoi, H. Kawahara, K. Yamade and J. Nishikawa, Cryobiology, 1999, 38, 131-139.

221 S. Lindow, D. Arny and C. Upper, Phytopathology, 1978, 68, 523-527.

222 H. Azad and N. W. Schaad, Phytopathology, 1988, 78, 95-100.

223 L. Corotto, P. Wolber and G. Warren, EMBO J., 1986, 5, 231.

224 S. Lindow, E. Lahue, A. Govindarajan, N. Panopoulos and D. Gies, Mol. Plant-Microbe Interact., 1989, 2, 262-272.

225 P. K. Wolber, C. A. Deininger, M. W. Southworth, J. Vandekerckhove, M. Van Montagu and G. J. Warren, Proc. Natl. Acad. Sci. U. S. A., 1986, 83, 7256.

226 A. G. Govindarajan and S. Lindow, J. Biol. Chem., 1988, 263, 9333-9338.

227 P. Phelps, T. H. Giddings, M. Prochoda and R. Fall, J. Bacteriol., 1986, 167, 496.

228 N. Cochet and P. Widehem, Appl. Microbiol. Biotechnol., 2000, 54, 153-161.

229 J. A. Ruggles, M. Nemecek-Marshall and R. Fall, J. Bacteriol., 1993, 175, 7216-7221.

230 L. Kozloff, M. Turner and F. Arellano, J. Bacteriol., 1991, 173, $6528-6536$.

231 M. Turner, F. Arellano and L. Kozloff, J. Bacteriol., 1990, 172, 2521.

232 L. Pooley and T. A. Brown, FEMS Microbiol. Lett., 1991, 77, 229-232.

233 C. A. Deininger, G. M. Mueller and P. K. Wolber, J. Bacteriol., 1988, 170, 669-675.

234 A. Blondeaux, J. F. Hamel, P. Widehem and N. Cochet, J. Ind. Microbiol. Biotechnol., 1999, 23, 514-519.

235 J. Rogers, R. Stall and M. Burke, Cryobiology, 1987, 24, 270-279.

236 M. Nemecek-Marshall, R. Laduca and R. Fall, J. Bacteriol., 1993, 175, 4062-4070.

237 D. C. Gross, Y. S. Cody, E. L. Proebsting Jr, G. K. Radamaker and R. A. Spotts, Appl. Environ. Microbiol., 1983, 46, 1370-1379.

238 R. D. O’Brien and S. E. Lindow, Appl. Environ. Microbiol., 1988, 54, 2281-2286.

239 E. Attard, H. Yang, A. M. Delort, P. Amato, U. Pöschl, C. Glaux, T. Koop and C. E. Morris, Atmos. Chem. Phys. Discuss., 2012, 12, 9491-9516.

240 H. Kawahara, Y. Tanaka and H. Obata, Biosci., Biotechnol., Biochem., 1995, 59, 1528-1532.

241 L. Kozloff, M. Schofield and M. Lute, J. Bacteriol., 1983, 153, 222.

242 S. E. Lindow, S. S. Hirano, W. R. Barchet, D. C. Arny and C. D. Upper, Plant Physiol., 1982, 70, 1090.

243 S. K. Henderson-Begg, T. Hill, R. Thyrhaug, M. Khan and B. F. Moffett, Atmos. Sci. Lett., 2009, 10, 215-219.

244 R. Mortazavi, C. T. Hayes and P. A. Ariya, Environ. Chem., 2008, 5, 373-381.

245 O. Möhler, D. G. Georgakopoulos, C. E. Morris, S. Benz, V. Ebert, S. Hunsmann, H. Saathoff, M. Schnaiter and R. Wagner, Biogeosciences, 2008, 5, 1425-1435.

246 K. Junge and B. D. Swanson, Biogeosciences, 2008, 5, 865-873.

247 Z. Levin and S. A. Yankofsky, J. Clim., 1983, 1964-1966.

248 P. Ward and P. DeMott, J. Wea. Mod, 1989, 21, 9-13.

249 A. L. Fall and R. Fall, Curr. Microbiol., 1998, 36, 370-376.

250 M. A. Ponder, S. J. Gilmour, P. W. Bergholz, C. A. Mindock, R. Hollingsworth, M. F. Thomashow and J. M. Tiedje, FEMS Microbiol. Ecol., 2005, 53, 103-115.

251 T. L. Kieft, Appl. Environ. Microbiol., 1988, 54, 1678-1681.

252 T. L. Kieft and V. Ahmadjian, Lichenologist, 1989, 21, 355-362.
253 S. Pouleur, C. Richard, J. G. Martin and H. Antoun, Appl. Environ. Microbiol., 1992, 58, 2960-2964.

254 C. Richard, J.-G. Martin and S. Pouleur, Phytoprotection, 1996, 77, 83-92.

255 L. Margulis, Symbiotic planet: a new look at evolution, Basic Books (AZ), 1999.

256 S. Pady and P. Gregory, Trans. Br. Mycol. Soc., 1963, 46, 609-613, IN620.

257 H. Tsumuki, H. Konno, T. Maeda and Y. Okamoto, J. Insect Physiol., 1992, 38, 119-125.

258 T. L. Kieft and T. Ruscetti, J. Bacteriol., 1990, 172, 3519-3523.

259 C. L. Heald and D. V. Spracklen, Geophys. Res. Lett., 2009, 36, L09806.

260 W. Elbert, P. E. Taylor, M. O. Andreae and U. Pöschl, Atmos. Chem. Phys., 2007, 7, 4569-4588.

261 J. Fröhlich-Nowoisky, D. A. Pickersgill, V. R. Després and U. Pöschl, Proc. Natl. Acad. Sci. U. S. A., 2009, 106, 12814-12819.

262 J. Huffman, B. Treutlein and U. Pöschl, Atmos. Chem. Phys., 2010, 10, 3215-3233.

263 K. Jayaweera and P. Flanagan, Geophys. Res. Lett., 1982, 9, 94-97.

264 R. Iannone, D. Chernoff, A. Pringle, S. Martin and A. Bertram, Atmos. Chem. Phys., 2011, 11, 1191-1201.

265 M. Sofiev, P. Siljamo, H. Ranta and A. Rantio-Lehtimäki, Int. J. Biometeorol., 2006, 50, 392-402.

266 H. Linskens and W. Jorde, Allergologie, 1986, 9, 55-58.

267 K. Diehl, C. Quick, S. Matthias-Maser, S. Mitra and R. Jaenicke, Atmos. Res., 2001, 58, 75-87.

268 N. von Blohn, S. K. Mitra, K. Diehl and S. Borrmann, Atmos. Res., 2005, 78, 182-189.

269 G. Schappi, P. E. Taylor, M. Pain, P. Cameron, A. Dent, I. A. Staff and C. Suphioglu, Clin. Exp. Allergy, 1999, 29, 633-641.

270 K. E. Yttri, C. Dye and G. Kiss, Atmos. Chem. Phys., 2007, 7, 4267-4279.

271 R. Schnell, Geophys. Res. Lett., 1975, 2, 500-502.

272 R. Fall and R. C. Schnell, J. Mar. Res., 1985, 43, 257-265.

273 P. A. Alpert, J. Y. Aller and D. A. Knopf, Phys. Chem. Chem. Phys., 2011, 13, 19882-19894.

274 P. A. Alpert, J. Y. Aller and D. A. Knopf, Atmos. Chem. Phys., 2011, 11, 5539-5555.

275 D. A. Knopf, P. A. Alpert, B. Wang and J. Y. Aller, Nat. Geosci., 2011, 4, 88-90.

276 M. T. Madigan, J. M. Martinko, D. A. Stahl and D. P. Clark, Brock Biology Of Microorganisms, Pearson Education, Inc., San Francisco, 13th edn, 2012.

277 T. Koop, B. P. Luo, A. Tsias and T. Peter, Nature, 2000, 406, 611-614.

278 A. Ito and J. E. Penner, Global Biogeochem. Cycles, 2005, 19, GB2028.

279 P. K. Hudson, D. M. Murphy, D. J. Cziczo, D. S. Thomson, J. A. de Gouw, C. Warneke, J. Holloway, J. R. Jost and G. Hubler, J. Geophys. Res., [Atmos.], 2004, 109, 11.

280 U. Lohmann, Geophys. Res. Lett., 2002, 29, 1052.

281 M. O. Andreae and A. Gelencsér, Atmos. Chem. Phys., 2006, 6, 3131-3148.

282 K. A. Koehler, P. J. DeMott, S. M. Kreidenweis, O. B. Popovicheva, M. D. Petters, C. M. Carrico, E. D. Kireeva, T. D. Khokhlova and N. K. Shonija, Phys. Chem. Chem. Phys., 2009, 11, 7906-7920.

283 V. Tishkova, B. Demirdjian, D. Ferry and M. Johnson, Phys. Chem. Chem. Phys., 2011, 13, 20729-20735.

284 O. B. Popovicheva, N. M. Persiantseva, E. E. Lukhovitskaya, N. K. Shonija, N. A. Zubareva, B. Demirdjian, D. Ferry and J. Suzanne, Geophys. Res. Lett., 2004, 31, L11104.

285 M. Posfai, J. R. Anderson, P. R. Buseck and H. Sievering, J. Geophys. Res., [Atmos.], 1999, 104, 21685-21693.

286 M. T. Baeza-Romero, J. M. Wilson, E. M. Fitzpatrick, J. M. Jones and A. Williams, Energy Fuels, 2010, 24, 439-445.

287 P. R. Buseck and M. Posfai, Proc. Natl. Acad. Sci. U. S. A., 1999, 96, 3372-3379.

288 M. Posfai, R. Simonics, J. Li, P. V. Hobbs and P. R. Buseck, J. Geophys. Res., [Atmos.], 2003, 108, 8483.

289 M. Posfai, A. Gelencser, R. Simonics, K. Arato, J. Li, P. V. Hobbs and P. R. Buseck, J. Geophys. Res., [Atmos.], 2004, 109, D06213. 
290 K. Adachi and P. R. Buseck, J. Geophys. Res., [Atmos.], 2011, 116, D05204.

291 B. Zobrist, C. Marcolli, T. Peter and T. Koop, J. Phys. Chem. A, 2008, 112, 3965-3975.

292 T. Koop, J. Bookhold, M. Shiraiwa and U. Poeschl, Phys. Chem. Chem. Phys., 2011, 13, 19238-19255.

293 B. J. Murray, Atmos. Chem. Phys., 2008, 8, 5423-5433.

294 A. Virtanen, J. Joutsensaari, T. Koop, J. Kannosto, P. Yli-Pirila, J. Leskinen, J. M. Makela, J. K. Holopainen, U. Poeschl, M. Kulmala, D. R. Worsnop and A. Laaksonen, Nature, 2010, 467, 824-827.

295 C. H. Twohy, A. D. Clarke, S. G. Warren, L. F. Radke and R. J. Charlson, J. Geophys. Res., [Atmos.], 1989, 94, 8623-8631.

296 K. A. Pratt, C. H. Twohy, S. M. Murphy, R. C. Moffet, A. J. Heymsfield, C. J. Gaston, P. J. DeMott, P. R. Field, T. R. Henn, D. C. Rogers, M. K. Gilles, J. H. Seinfeld and K. A. Prather, J. Geophys. Res., [Atmos.], 2010, 115, 17.

297 M. Kamphus, M. Ettner-Mahl, T. Klimach, F. Drewnick, L. Keller, D. J. Cziczo, S. Mertes, S. Borrmann and J. Curtius, Atmos. Chem. Phys., 2010, 10, 8077-8095.

298 J. P. Schwarz, R. S. Gao, D. W. Fahey, D. S. Thomson, L. A. Watts, J. C. Wilson, J. M. Reeves, M. Darbeheshti, D. G. Baumgardner, G. L. Kok, S. H. Chung, M. Schulz, J. Hendricks, A. Lauer, B. Kärcher, J. G. Slowik, K. H. Rosenlof, T. L. Thompson, A. O. Langford, M. Loewenstein and K. C. Aikin, J. Geophys. Res., 2006, 111, D16207.

299 S. Mertes, B. Verheggen, S. Walter, P. Connolly, M. Ebert, J. Schneider, K. N. Bower, J. Cozic, S. Weinbruch, U. Baltensperger and E. Weingartner, Aerosol Sci. Technol., 2007, 41, 848-864.

300 J. Cozic, S. Mertes, B. Verheggen, D. J. Cziczo, S. J. Gallavardin, S. Walter, U. Baltensperger and E. Weingartner, J. Geophys. Res., [Atmos.], 2008, 113, D15209.

301 M. Dymarska, B. J. Murray, L. M. Sun, M. L. Eastwood, D. A. Knopf and A. K. Bertram, J. Geophys. Res., 2006, 111, D04204.

302 O. Möhler, C. Linke, H. Saathoff, M. Schnaiter, R. Wagner, A. Mangold, M. Krämer and U. Schurath, Meteorol. Z., 2005, 14, 477-484.

303 I. Crawford, O. Möhler, M. Schnaiter, H. Saathoff, D. Liu, G. McMeeking, C. Linke, M. Flynn, K. N. Bower, P. J. Connolly, M. W. Gallagher and H. Coe, Atmos. Chem. Phys., 2011, 11, 9549-9561.

304 O. Möhler, S. Buttner, C. Linke, M. Schnaiter, H. Saathoff, O. Stetzer, R. Wagner, M. Krämer, A. Mangold, V. Ebert and U. Schurath, J. Geophys. Res., [Atmos.], 2005, 110, D11210.

305 Z. A. Kanji and J. P. D. Abbatt, J. Geophys. Res., [Atmos.], 2006, 111, 31-41.

306 Z. A. Kanji, P. J. DeMott, O. Möhler and J. P. D. Abbatt, Atmos. Chem. Phys., 2011, 11, 31-41.

307 B. Gorbunov, A. Baklanov, N. Kakutkina, H. L. Windsor and R. Toumi, J. Aerosol Sci., 2001, 32, 199-215.

308 A. E. Pashenko and B. Z. Gorbunov, J. Aerosol Sci., 1987, 18, 269-275.

309 O. Popovicheva, E. Kireeva, N. Persiantseva, T. Khokhlova, N. Shonija, V. Tishkova and B. Demirdjian, Atmos. Res., 2008, 90, 326-337.

310 M. D. Petters, M. T. Parsons, A. J. Prenni, P. J. DeMott, S. M. Kreidenweis, C. M. Carrico, A. P. Sullivan, G. R. McMeeking, E. Levin, C. E. Wold, J. L. Collett and H. Moosmuller, J. Geophys. Res., [Atmos.], 2009, 114, 10.

311 O. Möhler, S. Benz, H. Saathoff, M. Schnaiter, R. Wagner, J. Schneider, S. Walter, V. Ebert and S. Wagner, Environ. Res. Lett., 2008, 3, 025007.

312 A. Schmidt, B. Ostro, K. S. Carslaw, M. Wilson, T. Thordarson, G. W. Mann and A. J. Simmons, Proc. Natl. Acad. Sci. U. S. A., 2011, 108, 15710-15715.

313 A. Robock, Rev. Geophys., 2000, 38, 191-219.

314 K. Isono, M. Komabayasi and A. Ono, Nature, 1959, 183, 317-318.
315 P. V. Hobbs, C. M. Fullerton and G. C. Bluhm, Nature Phys. Sci. (London), 1971, 230, 90-91.

316 A. J. Prenni, P. J. DeMott, D. C. Rogers, S. M. Kreidenweis, G. M. McFarquhar, G. Zhang and M. R. Poellot, Tellus, Ser. B, 2009, 61, 436- 448.

317 R. C. Schnell and A. C. Delany, Nature, 1976, 264, 535-536.

318 H. Bingemer, H. Klein, M. Ebert, W. Haunold, U. Bundke, T. Herrmann, K. Kandler, D. Müller-Ebert, S. Weinbruch, A. Judt, A. Wéber, B. Nillius, K. Ardon-Dryer, Z. Levin and J. Curtius, Atmos. Chem. Phys., 2012, 12, 857-867.

319 A. J. Durant, C. Bonadonna and C. J. Horwell, Elements, 2010, 6, 235-240.

320 A. J. Durant, R. A. Shaw, W. I. Rose, Y. Mi and G. G. J. Ernst, J. Geophys. Res., 2008, 113, D09206.

321 G. Heiken, Geol. Soc. Am. Bull., 1972, 83, 1961-1988.

322 S. J. Norris, I. M. Brooks, G. de Leeuw, A. Sirevaag, C. Leck, B. J. Brooks, C. E. Birch and M. Tjernström, Ocean Sci., 2011, 7, $129-139$.

323 C. J. Horwell and P. J. Baxter, Bull. Volcanol. (Heidelberg), 2006, 69, $1-24$.

324 T. L. Lathem, P. Kumar, A. Nenes, J. Dufek, I. N. Sokolik, M. Trail and A. Russell, Geophys. Res. Lett., 2011, 38, L11802.

325 Y. S. Djikaev and E. Ruckenstein, J. Phys. Chem. A, 2008, 112, $11677-11687$.

326 C. Gurganus, A. B. Kostinski and R. A. Shaw, J. Phys. Chem. Lett., 2011, 2, 1449-1454.

327 B. Vonnegut, J. Clim. Appl. Meteorol., 1987, 26, 322.

328 U. Schumann, B. Weinzierl, O. Reitebuch, H. Schlager, A. Minikin, C. Forster, R. Baumann, T. Sailer, K. Graf, H. Mannstein, C. Voigt, S. Rahm, R. Simmet, M. Scheibe, M. Lichtenstern, P. Stock, H. Rüba, D. Schäuble, A. Tafferner, M. Rautenhaus, T. Gerz, H. Ziereis, M. Krautstrunk, C. Mallaun, J. F. Gayet, K. Lieke, K. Kandler, M. Ebert, S. Weinbruch, A. Stohl, J. Gasteiger, S. Groß, V. Freudenthaler, M. Wiegner, A. Ansmann, M. Tesche, H. Olafsson and K. Sturm, Atmos. Chem. Phys., 2011, 11, 2245-2279.

329 M. Ebert, A. Worringen, N. Benker, S. Mertes, E. Weingartner and S. Weinbruch, Atmos. Chem. Phys., 2011, 11, 2805-2816.

330 D. J. Cziczo, O. Stetzer, A. Worringen, M. Ebert, S. Weinbruch, M. Kamphus, S. J. Gallavardin, J. Curtius, S. Borrmann, K. D. Froyd, S. Mertes, O. Möhler and U. Lohmann, Nat. Geosci., 2009, 2, 333-336.

331 R. A. Glaccum and J. M. Prospero, Mar. Geol., 1980, 37, 295-321.

332 J. M. Prospero, R. A. Glaccum and R. T. Nees, Nature, 1981, 289, 570-572.

333 M. Leinen, J. M. Prospero, E. Arnold and M. Blank, J. Geophys. Res., [Atmos.], 1994, 99, 21017-21023.

334 E. Arnold, J. Merrill, M. Leinen and J. King, Global Planet. Change, 1998, 18, 137-159.

335 K. Kandler, L. Schütz, C. Deutscher, M. Ebert, H. Hofmann, S. Jäckel, R. Jaenicke, P. Knippertz, K. Lieke, A. Massling, A. Petzold, A. Schladitz, B. Weinzierl, A. Wiedensohler, S. Zorn and S. Weinbruch, Tellus, Ser. B, 2009, 61, 32-50.

336 K. Kandler, L. Schütz, S. Jäckel, K. Lieke, C. Emmel, D. MullerEbert, M. Ebert, D. Scheuvens, A. Schladitz, B. Segvic, A. Wiedensohler and S. Weinbruch, Tellus, Ser. B, 2011, 63, 459-474.

337 R. T. Downs and M. Hall-Wallace, Am. Mineral., 2003, 88, 247-250.

338 S. Yankofsky, Z. Levin, T. Bertold and N. Sandlerman, J. Appl. Meteorol., 1981, 20, 1013-1019.

339 H. K. Kim, C. Orser, S. E. Lindow and D. Sands, Plant Dis., 1987, 71, 994-996.

340 A. Sesartic, U. Lohmann and T. Storelvmo, Atmos. Chem. Phys. Discuss., 2011, 11, 1457-1488.

341 P. J. DeMott and D. C. Rogers, J. Atmos. Sci., 1990, 47, 1056-1064. 